1 Capacity of Skirted Foundations in Sand-over-Clay under Combined

\title{
V-H-M Loading
}

$4 \quad{ }^{1}$ Associate Professor ( $\left.\mathrm{PhD}\right)$, College of Civil Engineering, Hunan University, Changsha 5 410082, P. R. China; Visiting Research Fellow, School of Civil and Resource 6 Engineering, The University of Western Australia, 35 Stirling Highway, Crawley, WA 7 6009, Tel: +61 (0)8 6488 8182, Fax:+61 (0)8 6488 1018; Email: xjzouhd@hnu.edu.cn

$8{ }^{2}$ Professor (PhD, MIEAust), School of Civil, Environmental and Mining Engineering, 9 The University of Western Australia, 35 Stirling Highway, Crawley, WA 6009, Tel:

10 +61 86488 8182, Fax: +61 86488 1018, Email: yuxia.hu@uwa.edu.au

$11{ }^{3}$ Senior Research Fellow (BEng, MEng, PhD, MIEAust), Centre for Offshore 12 Foundation Systems (COFS), The University of Western Australia, 35 Stirling 13 Highway, Crawley, WA 6009, Tel: +61 86488 7358, Fax: +61 86488 1044, Email: 14 muhammad.hossain@uwa.edu.au

$15{ }^{4}$ Corresponding author, Associate professor $(\mathrm{PhD})$, State Key laboratory of Subtropical 16 Building Science, South China Institute of Geotechnical Engineering. State, South 17 China University of Technology, 381 Wushan Road, Guangzhou 510640 China, Tel: 18 +8620 87111029, Fax: +86 20 87111029; Email: michaelmizhou@163.com

19 - Number of Words: 4077 (text only)

20 - Number of Tables: 03

$21 \quad$ - Number of Figures: 17 


\section{V-H-M Loading}

\section{Abstract}

Circular skirted foundations are used widely in the offshore oil and gas industry and renewable energy industry to support subsea infrastructure and founding turbines. The

31 foundations are subjected to combined vertical-horizontal-moment $(V-H-M)$ loadings during operation. This paper describes an extensive investigation of the response of installed circular skirted foundations under operational loadings in sand-over-clay. The overarching aim was to examine the influence of the presence of a sand layer on the combined load capacity. A detailed parametric study was undertaken through small strain finite element analyses, varying the thickness of the sand layer, embedment depth of the foundation (or skirt length), and level of vertical load mobilization.

The effect of the surface sand layer was profound for thicker sand layer of $T_{\mathrm{s}} / D>0.2$.

39 Normalized failure envelopes were presented in $v-h, v-m$ and $h-m$ spaces. The FE results 40 on the former two spaces showed unique trend, but not on the latter. New approximating 41 expressions for describing the failure envelopes as a function of the sand layer thickness ratio, skirt length ratio and vertical load mobilization level were proposed.

KEYWORDS: bearing capacity; failure; footings/foundations; numerical modelling;

44 offshore engineering; sands 
46

47

48

49

50

$51 \quad E$

52

$53 \quad H_{\text {ult }}$

$54 \quad h$

$55 \quad h_{0}$

$56 \quad h_{0, \mathrm{Ts}=0}$

57

58

59

$60 \quad M_{\text {ult }}$

$61 \quad M^{*}$

62

63

A foundation base area at skirt tip level

fitting constant

cohesion

foundation diameter

skirt length

Young's modulus

horizontal load

uniaxial (pure) horizontal capacity

$h=H / H_{\mathrm{ult}}$

dimensionless uniaxial horizontal capacity, $h_{0}=H_{\mathrm{ul}} / A s_{\mathrm{u} 0}$

$h_{0}$ in absence of sand layer

clay strength gradient

moment

maximum moment

uniaxial moment capacity

moment capacity at $h=0$

$m=M / M_{\mathrm{ult}}$

$m^{*}=M / M^{*}$ 
64 $m_{0}$ dimensionless uniaxial moment capacity, $m_{0}=M_{\mathrm{ul}} / A s_{\mathrm{u} 0}$

65 $m_{0, \mathrm{Ts}=0} \quad m_{0}$ in absence of sand layer

66 $m_{\max } \quad m_{\max }=M_{\max } / M_{\text {ult }}$

$67 \quad N_{\mathrm{c},} N_{\gamma} \quad$ dimensionless bearing capacity factors

$68 s_{\mathrm{u}}$

$69 \quad s_{\mathrm{u} 0}$

$70 \quad s_{\text {umc }}$

$71 \quad t$

$72 \quad T_{\mathrm{s}}$

$73 u$

$74 \quad V$

$75 \quad V_{\text {ult }}$

$76 v$

$77 \quad v_{0}$

$78 \quad v_{0, \mathrm{Ts}=0}$

79

$w$

$80 \quad z$

$81 \theta$

82
$\alpha$
fitting parameter 
83

84

85

86

87

88

89 $\beta \quad$ fitting parameter

$\gamma_{\mathrm{c}}^{\prime} \quad$ effective unit weight of clay

effective unit weight of sand

friction angle

dilation angle

Poisson's ratio

clay strength non-homogeneity, $k D / s_{\text {umc }}$ 
91 Circular skirted foundations (colloquially known as 'bucket foundations' or 'suction

92 caissons') are used widely in the offshore oil and gas industry (Wang et al., 2006;

93 Randolph et al., 2011). In deep water environment they are employed to support subsea

94 infrastructure, such as pipeline end manifolds and terminations, valve protection

95 systems; and in shallow water environment to support gravity based structures. In the

96 offshore renewable energy industry, circular buckets are recently identified as a

97 promising foundation concept for supporting wind turbines either directly by means of

98 a monopod, tripod or tetrapod system, or through a jacket structure. The application

99 versatility is being broadened due to their ease of installation and cost effectiveness

100 (Lian, 2014).

101 Skirted foundations are installed by pumping water from inside the skirt after they are 102 allowed to penetrate under their self-weight. The difference between the hydrostatic

103 water pressure outside the skirt and the reduced water pressure inside provides a

104 differential pressure, or suction, that acts as a penetration force. This leads a deformable

105 soil plug to be trapped inside the skirt (Vulpe, 2015).

106 In the operation phase, as is the focus of this paper, skirted foundations are required to

107 withstand combined $V-H-M$ (vertical-horizontal-moment) loading imposed by dead,

108 environmental and in-service loads. The traditional methods for calculating

109 corresponding capacity under general loading (rely on classical bearing capacity theory

110 along with shape, depth and inclination factors; e.g. DNV, 1992; ISO, 2003) have now

111 been superseded by three-dimensional failure envelopes, with the corresponding

112 advantages noted by Gourvenec and Barnett (2011) and others. Along with the classical

113 bearing capacity theory, the failure envelope method is widely used in current design

114 for bucket foundation. However, the failure envelopes with approximating expressions 
115 have been proposed either for clay (e.g. Ukritchon et al., 1998; Bransby and Randolph, 116 1999; Taiebat and Carter, 2000; Randolph and Puzrin, 2003; Gourvenec, 2008; Yun and

117 Bransby, 2007a; Gourvenec, 2008; Bransby and Yun, 2009; Gourvenec and Barnett, 118 2011; Gourvenec and Mana, 2011; Martin, 2001; Barari and Ibsen, 2012; Bienen et al., 119 2012; Hung and Kim, 2012, 2014; Kourkoulis et al., 2014; Vulpe et al., 2013, 2014; 120 Vulpe, 2015) or for sand (e.g. Byrne and Houlsby, 2004; Andersen et al., 2008; Ibsen 121 et al., 2014; Park et al., 2016). As of concern, no investigation was carried out for skirted 122 foundations on layered soils particularly on sand-over-clay, which is commonly 123 encountered in some petroleum and renewable energy active regions e.g. in the Yellow

124 Sea of Korea, North Sea, Gulf of Mexico, South China Sea, offshore India and Thailand. 125 Except, Park and Park (2017), who investigated only vertical bearing capacity of skirted 126 foundations in sand-over-clay, and the skirt was rested within the sand layer did not 127 penetrate into the bottom clay layer.

128 This paper reports the results from an extensive investigation carried out to explore the 129 kinematic failure mechanisms and capacity of skirted foundations subjected to general $130 V$ - $H$-M loading with 3 degree-of-freedom (3-DOF) on sand-over-clay deposits, with the 131 skirt tip being into the bottom clay layer. Three-dimensional (3D) small strain analyses 132 were undertaken, varying the thickness of the sand layer relative to the foundation 133 diameter and the skirt length relative to the sand layer thickness. Of particular interest 134 was the effect of the surface sand layer on the capacity. Failure envelopes and 135 approximating expressions were proposed to predict the ultimate limit states of skirted 136 foundations in sand-over-clay under combined in-plane $V-H-M$ loading. 


\subsection{Geometry and Parameters}

139 Bransby and Yun (2009), Vulpe (2015) and others have showed that the soil plug

140 trapped inside the skirt compartment during installation of the foundation significantly

141 influence the uniaxial capacity and shape and size of the failure envelopes, leading to

142 the necessity of simulation of a skirted foundation rather than a solid cylinder. This

143 study has considered a circular skirted foundation of diameter $D$, skirt length $d$ and skirt

144 thickness $t$, founded on a sand-over-normally consolidated clay deposit, as illustrated

145 schematically in Figure 1. The top sand layer has cohesion $c$, friction angle $\phi$ and

146 dilation angle $\psi$, effective unit weight $\gamma_{\mathrm{s}}^{\prime}$, and thickness $T_{\mathrm{s}}$, and the underlying clay

147 layer has non-uniform undrained shear strength $s_{\mathrm{u}}=s_{\mathrm{umc}}+k z$, and effective unit weight

$148 \gamma_{\mathrm{c} .}^{\prime} s_{\text {umc }}$ is the undrained shear strength at the sand-clay interface line, $k$ is the rate of

149 increase of $s_{\mathrm{u}}$ with depth $z$ (from the mudline).

150 In this study, the skirt length was selected as the ratio to the foundation diameter of $d / D$

$151=0.25,0.50,0.75$ and 1.00 , with relative thickness of the skirt being $t / D=0.005$. The

152 thickness of the sand layer was varied relative to the foundation diameter as $T_{\mathrm{s}} / D=0.0$,

$153 \quad 0.2,0.4$ and 0.6. In all the cases, the skirt tip was placed in the clay layer. The submerged

154 unit weight for the clay and sand layers were chosen typically with a ratio of $\gamma_{\mathrm{c}}^{\prime} \gamma_{\mathrm{s}}^{\prime}=$

$1556 / 8=0.75$. The typical effective unit weight of clay $\gamma_{\mathrm{c}}^{\prime}=6 \mathrm{kN} / \mathrm{m}^{3}$ (Zhou et al., 2013;

156 Zhou et al., 2016) and that of sand $\gamma_{\mathrm{s}}^{\prime}=8 \mathrm{kN} / \mathrm{m}^{3}$ were chosen. The notation for loads

157 and displacements are assembled in Table 1.

158 
161 All 3D small strain FE analyses were performed using the commercial FE package 162 Abaqus/Explicit (Dassault Systèmes, 2013) because Abaqus/Explicit is more stable 163 than Abaqus/implicit for analysis considering a sand layer with similar accuracy. The 164 soil domain was chosen as $10 D$ in diameter and $4 D$ in depth beneath the tip of the installed foundation to ensure that the boundaries were well outside the plastic zone. Only a half sector of the 3D domain was involved accounting for the inherent symmetry associated with in-plane $V, H$, and $M$ loading. A typical mesh is shown in Figure 2, representing a semi-cylindrical section through a diametrical plane of a circular skirted foundation. Based on a mesh convergence study, the typical soil element size around the skirt was adopted as $0.067 D$. The interfaces between the skirt and sand/clay was simulated using the penalty function in Abaqus (Dassault Systèmes, 2013). Common nodes connected the foundation with the soil at the foundation-soil interface, preventing any separation occurring under tension. Due to the suction developed within the soil plug trapped inside the skirt compartment, the assumption of fully bonded (i.e. fully rough) contact model for the plug soil-skirt inner surface both in sand and clay was reasonable to simplify the problem (following Bransby and Randolph, 1998; Taibet and Carter, 2000; Bransby and Yun, 2009; Huang \& Kim, 2012, 2014). The interface between the soil-skirt outer surface was also assumed to be fully rough, and the detachment between the skirt and the soil was prevented (Yun and Bransby, 2007a, 2007b; Gourvenec, 2008; Bransby and Yun, 2009; Barari and Ibsen, 2012; Huang \& Kim, 2012, 2014), to make the calculation more stable. Except, for the validation exercise, the interface was assumed to be smooth because the surface of the model steel caisson was anodised (and not sand blasted). Displacement boundary conditions prevented out of plane displacements of the vertical faces (i.e. the flat diametrical plane 
on the front of the mesh, and around the circumference), and the base of the mesh was

186 fixed in all three coordinate directions.

187

188

\subsection{Constitutive Law and Material Properties}

For the sand layer, the properties of the commercially available superfine silica sand that has been used in a number of investigations at the University of Western Australia were used as an abundance of reliable data regarding the geotechnical properties is readily available (Cheong, 2002; Lee et al., 2013; Teh et al., 2010; Hu et al., 2014). The poperies of the sand material are: specific gravity, $G_{\mathrm{s}}=2.65$; average effective particle size $d_{50}=0.19 \mathrm{~mm} ;$ maximum void ratio, $e_{\max }=0.75 ;$ minimum void ratio, $e_{\min }=0.45$. An elastic modulus $E=50000 \mathrm{kPa}$ with cohesion $c=0.1 \mathrm{kPa}$ (for maintaining numerical stability), a friction angle $\phi=32^{\circ}$, and a dilation angle $\psi=2^{\circ}$ were considered for medium dense fine silica sand commonly encountered in the surface layer of seabed sediments. A Poisson's ratio of $v=0.3$ was adopted assuming drained conditions. The sand was modelled as an elastic-perfectly plastic material obeying Mohr-Coulomb yield criterion, with non-associated flow.

The clay layer was modelled as an elasto-plastic material obeying a Tresca yield criterion, with associated flow. All the analyses simulated undrained conditions and adopted a Poisson's ratio $v=0.49$ (sufficiently high to give minimal volumetric strains, while maintaining numerical stability), friction and dilation angles $\phi=\psi=0$, and a uniform stiffness ratio $E / s_{\mathrm{u}}=500$ (where $E$ is the Young's modulus) throughout the clay profile. The stiffness ratio is within the range commonly adopted for soft clays, but the precise value has negligible effect on the results presented. A number of values of clay strength non-homogeneity were prescribed as $\kappa_{\mathrm{c}}=k D / s_{\mathrm{umc}}=0 \sim 3.0$, varying the clay strength at the interface $s_{\text {umc }}$ as $1.3 \sim 15 \mathrm{kPa}$, which are commonly encountered in the 
field (Menzies and Roper, 2008). The geostatic stress conditions were modelled using $K_{0}=1-\sin (\phi)=1-\sin \left(32^{\circ}\right)=0.47$ for the sand layer, and $K_{0}=1-\sin (\phi)=1-\sin \left(0^{\circ}\right)=1$

211 for the clay layer (Jacky, 1944). The influence of the values of $K_{0}$ on the skirted

212 foundation response was not investigated. It should be noted that the elastic properties $213(E, v)$ and $K_{0}$ values have been shown to have minimal influence on the calculated 214 bearing capacity of the foundation (Potts et al., 2001; Lee and Salgado, 2005).

\section{$215 \quad 2.4 \quad$ Sign Convention and Notation}

216 Sign conventions for loads and displacements presented in this paper obey a right217 handed axes and clockwise positive convention as proposed by Butterfield et al. (1997). 218 The adopted notations are summarised in Table 1. The ultimate loads are those for 219 uniaxial loading (e.g. $H=M=0$ for $V_{\mathrm{ult}}$ ). However, for moment loading, the maximum 220 moment (denoted by $M_{\max }$ and corresponding $m_{\max }$ ) is mobilised at a positive horizontal 221 load $H>0$ due to the nature of offshore operational loading.

\subsection{Loading Methods and Paths}

223 The reference point (RP) for applying displacements was located at the centre of the 224 circle at the skirt tip level (see Figure 1). Uniaxial vertical $\left(V_{\mathrm{ult}}\right)$, horizontal $\left(H_{\mathrm{ult}}\right)$ and 225 moment $\left(M_{\mathrm{ult}}\right)$ capacities (i.e. obtained in the absence of other load components, for 226 example $V$ for $H=M=0$ ) were obtained with displacement-controlled probes applied 227 to the RP until failure was reached - manifested through constant load with increasing 228 displacement.

229 General combined $V-H-M$ loading was achieved by applying a vertical load as a direct 230 force, after which a series of constant-ratio displacement probes of translation $(u)$ and 231 rotation $(\theta)$ were applied to the RP. The applied vertical load level was defined as a 
232 proportion of the uniaxial vertical capacity ( $\left.V_{\mathrm{ult}}\right)$. The vertical load level is described by $233 v=V / V_{\text {ult }}$ where $v$ took values of $0.0,0.5$ or 0.75 . In general, between 10 and 15 probe 234 tests are required to construct a failure envelope for each combination of the vertical 235 load level, skirt length ratio and sand layer thickness ratio. Probe tests at a fixed 236 displacement ratio give rise to load paths that approach the failure envelope from the 237 origin. The load paths are initially following the gradients determined by the elastic 238 stiffness of the surrounding soil. With the internal plastic yielding of the surrounding 239 soil, the load path gradients start to change till they reach the failure envelope. All 240 together around 350 analyses were carried out to establish failure envelopes for various 241 loading combinations under different layered soil profiles.

242 The swipe test, introduced by Tan (1990), is found to be convenient to determine a 243 complete failure envelope in a two-dimensional loading plane from a single test, which

244 tracks a load path close to the true failure envelope under various conditions. However, 245 in some circumstances especially for 3D loading on skirted foundations (i.e. skirt length $246 d / D>0$ ), previous studies (e.g. Supachawarote et al., 2005) have confirmed that a swipe 247 path may considerably undercut the true failure envelope. For this reason, swipe tests 248 were used only for validation analyses on a surface foundation (i.e. $d / D=0$ ) subjected 249 to combined $V-H$ or $V-M$ loading, while the fixed-ratio displacement probe method 250 (Bransby and Randolph, 1997) was employed to carry out all the other analyses.

\section{$251 \quad 2.6 \quad$ Validation}

252 Validation exercises were carried out against existing theoretical solutions and results 253 from FE analyses. For a surface flat circular footing resting on clay with strength non254 homogeneity $\kappa_{\mathrm{c}}=0$ and 3 , analyses were carried out under uniaxial vertical 255 displacement using implicit and explicit algorithms of Abaqus. Both smooth and rough 
256 footing base were considered. The values of dimensionless uniaxial vertical capacity, $257 v_{0}=V_{\mathrm{ult}} / A s_{\mathrm{u} 0}\left(V_{\mathrm{ult}}\right.$ represents the ultimate limit state under uniaxial vertical loading, $A$

$258=\pi D^{2} / 4$, and $s_{\mathrm{u} 0}$ is the undrained shear strength at the skirt tip level), which can be taken 259 as vertical bearing factor, $N_{\mathrm{c}}$, from this study show very good agreement with the 260 existing solutions, as tabulated in Table 2.

261 Similar analyses were carried out for a surface flat circular footing on silica sand 262 considering $\phi=30^{\circ}$ and base roughness $\alpha=0,0.2$ and 1 . The results from this study 263 are $N_{\gamma}=7.05,10.18,14.4$ for $\alpha=0,0.2$ and 1 respectively. These values are very close 264 to the corresponding lower bound plasticity solutions of $N_{\gamma}=6.935,9.891,14.13$ 265 (Cassidy and Houlsby, 2002) with the FE results marginally higher within 3\% 266 difference.

267 For a surface flat circular footing on uniform clay $\left(\kappa_{\mathfrak{c}}=0\right), 3 \mathrm{D}$ analyses were also 268 carried out to construct $H-M$ and $V-H$ envelopes. The results of this study are compared 269 with the FE results presented by Taiebat and Carter (2000) in Figure 3. Similar shapes 270 of $H-M$ and $V-H$ envelopes can be seen. The slight discrepancy in terms of moment 271 capacity might be due to the analysis methods used: 3D-displacement controlled 272 analysis in this study and 3D-load controlled analysis by Taiebat and Carter (2000).

273 The good agreements between the current results with the existing results of surface 274 footings on clay and sand provide confidence in the numerical model used and the 275 accuracy of the corresponding results. Furthermore, the numerical comparisons in 276 Table 2 confirm the suitability of the explicit algorithm of Abaqus used for the 277 subsequent FE analyses of skirted foundations in sand-over-clay for better convergent 278 calculation, relative to the implicit algorithm. Moreover, during the dynamic explicit 279 calculations, the time step needed to be defined appropriately to limit the ratio of the 
280 kinematic energy to the internal energy to be $<10 \%$ of the whole model domain, 281 resulting in a quasi-static calculation required by this study.

\section{RESULTS AND DISCUSSION}

\subsection{Uniaxial Capacity}

In order to explore the effect of skirted foundation embedment depth (or skirt length) and the thickness of the sand layer on the vertical bearing capacity, the foundation skirt length ratio varied as $d / D=0.00,0.25,0.50,0.75$ and 1.00 with the sand layer thickness as $T_{\mathrm{s}} / D=0,0.2,0.4$ and 0.6 . The clay non-homogeneity $\kappa_{\mathrm{c}}$ ranged from 0 to 3 .

The FE results of the skirted foundations on single layer non-homogeneous clay $\left(T_{\mathrm{s}} / D\right.$ $=0, \kappa_{\mathrm{c}}=3$ ) are plotted in Figure 4. Figure 4a shows the typical responses of the normalised vertical load $V / A s_{\mathrm{u} 0}$ against the normalised displacement $w / D$ for various skirt length ratio $d / D$. It is apparent that the ultimate load and the corresponding attainment depth (with $w / D<0.1$ ) increases with increasing $d / D$. The values of the ultimate vertical bearing capacity $v_{0, \mathrm{Ts}=0}=V_{\mathrm{ult}} / A s_{\mathrm{u} 0}\left(\right.$ or $\left.N_{\mathrm{c}}\right)$ for each $d / D$ were picked and are plotted in Figure 4b. The ultimate vertical bearing capacities of skirted foundations in non-homogeneous clay have been reported by Gourvenec and Mana (2001) and Hung and Kim (2014) from FE analyses and Martin (2001) from theoretical upper bound (UB) and lower bound (LB) solutions. The results for rough-based and rough-sided skirted foundations, as is the case for this study, are included in Figure $4 \mathrm{~b}$ for comparison. Note, (i) for all of them, the values for $\kappa_{\mathrm{c}}=3$ are not given, and hence were calculated through linear interpolation from the values for the closest upper and lower range of $\kappa_{\mathrm{c}}$; (ii) for Hung and Kim (2014), $s_{\mathrm{u} 0}$ was taken as the strength at a depth 
of $0.25 D$ beneath the skirt tip level. As such, the values were adjusted according to $s_{\mathrm{u} 0}$ at the skirt tip level. All the results from FE analyses are consistent, and nicely bracketed by the lower and upper bound solutions. The trend of increasing $v_{0}$ with increasing $d / D$ can be approximated as

$$
v_{0, \mathrm{Ts}=0}=8.05+8.64\left(\frac{d}{D}\right)\left[1-0.47\left(\frac{d}{D}\right)\right] \quad \text { for } \kappa_{\mathrm{c}}=3, d / D \leq 1.0
$$

Further analyses were carried out for $\kappa_{\mathrm{c}}=0.12 \sim 0.6$, and the results are shown in Figure $4 c$ along with existing FE results and UB and LB solutions. The values for the small range of $\kappa_{\mathrm{c}}=0.12 \sim 0.6$ fall in a tight band, and all the FE results agree reasonably and bounded by UB and LB solutions. The FE results can be best fitted as

$$
v_{0, \mathrm{Ts}=0}=6.27+10.59\left(\frac{d}{D}\right)\left[1-0.43\left(\frac{d}{D}\right)\right] \quad \text { for } \kappa_{\mathrm{c}}=0.12 \sim 0.6, d / D \leq 1.0
$$

The skirted foundations with skirt depth $d / D>T_{\mathrm{s}} / D$ were analysed under uniaxial vertical loading. The various skirt length ratios of $d / D=0.25,0.50,0.75$ and 1.00 were combined with sand layer thickness ratios of $T_{\mathrm{s}} / D=0.1,0.2,0.4$ and $0.6\left(\kappa_{\mathrm{c}}=3\right)$. Figure 5a displays load-displacement responses with all cases reaching the ultimate loading at the displacement of $w / D<0.1$. The normalised vertical capacities $\left(v_{0}=V_{\mathrm{ult}} / A s_{\mathrm{u} 0}\right)$ are displayed in Figure $5 \mathrm{~b}$ as a function of $T_{\mathrm{s}} / D$ and $d / D$, reflecting the trend of increasing capacity with increasing skirt length and sand layer thickness. In this sand-over-nonhomogeneous clay deposit, $v_{0}$ increases with increasing $T_{\mathrm{s}} / D$ partly due to the increasing contribution from the sand layer and partly owing to increasing undrained strength at the sand-clay interface and below. It can also be seen from Figure $5 b$ that, where the sand layer is thin (i.e. $T_{\mathrm{S}} / D<0.2$ ), the influence of the sand layer is negligible. The values of $v_{0}$ for various $T_{\mathrm{s}} / D$ and $\kappa_{\mathrm{c}}$ normalised by corresponding $v_{0, \mathrm{Ts}=0}$ (i.e. those for 
$\left.325 T_{\mathrm{s}} / D=0\right)$ plotted against $x=\frac{\left(T_{s} / D\right)}{(d / D)^{a}}$ (where $a$ is a constant) show a unique trend, which 326 can be approximated as (Figure 5c)

$v_{0}=v_{0, \mathrm{Ts}=0}[1-0.2 x(1-6.55 x)] \geq 1$

328 where $a=0.17$ for uniaxial vertical loading with $d / D>T_{\mathrm{S}} / D$. Park and Park (2017) 329 presented a framework for assessing vertical capacities for skirted foundations in sand 330 over clay deposits. The calculated normalised capacities using that framework, the soil 331 properties used in this study, and skirt length equals to sand layer thickness (i.e. $d / D=$ $\left.332 T_{\mathrm{s}} / D\right)$ also converge with the trend from this study.

333 The FE results of the skirted foundations under uniaxial horizontal displacement are 334 shown in Figure 6. Without the sand layer on top (i.e. $T_{\mathrm{s}} / D=0.0$ ), the ultimate 335 horizontal capacities $h_{0, \mathrm{Ts}=0}=H_{\mathrm{ult}} / A s_{\mathrm{u} 0}$ for various skirt length ratios of $d / D=0.25,0.50$, 3360.75 and 1.00, but with $\kappa_{\mathrm{c}}=3$ and $0.12 \sim 0.6$ are plotted in Figures 6a and 6b. The FE 337 results reported by Hung and Kim (2014) for all $d / D$ and $\kappa_{\mathrm{c}}=3$ and 0.6; and FE and 338 UB solutions by Gourvenec (2007) and Randolph and Puzrin (2003), respectively, for $339 d / D=0$ and regardless of $\kappa_{\mathrm{c}}$ show an excellent consistency. The trend of the results has 340 an identical shape to the one in Figure $4 \mathrm{~b}$ for uniaxial vertical loading. Thus this trend 341 can be expressed as

$$
h_{0, \mathrm{Ts}=0}=1+6.89\left(\frac{d}{D}\right)\left[1-0.42\left(\frac{d}{D}\right)\right] \quad \text { for } \kappa_{\mathrm{c}}=3, d / D \leq 1.0
$$

$$
h_{0, \mathrm{Ts}=0}=1+8.16\left(\frac{d}{D}\right)\left[1-0.39\left(\frac{d}{D}\right)\right] \quad \text { for } \kappa_{\mathrm{c}}=0.12 \sim 0.6, d / D \leq 1.0
$$

344 All the results of $h_{0}$ for various sand layer thickness ratios, skirt lengths and clay strength non-homogeneities are depicted in Figure 6c, and can be expressed as 
347 where $x=\frac{\left(T_{s} / D\right)}{(d / D)^{a}}$ and $a=0.65$.

348 Similarly, for a skirted foundation subjected to rotation only, the ultimate moment 349 capacities $m_{0, \mathrm{Ts}=0}=M_{\mathrm{ult}} / A D s_{\mathrm{u} 0}$ for $T_{\mathrm{s}} / D=0.0$ and for various skirt length ratios of $d / D$ $350=0.25,0.50,0.75$ and 1.00, but with $\kappa_{\mathrm{c}}=3$ and 0.12 0.6 are plotted in Figures 7a and $3517 \mathrm{~b}$, respectively. The UB solutions reported by Gourvenec (2007) and Randolph and 352 Puzrin (2003) for $d / D=0$ and $\kappa_{\mathrm{c}}=3$ and 0.12 0.6 (calculated through interpolation as 353 the values were given for $\kappa_{\mathrm{c}}=0,2$ and 6) show a reasonable agreement. By comparing 354 with Figures 4b, 6a and 6b where the corresponding capacity increases convexly, values 355 of $m_{0, T s=0}$ in Figures $7 \mathrm{a}$ and $7 \mathrm{~b}$ increases concavely, which may be presented as

$$
m_{0, \mathrm{Ts}=0}=0.97+0.35\left(\frac{d}{D}\right)\left[1+3.57\left(\frac{d}{D}\right)\right] \quad \text { for } \kappa_{\mathrm{c}}=3, d / D \leq 1.0
$$

$$
m_{0, \mathrm{Ts}=0}=0.7+\left(\frac{d}{D}\right)\left[1+1.5\left(\frac{d}{D}\right)\right] \quad \text { for } \kappa_{\mathrm{c}}=0.12 \sim 0.6, d / D \leq 1.0
$$

358 The trend of $m_{0} / m_{0, \mathrm{Ts}=0}$ in Figure $7 \mathrm{c}$ is, however, similar to that in Figures $5 \mathrm{c}$ and $6 \mathrm{c}$.

359 The best fit through the results in Figure $7 \mathrm{c}$ gives the following expression

$$
m_{0}=m_{0, \mathrm{Ts}=0}[1+0.09 x(1+11.56 x)]
$$

$361 \quad$ with $x=\frac{\left(T_{s} / D\right)}{(d / D)^{a}}$ and $a=0.52$.

362 From Figures $5 \mathrm{c} \sim 7 \mathrm{c}$, clay strength non-homogeneity $\kappa_{\mathrm{c}}$ has negligible effect on non363 dimensional capacities, which is consistent to Hung and Kim (2014). As such, in the 364 following investigation, only $\kappa_{\mathrm{c}}=3$ has been considered. 
367 In order to show the effect of the surface sand layer, the failure envelopes in $V-H$ space $368(M=0)$ and $V$-M space $(H=0)$ of skirted foundations in sand over clay with various 369 skirt length ratios of $d / D=0.25,0.5,0.75,1$ and sand layer thickness ratios of $T_{\mathrm{S}} / D=$ $3700.2,0.4,0.6$ are shown in Figure 8 and Figure 9 respectively. The data points with "star" 371 markers indicate the foundation capacity on clay (i.e. $T_{\mathrm{s}} / D=0$, from Figure 5,6 or 7 ). 372 Figures 8 and 9 illustrate the envelopes under ultimate states in terms of normalised 373 loads. Similar to uniaxial capacities, for each $d / D$, a thin sand layer $\left(T_{\mathrm{s}} / D=0 \sim 0.2\right)$ has 374 little effect on the ultimate loads. This means the envelopes in both $V-H$ and $V-M$ spaces 375 only expand a little (see the difference between the star markers and the curve for $T_{\mathrm{s}} / D$ $376=0.2$ in Figures 8 and 9). However, for a thicker sand layer with $T_{\mathrm{s}} / D>0.2$, the 377 envelopes expand sharply. The interaction of the vertical and moment degrees-of378 freedom (Figure 9) is slightly stronger than that in the $V-H$ space (Figure 8) i.e., 379 compared to the horizontal capacity, the moment capacity reduces more quickly with 380 increasing vertical load.

381 Figure 10 shows the failure envelopes in $H-M$ space $(V=0)$ and their dependence on 382 sand layer thickness ratio $\left(T_{\mathrm{s}} / D\right)$ and foundation skirt length ratio $(d / D)$. With the 383 combination of vertical and moment loading of the foundation, the failure envelopes 384 become oblique. The obliqueness become more server with larger skirt length. For a 385 constant skirt length ratio, the ultimate moment loading increases with increasing sand 386 layer thickness ratio. This is attributed to the increased capacity from the thicker sand 387 layer and the stronger clay embedded deeper underneath the sand. As such, it is 388 apparent that the failure envelopes are a function of both $d / D$ and $T_{\mathrm{s}} / D$. The envelopes 389 for $d / D=0.5$ and $T_{\mathrm{s}} / D=0$ from Hung and Kim (2014) have been included in Figures $3908 \mathrm{c}, 9 \mathrm{c}$ and 10c, evidencing reasonable consistency. 


\subsection{Approximating Expression}

392 Figure 11 represents the ultimate states normalised by the corresponding uniaxial load,

$393 v=V / V_{\mathrm{ult}}, h=H / H_{\mathrm{ult}}$, and $m=M / M_{\mathrm{ult}}$, indicating the shape of the relative size of the

394 failure envelopes. First, expressions were developed for $V-H$ and $V-M$ envelopes. All

395 the results presented in Figures 8 and 9 are normalised and plotted in Figures 11a and

$39611 \mathrm{~b}$ respectively. The values show a unique trend in each space, regardless of skirt

397 length ratio and the sand layer thickness ratio, which can be described using a power

398 law respectively as.

$399 h=\left(1-v^{3}\right)^{1 / 2}$

$400 \quad m=\left(1-v^{3}\right)^{1 / 2.4}$

401 The exponents (1/2 for Equation 10 and 1/2.4 for Equation 11) show the coupling 402 effects between different loadings: the vertical loading has more effect on the horizontal 403 capacity (exponent of 1/2) than on the moment loading capacity (exponent of 1/2.4). 404 The results are in excellent agreement with the unique curves, regardless of $d / D$ and $\kappa_{\mathrm{c}}$, 405 reported by Hung and Kim (2014).

406 Failure envelopes in clay were proposed for skirted foundations by Gourvnec and 407 Barnett (2011) and hybrid foundations by Bienen et al. (2012) using FE analysis results. 408 Randolph and House (2002) reported a failure envelope in $V$ - $H$ space for a suction 409 caisson (with skirt length ratio of $d / D \sim 1.41$ and the padeye at the top). These envelopes 410 are also included in Figure 11. It can be seen that the exponents for horizontal or 411 moment loadings are lower for skirted foundations, whereas the exponents for both 412 vertical and horizontal or moment loadings are significantly lower for hybrid 413 foundations. 
414 Figure 12 shows the envelopes in $h-m^{*}$ (where $m^{*}$ has been calculated normalising $M$

415 by the corresponding moment $M^{*}$ at $h=0$ ) space with $v=0$, indicating strong 416 dependence on $d / D$ and $T_{\mathrm{s}} / D$. Analyses have also been performed considering $v=0.5$ 417 and 0.75 with the aim of exploring corresponding effect on the failure envelopes and 418 combined capacity. The results are plotted in Figures $13,14,15,16$ for $d / D=0.25,0.5$, $4190.75,1.0$ respectively. It is seen that for a shallow skirt length ratio of $d / D=0.25$ with 420 a thin sand layer (i.e. $T_{\mathrm{s}} / D \leq 0.2$ ), the effect of vertical mobilisation is not obvious. For 421 longer skirt length ratio $d / D \geq 0.5$, the effect of vertical loading is more prominent for 422 all values of $v$. It can be seen that a larger $h-m^{*}$ failure envelope can be obtained for 423 higher vertical mobilisation. The similar findings have been reported for spudcan 424 foundations (Zhang et al., 2011, 2014). The data for various combinations of $d / D$ and $425 T_{\mathrm{s}} / D$ (as tabulated in Table 3$)$, normalised by the corresponding value for $v=0\left(h_{\mathrm{v}}=0\right.$ 426 or $m *_{v}=0$ ), are plotted in Figure 17 showing a reasonably unique trend of decreasing $427 h / h_{\mathrm{v}=0}$ or $m * / m *_{\mathrm{v}=0}$ with increasing $v$, which can be approximated as

$428\left(\frac{h}{h_{\mathrm{v}=0}}\right)^{0.21}=1+0.1 v(1-2.7 v)$

$429\left(\frac{m^{*}}{m^{*}{ }_{\mathrm{v}=0}}\right)^{0.21}=1+0.07 v(1-3.29 v)$

430 For coupled $V-H-M$ capacity, following Bienen et al. (2012) a conservative expression 431 can be developed combining Equations 10 and 11 as

$432|h|^{2}+m^{* 2.4}+v^{3}=1$

433 The approximation can alternatively be defined following Gourvenec and Barnett 434 (2011) and Vulpe (2015) according to 
436 where $\alpha$ and $\beta$ are fitting parameters dependent on the foundation skirt length ratio and

437 the sand layer thickness ratio. The values are tabulated in Table 3.

\section{SUMMARY DESIGN PROCEDURE}

440 A suggested procedure for estimating uniaxial or combined capacity for skirted

441 foundations in sand-over-clay with the skirt tip installed in the underlying clay layer is

442 outlined here. The procedure is based on the considered sand friction angle $\phi=32^{\circ}$, and

443 a dilation angle $\psi=2^{\circ}$, and clay undrained shear strength non-homogeneity $\kappa_{\mathrm{c}}=k D / s_{\text {umc }}$

$444=0.12 \sim 3.0$. The procedure can be modified for other sand and clay strength properties,

445 quantifying the corresponding effects and maintaining equivalent principles.

446 1. From the installation record, determine the skirt embedment depth $d$, and from 447 the site specific soil investigation report, determine the sand layer thickness $T_{\mathrm{s}}$.

$448 \quad 2$. For the given foundation diameter $D$, calculate $d / D$ and $T_{\mathrm{s}} / D$.

449 3. Calculate uniaxial vertical load capacity $v$, horizontal load capacity $h$ and $450 \quad$ moment capacity $m$ using Equations 3, 6 and 9 respectively.

4. Establish $v$ - $h$ and $m$ - $h$ failure envelopes using Equations 10 and 11, respectively, with the effect of vertical mobilisation quantified using Equations 12 and 13, respectively.

5. Estimate $v-h-m *$ capacity using Equations 14 or 15 with the corresponding constants in Table 3. 
457 A series of small strain FE analyses were carried out on circular skirted foundations

458 installed in the underlying clay layer of sand-over-non-homogeneous clay deposits. The 459 combined capacity of a foundation was shown to be a function of the sand layer 460 thickness ratio, foundation skirt length ratio and vertical load mobilisation level. The 461 following key conclusions can be drawn from the results presented in this paper.

462 a) Uniaxial vertical, horizontal and moment load capacities of skirted foundations on 463 sand-over-clay deposits, normalised by the corresponding capacity in the absence of 464 the sand layer, showed unique trend against $\frac{\left(T_{s} / D\right)}{(d / D)}$. Equations 3,6 and 9 can be used 465 to calculate the capacities respectively.

466 b) Failure envelope in either $V-H$ or $V-M$ space expanded very slowly up to the sand 467 layer thickness of $T_{\mathrm{s}} / D=0.2$, and then sharply for $T_{\mathrm{s}} / D>0.2$. The interaction of the 468 vertical and moment degrees-of-freedom was slightly stronger than that in the $V$ - $H$ 469 space i.e., compared to the horizontal capacity, the moment capacity reduces more 470 quickly with increasing vertical load.

471 c) For any vertical load mobilisation level ( $v)$, all results converge on $v$ - $h$ and $v-m$ spaces 472 regardless of the sand layer thickness ratio and skirt length ratio. The normalised failure 473 envelopes were expressed by Equations 10 and 11 respectively.

474 d) Complex interaction on $h-m^{*}$ space resulted non-unique normalised failure 475 envelopes with strong dependence on the sand layer thickness ratio, skirt length ratio, 476 and vertical load mobilisation level. Nonetheless, expressions (Equations 14 and 15) 477 were proposed to approximate the failure envelopes. 
478 The proposed expressions will enable practitioners to derive the failure envelopes in 479 the field during preliminary design. The design framework was established based on 480 the properties of a silica sand with friction angle $=32^{\circ}$ and dilation angle $=2^{\circ}$ with no 481 particle breakage. Caution should be exercised for applying the framework for sands 482 with other friction and dilation angles and for other sands with potential particle 483 breakage.

\section{ACKNOWLEDGEMENTS}

486 The research presented here was undertaken with support from the Australian Research 487 Council (ARC) Discovery Grant (DP1096764), the National Natural Science 488 Foundation of China (Grant No. 51378197 \& No. 51578231) and supported by the 489 Fundamental Research Funds for the Central Universities of China (D2171820), Water 490 conservancy science and technology innovation project of Guangdong province(2015491 17), Science and Technology Program of POWERCHINA Huadong Engineering 492 Corporation Limited (SD2013-10) and Science and Technology Program of 493 Guangzhou (201707020047).The work forms part of the activities of the Centre for 494 Offshore Foundation Systems (COFS), currently supported as a node of the Australian 495 Research Council Centre of Excellence for Geotechnical Science and Engineering and 496 as a Centre of Excellence by the Lloyd's Register Foundation. This support is gratefully 497 acknowledged, as is the benefit of discussion with Dr Long Yu, Dr Dong Wang and Dr 498 Xu Li. 
501

502

503 
Andersen, K. H., Jostad, H. P. Dyvik, R. 2008. Penetration resistance of offshore skirted foundations and anchors in dense sand. J. Geotech. Geoenvironmental Eng. ASCE, 134(1), 106-116.

Barari, A. Ibsen, L. B. 2012. Undrained response of bucket foundations to moment loading. Applied Ocean Research, 36, 12-21.

Barari, A. Ibsen, L. B. 2012. Undrained response of bucket foundations to moment loading. Applied Ocean Research, 36(3), 12-21.

Bienen, B., Gaudin, C., Cassidy, M.J., Rausch, L., Purwana, O.A. Krisdani, H. 2012. Numerical modelling of a hybrid skirted foundation under combined loading. Computers and Geotechnics, 45, 127-139.

Bransby, M. Randolph, M.F.1997. Shallow foundations subject to combined loadings. Proceedings of the 9th International Conference on Computer Methods and Advances in Geomechanics. Wuhan, November. Edited by J. Yuan. AA Balkema, Rotterdam, pp. 1947-1952.

Bransby, M. Randolph, M.F. 1998. Combined loading of skirted foundations. Géotechnique, 48(5), 637-655.

Bransby, M. Randolph, M.F. 1999. The effect of skirted foundation shape on response to combined VMH loadings. International Journal of Offshore and Polar Engineering, 9(3).

Bransby, M. Yun, G.J. 2009. The undrained capacity of skirted strip foundations under combined loading. Géotechnique, 59(2), 115-125.

Barari, A. and L. B. Ibsen. 2012. Undrained response of bucket foundations to moment 
528

Butterfield, R., Houlsby, G.T. Gottardi, G. 1997. Standardized sign conventions and notation for generally loaded foundations. Géotechnique, 47(5), 1051-1054.

Byron, W. B. Houlsby, G.T. 2004. Experimental Investigations of the response of suction caissons to transient combined loading. J. Geotech. Geoenvironmental Eng., ASCE, 130(3), 240-253.

Cheong,J. 2002. Physical testing of jack-up footings on sand subjected to torsion. Honours thesis, University of Western Australia, Perth, Australia.

Cox, A. D. Eason, G. Hopkins, H. G. 1961. Axially symmetric plastic deformations in soils. Philosophical Transactions of the Royal Society A Mathematical Physical \& Engineering Sciences, 254(1036), 1-45.

Jacky, J. 1944. The coefficient of earth pressure at rest. In Hungarian (A nyugalmi nyomas tenyezoje). Journal of the Society of Hungarian Architects and Engineers, Budapest, Hungry, 355-358.

Lee, J., Salgado, R., 2005. Estimation of bearing capacity of circular footings on sands based on cone penetration test. Journal of Geotechnical and Geoenvironmental Engineering 131(4), 442-452.

Lee, K.K. Cassidy, M.J., Randolph, M.F. 2013Bearing capacity on sand overlying clay soils:Experimental and finite element investigation of potential punch-through filure, geotechnique 63(15)1271-1284

Lian, J., Chen, F., Wang, H. 2014. Laboratory tests on soil-skirt interaction and penetration resistance of suction caissons during installation in sand. Ocean Engineering, 84(3), 1-13. 
DNV (Det Norske Veritas) 1992. Foundations, classifications notes no. 30.4. Oslo, Norway.Gourvenec, S.M. 2007. Failure envelopes for offshore shallow foundations under general loading. Géotechnique 57(9), 715-728.

Houlsby, G.T., Martin, C.M., 2003. Undrained bearing capacity factors for conical footings on clay. Géotechnique 53(5), 513-520.

Hung L.C., Kim S.R., 2012. Evaluation of vertical and horizontal bearing capacities of bucket foundations in clay. Ocean Engineering 52, 75-82.

Hung L.C., Kim S.R., 2014. Evaluation of undrained bearing capacities of bucket foundations under combined loads. Marine Georesources \& Geotechnology 32, 76-92.

Randolph, M. F. Puzrin A (2003)Upper bound limit analysis of circular foundations on clay under general loading. Géotechnique 53.9:785-796.

Gourvenec, S. (2007). Failure envelopes for offshore shallow foundations under general loading Geotechnique 57, No. 9, 715-728 Gourvenec, S.M. 2008. Effect of embedment on the undrained capacity of shallow foundations under general loading. Géotechnique 58(3), 177-185.

Gourvenec, S.M, Mana, D.S.K., 2011. Undrained vertical bearing capacity factors for shallow foundations. Géotechnique Letters 1, 101-108.

Gourvenec, S.M., Randolph, M.F. 2003. Effect of strength non-homogeneity on the shape of failure envelopes for combined loading of strip and circular foundations on clay. Géotechnique53(6), 575-586.

571 Gourvenec, S. 2008. Effect of embedment on the undrained capacity of shallow foundations under general loading. Geotechnique 58(3): 177-185. 
573 Gourvenec, S. M. Barnett, S. 2011. Undrained failure envelope for skirted foundations under general loading.Géotechnique61(3), 263-270.

Hu,P. Stanier, S.A., Cassidy,M.J., Wang D. 2014 Predicting peak resistance of spudcan penetrating sand overlying clay, J. Geotech. Geoenviron. Eng.,140(2)04013009

Ibsen, L. B., Larsen, K. A. Barari, A. 2014. Calibration of failure criteria for bucket foundations on drained sand under genral loading. J. Geotech. Geoenvironmental Eng.ASCE140(7), 04014033.

ISO (International Standadization Organization) 2003. ISO 19901-4: Petroleum and natural gas industries - specific requirements for offshore structures - Part 4: Geotechnical and foundationn design considerations, $1^{\text {st }}$ Ed., Geneva, Switzerland.

Kourkoulis, R.S., Lekkakis, P.C., Gelagoti, F.M. Kaynia, A.M. 2014. Suction caisson foundations for offshore wind turbines subjected to wave and earthquake loading: effect of soil-foundation interface. Géotechnique64(3), 171-185.

Park, J.S., Park, D., Yoo, J.K. 2016. Vertical bearing capacity of bucket foundations in sand. Ocean Engineering 121, 453-461.

Park, J.S., Park, D., 2017. Vertical bearing capacity of bucket foundation in sand overlying clay. Ocean Engineering 134, 62-76.

Potts, D.M. Zdravkovic, L., Zdravković, L., 2001. Finite element analysis in geotechnical engineering: application. Thomas Telford.

Randolph, M.F. House, A.R. 2002. Analysis of Suction Caisson Capacity in Clay. Offshore Technology Conference. 
Randolph, M. F., Gaudin, C., Gourvenec, S. M., White, D. J., Boylan, N., Cassidy, M. J. 2011. Recent advances in offshore geotechnics for deep water oil and gas developments. Ocean Engineering, 38(7), 818-834.

Simulia D.S., 2013. ABAQUS Documentation v6.13, Dassault Systemes Simulia Corp., Providence, RI, USA.Abaqus 2013. ABAQUS Documentation, Dassault Systemes, Providence, RI

Supachawarote, C., Randolph, M.F. Gourvenec, S.M. 2005. The effect of crack formation on the inclined pull-out capacity of suction caissons. Proc. 11th Int. Assoc. for Computer Methods and Advances in Geomechanics Conf., Turin, pp. $577-584$.

Taiebat, H.A. Carter, J.P. 2000. Numerical studies of the bearing capacity of shallow foundations on cohesive soil subjected to combined loading. Géotechnique50(4), 409-418.

Tan, F.S.C. 1990. Centrifuge and theoretical modelling of conical footings on sand, University of Cambridge.

Tani, K. Craig, W. 1995. Bearing capacity of circular foundations on soft clay of strength increasing with depth. Soils and Foundations35(4), 21-35.

Teh K.L., Leung, C.F., Chow, Y.K., Caissdy, M.j. Quah,M. 2010 Centrifuge model study of spudcan penetration in sand overlying clay. Geotechnique,60(11),825842

Ukritchon, B., Whittle, A.J. Sloan, S.W. 1998. Undrained limit analyses for combined loading of strip footings on clay. Journal of Geotechnical and Geoenvironmental Engineering124(3), 265-276. 
618 Vulpe, C. 2015. Design method for the undrained capacity of skirted circular foundations under combined loading: effect of deformable soil plug. Geotechnique65(8), 669-83.

Vulpe, C., Bienen, B. Gaudin, C. 2013. Predicting the undrained capacity of skirted spudcans under combined loading. Ocean Engineering74, 187-188.

Vulpe, C., Gourvenec, S.M. Power, M. 2014. A generalised failure envelope for 624 undrained capacity of circular shallow foundations under general loading.

Wang, Y., Lu, X., Wang, S., Shi, Z. 2006. The response of bucket foundation under 627 horizontal dynamic loading. Ocean Engineering, 33(7), 964-973.

Yun, G.J. Bransby, M.F. 2007a. The horizontal-moment capacity of embedded 629 foundations in undrained soil. Canadian Geotechnical Journal, 44(4), 409-427.

Yun, G. and M. F. Bransby. 2007b. The undrained vertical bearing capacity of skirted foundations. Soils and Foundations 47(3), 493-506.

Zhang, Y., Bienen, B., Cassidy, M. J., Gourvenec, S. 2011. The undrained bearing capacity of a spudcan foundation under combined loading in soft clay. Marine

Zhang, Y., Bienen, B., Cassidy, M. J. 2014. Jack-up push-over analyses featuring a new force resultant model for spudcans in soft clay. Ocean Engineering, 81(2), 139149. 
640 Zhou M, Hossain MS, Hu Y and Liu HL 2016. Scale Issues and Interpretation of Ball 641 Penetration in Stratified Deposits in Centrifuge Testing, Journal of geotechnical 642 and Geoenviroment Engineering. 142(5 
644

\begin{tabular}{|l|c|c|c|}
\hline & Vertical & Horizontal & Rotational \\
\hline Load & $V$ & $H$ & $M$ \\
\hline Ultimate load & $V_{\mathrm{ult}}$ & $H_{\mathrm{ult}}$ & $M_{\mathrm{ult}}$ \\
\hline Dimensionless load & $V / A s_{\mathrm{u} 0}$ & $H / A s_{\mathrm{u} 0}$ & $M / A D s_{\mathrm{u} 0}$ \\
\hline Dimensionless ultimate & $v_{0}=V_{\mathrm{ul}} / A s_{\mathrm{u} 0}$ & $h_{0}=H_{\mathrm{ul}} / A s_{\mathrm{u} 0}$ & $m_{0}=M_{\mathrm{ul}} / A D s_{\mathrm{u} 0}$ \\
\hline load & $v=V / V_{\mathrm{ult}}$ & $h=H / H_{\mathrm{ult}}$ & $\begin{array}{c}m=M / M_{\mathrm{ult}} \\
m^{*}=M / M^{*}\end{array}$ \\
\hline Normalised load & & $u$ & $\theta$ \\
\hline Displacement & $w$ & & \\
\hline
\end{tabular}

645

646

647 
Table 2 Solutions for surface circular footings subjected to uniaxial vertical loading

\begin{tabular}{|c|c|c|c|}
\hline $\begin{array}{c}\text { Clay strength non- } \\
\text { homogeneity, } \kappa_{c}=k D / s_{u m}\end{array}$ & $\begin{array}{l}\text { Interface } \\
\text { roughness }\end{array}$ & $\begin{array}{l}\text { Dimensionless uniaxial } \\
\text { capacity, } v_{0}=V_{\mathrm{ult}} / A s \mathrm{u} 0 \text {, whi } \\
\text { taken as bearing capacity }\end{array}$ & $\begin{array}{l}\text { hrtical } \\
\text { h can be } \\
\text { ctor, } N_{c}\end{array}$ \\
\hline \multirow{5}{*}{0} & \multirow{5}{*}{ Smooth } & Tani and Craig (1995) & 5.69 \\
\hline & & Taiebat and Carter (2000) & 5.70 \\
\hline & & Houlsby and Martin (2003) & 5.69 \\
\hline & & $\begin{array}{l}\text { Gourvenec and Mana } \\
(2011)\end{array}$ & 5.549 \\
\hline & & This study (Implicit) & 5.602 \\
\hline \multirow{6}{*}{0} & \multirow{6}{*}{ Rough } & Cox et al. (1961) & 6.05 \\
\hline & & Tani and Craig (1995) & 6.34 \\
\hline & & $\begin{array}{l}\text { Gourvenec and Randolph } \\
(2003)\end{array}$ & 5.91 \\
\hline & & Houlsby and Martin (2003) & 6.05 \\
\hline & & This study (Implicit) & 6.011 \\
\hline & & This study (Explicit) & 6.086 \\
\hline \multirow{4}{*}{3} & \multirow{4}{*}{ Rough } & Houlsby and Martin (2003) & 8.21 \\
\hline & & $\begin{array}{l}\text { Gourvenec and Randolph } \\
(2003)\end{array}$ & 8.04 \\
\hline & & This study (Implicit) & 8.028 \\
\hline & & This study (Explicit) & 8.051 \\
\hline
\end{tabular}


Table 3 Values of $\alpha$ and $\beta$ for Equation 15

\begin{tabular}{|c|c|c|c|c|c|c|}
\hline$T_{\mathrm{s}} / D$ & $d / D$ & $v$ & $\begin{array}{c}H_{\text {ult }} \\
(\mathbf{k N})\end{array}$ & $\begin{array}{c}M^{*} \\
(\mathbf{k N} . \mathbf{m})\end{array}$ & $\alpha$ & $\beta$ \\
\hline 0 & 1.00 & 0 & 5.071 & 2.565 & 1.834 & -0.714 \\
\hline 0 & 0.75 & 0 & 4.411 & 1.948 & 1.850 & -0.675 \\
\hline 0 & 0.50 & 0 & 3.633 & 1.462 & 1.715 & -0.582 \\
\hline 0 & 0.25 & 0 & 2.785 & 1.118 & 1.947 & -0.349 \\
\hline 0.1 & 0.25 & 0 & 2.742 & 1.19 & 2.032 & -0.409 \\
\hline 0.2 & 1.00 & 0 & 5.121 & 2.950 & 1.855 & -0.741 \\
\hline 0.2 & 0.75 & 0 & 4.506 & 2.081 & 1.669 & -0.660 \\
\hline 0.2 & 0.50 & 0 & 3.814 & 1.570 & 1.682 & -0.624 \\
\hline 0.2 & 0.25 & 0 & 3.210 & 1.310 & 2.139 & -0.578 \\
\hline 0.4 & 1.00 & 0 & 5.494 & 3.314 & 1.940 & -0.824 \\
\hline 0.4 & 0.75 & 0 & 5.130 & 2.500 & 1.755 & -0.712 \\
\hline 0.4 & 0.50 & 0 & 4.958 & 1.920 & 1.667 & -0.640 \\
\hline 0.4 & 0.25 & 0 & 3.210 & 1.310 & 1.977 & -0.508 \\
\hline 0.6 & 1.00 & 0 & 6.494 & 3.950 & 1.973 & -0.869 \\
\hline 0.6 & 0.75 & 0 & 6.646 & 3.150 & 1.947 & -0.822 \\
\hline 0.1 & 0.25 & 0.50 & 2.403 & 1.080 & 2.091 & -0.417 \\
\hline 0.1 & 0.25 & 0.75 & 2.119 & 0.900 & 2.046 & -0.454 \\
\hline 0.2 & 0.25 & 0.50 & 2.911 & 1.240 & 1.883 & -0.534 \\
\hline 0.2 & 0.25 & 0.75 & 2.650 & 1.030 & 1.601 & -0.523 \\
\hline 0.2 & 0.50 & 0.50 & 3.619 & 1.480 & 1.609 & -0.604 \\
\hline 0.2 & 0.50 & 0.75 & 2.909 & 1.180 & 1.709 & -0.658 \\
\hline 0.4 & 0.50 & 0.50 & 4.292 & 1.520 & 1.238 & -0.541 \\
\hline 0.4 & 0.50 & 0.75 & 3.200 & 1.250 & 1.812 & -0.760 \\
\hline 0.2 & 0.75 & 0.50 & 4.107 & 1.900 & 1.682 & -0.670 \\
\hline 0.2 & 0.75 & 0.75 & 3.301 & 1.600 & 1.622 & -0.662 \\
\hline 0.4 & 0.75 & 0.50 & 4.531 & 2.000 & 1.659 & -0.682 \\
\hline 0.4 & 0.75 & 0.75 & 3.952 & 1.630 & 1.571 & -0.637 \\
\hline 0.6 & 0.75 & 0.50 & 6.090 & 2.780 & 1.770 & -0.737 \\
\hline 0.6 & 0.75 & 0.75 & 4.870 & 2.350 & 2.078 & -0.968 \\
\hline 0.2 & 1.00 & 0.50 & 4.811 & 2.650 & 1.680 & -0.677 \\
\hline
\end{tabular}


654

\begin{tabular}{|l|l|l|l|l|l|l|}
\hline 0.2 & 1.00 & 0.75 & 3.895 & 2.100 & 1.830 & -0.762 \\
\hline 0.4 & 1.00 & 0.50 & 5.084 & 2.900 & 1.918 & -0.838 \\
\hline 0.4 & 1.00 & 0.75 & 3.968 & 2.400 & 2.181 & -1.037 \\
\hline 0.6 & 1.00 & 0.50 & 5.247 & 3.450 & 1.986 & -0.901 \\
\hline 0.6 & 1.00 & 0.75 & 3.872 & 2.900 & 1.879 & -0.830 \\
\hline
\end{tabular}


655

656

657

658

659

660

661

662

663

664

665

666

667

668

669

670

671

672

673

674

675

676

677

\section{Number of Figures: 17}

Figure 1 Schematic diagram of a skirted foundation subjected to $V$ - $H$ - $M$ loading in sand-over-clay

Figure 2 Typical mesh used in FE analyses

Figure 3 Failure envelopes of surface circular footing on uniform clay $(d / D=0$, $\left.T_{\mathrm{s}} / D=0, \kappa_{\mathrm{c}}=0\right)$ : (a) Failure envelopes in $H-M$ space $(V=0)$; (b) Failure envelopes in $V$ - $H$ space $(M=0)$

Figure 4 Skirted foundation in clay under uniaxial vertical loading: (a) Typical vertical load-displacement response in clay $\left(T_{\mathrm{s}} / D=0, \kappa_{\mathrm{c}}=3\right) ;(\mathrm{b})$ Ultimate uniaxial vertical load $\left(T_{\mathrm{s}} / D=0, \kappa_{\mathrm{c}}=3\right)$; (c) Ultimate uniaxial $\operatorname{vertical~load}\left(T_{\mathrm{s}} / D=0, \kappa_{\mathrm{c}}=0.12 \sim 0.6\right)$

Figure 5 Skirted foundations in sand-over-clay under uniaxial vertical loading: (a) Vertical load-displacement response $\left(\kappa_{\mathrm{c}}=3\right)$; (b) Ultimate uniaxial vertical load $\left(\kappa_{\mathrm{c}}=3\right)$; (c) Normalised ultimate uniaxial vertical load $\left(\kappa_{\mathrm{c}}\right.$ $=0.12 \sim 3)$

Figure 6 Skirted foundations under uniaxial horizontal loading: (a) Ultimate uniaxial horizontal load in clay $\left(T_{\mathrm{s}} / D=0, \kappa_{\mathrm{c}}=3\right)$; (b) Ultimate uniaxial horizontal load in clay $\left(T_{\mathrm{s}} / D=0, \kappa_{\mathrm{c}}=0.12 \sim 0.6\right)$; (c) Normalised ultimate uniaxial horizontal load in sand-over-clay $\left(\kappa_{\mathrm{c}}=0.12 \sim 3\right)$

Figure 7 Skirted foundations under uniaxial moment loading: (a) Ultimate uniaxial moment load in clay $\left(T_{\mathrm{s}} / D=0, \kappa_{\mathrm{c}}=3\right)$; (b) Ultimate uniaxial moment load in clay $\left(T_{\mathrm{s}} / D=0, \kappa_{\mathrm{c}}=0.12 \sim 0.6\right)$; (c) Normalised ultimate uniaxial moment load in sand-over-clay $\left(\kappa_{\mathrm{c}}=0.12 \sim 3\right)$ 
678 Figure 8 Failure envelopes in $V-H$ space: (a) $d / D=1.0$; (b) $d / D=0.75$; (c) $d / D=$ $0.5 ;(\mathrm{d}) d / D=0.25$

680

Figure 9 Failure envelopes in $V-M$ space: (a) $d / D=1.0$; (b) $d / D=0.75$; (c) $d / D=$ 681 $0.5 ;(\mathrm{d}) d / D=0.25$

Figure 10 Failure envelopes in $H-M$ space: (a) $d / D=1.0$; (b) $d / D=0.75$; (c) $d / D=$ 683 $0.5 ;(\mathrm{d}) d / D=0.25$

Figure $11 \quad$ Normalised failure envelopes: (a) $v$ - $h$ space; (b) $v-m$ space

Figure 12 Normalised failure envelopes in $h-m$ space $(v=0)$ : (a) $d / D=1.0$; (b) $d / D$ 686 $=0.75 ;$ (c) $d / D=0.5 ;(\mathrm{d}) d / D=0.25$

Figure 13 Effect of vertical mobilisation $v$ on normalised failure envelopes in $h-m$ 688 space: $d / D=0.25:$ (a) $T_{\mathrm{s}} / D=0.1$; (b) $T_{\mathrm{s}} / D=0.2$

Figure 14 Effect of vertical mobilisation $v$ on normalised failure envelopes in $h-m$ 690 space: $d / D=0.5:$ (a) $T_{\mathrm{s}} / D=0.2 ;$ (b) $T_{\mathrm{s}} / D=0.4$

Figure 15 Effect of vertical mobilisation $v$ on normalised failure envelopes in $h-m$ 692 space: $d / D=0.75:$ (a) $T_{\mathrm{s}} / D=0.2 ;$ (b) $T_{\mathrm{s}} / D=0.4$; (c) $T_{\mathrm{s}} / D=0.6$

Figure 16 Effect of vertical mobilisation $v$ on normalised failure envelopes in $h-m$ 694 space: $d / D=1.0$ : (a) $T_{\mathrm{s}} / D=0.2$; (b) $T_{\mathrm{s}} / D=0.4$; (c) $T_{\mathrm{s}} / D=0.6$ 


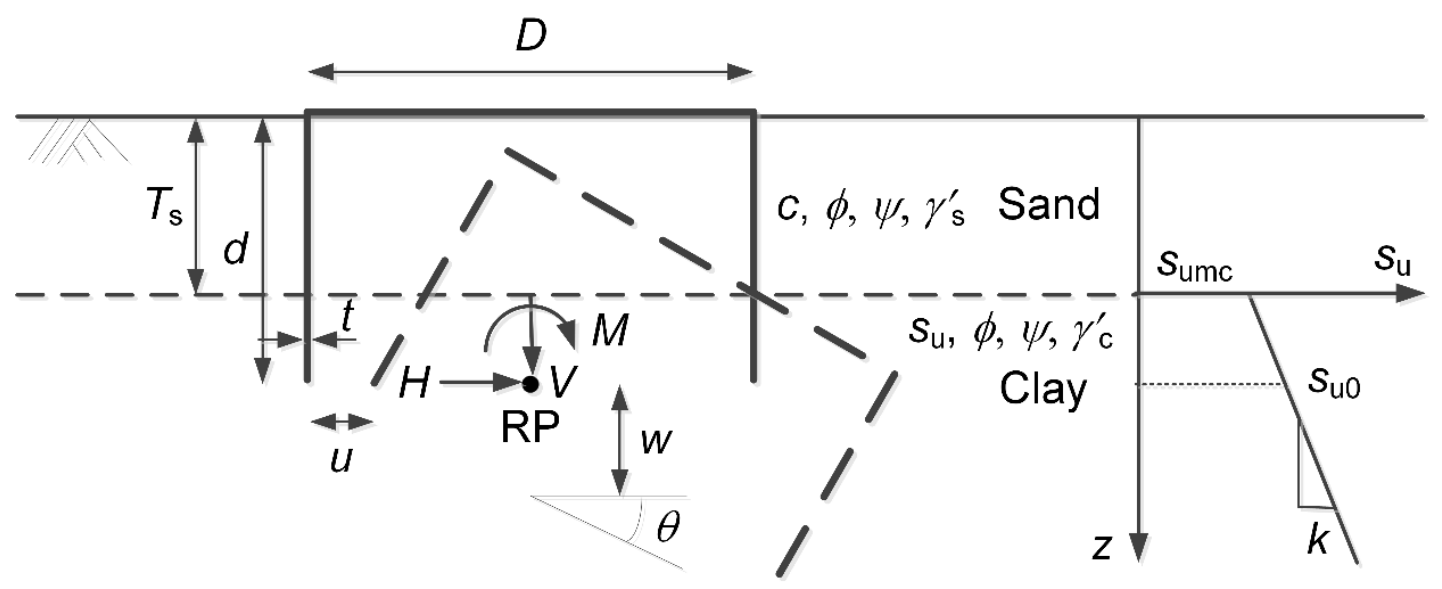

698

699

700 Figure 1 Schematic diagram of a skirted foundation subjected to $V$ - $H$ - $M$ loading 701 in sand-over-clay

702

703 


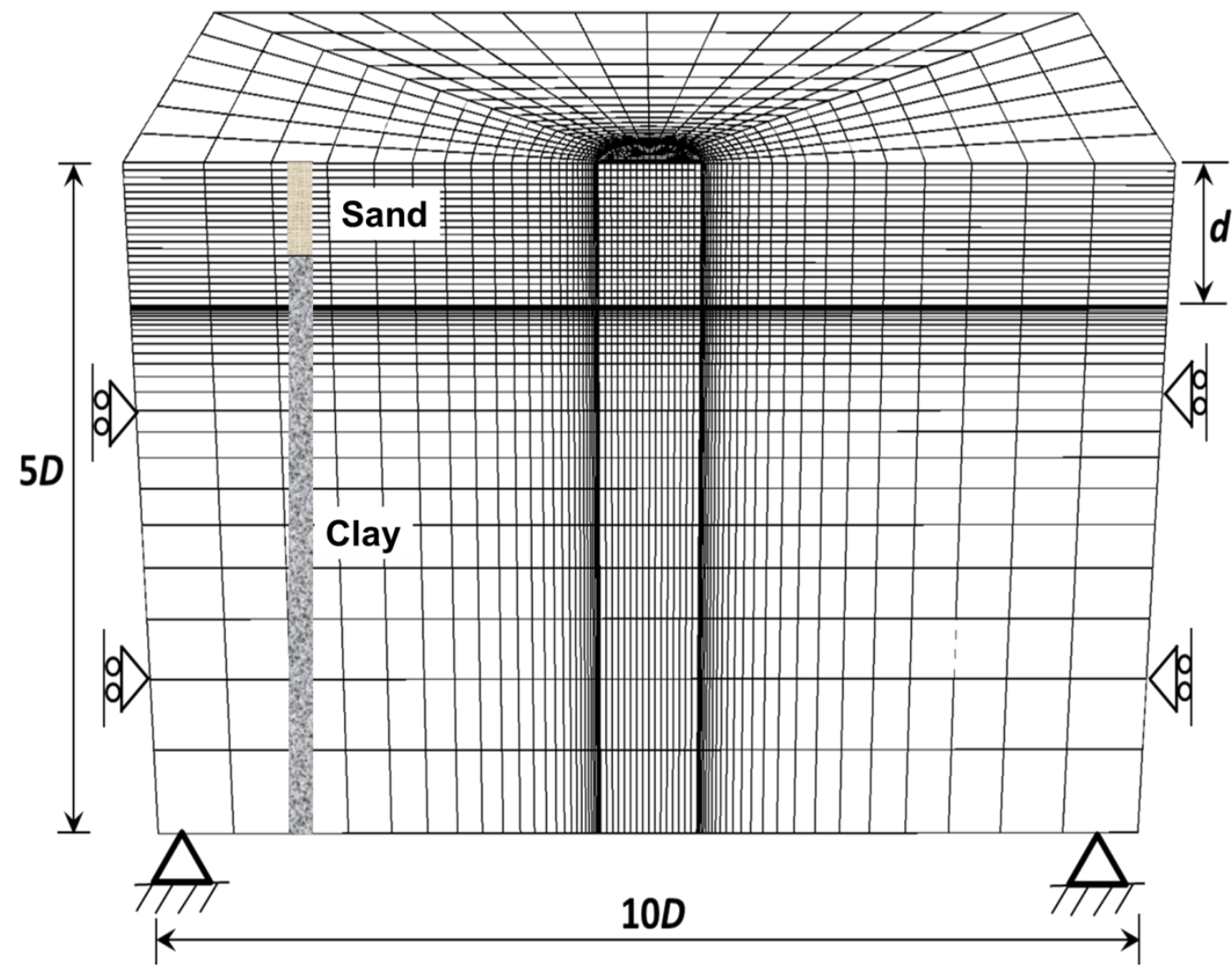

707

708 


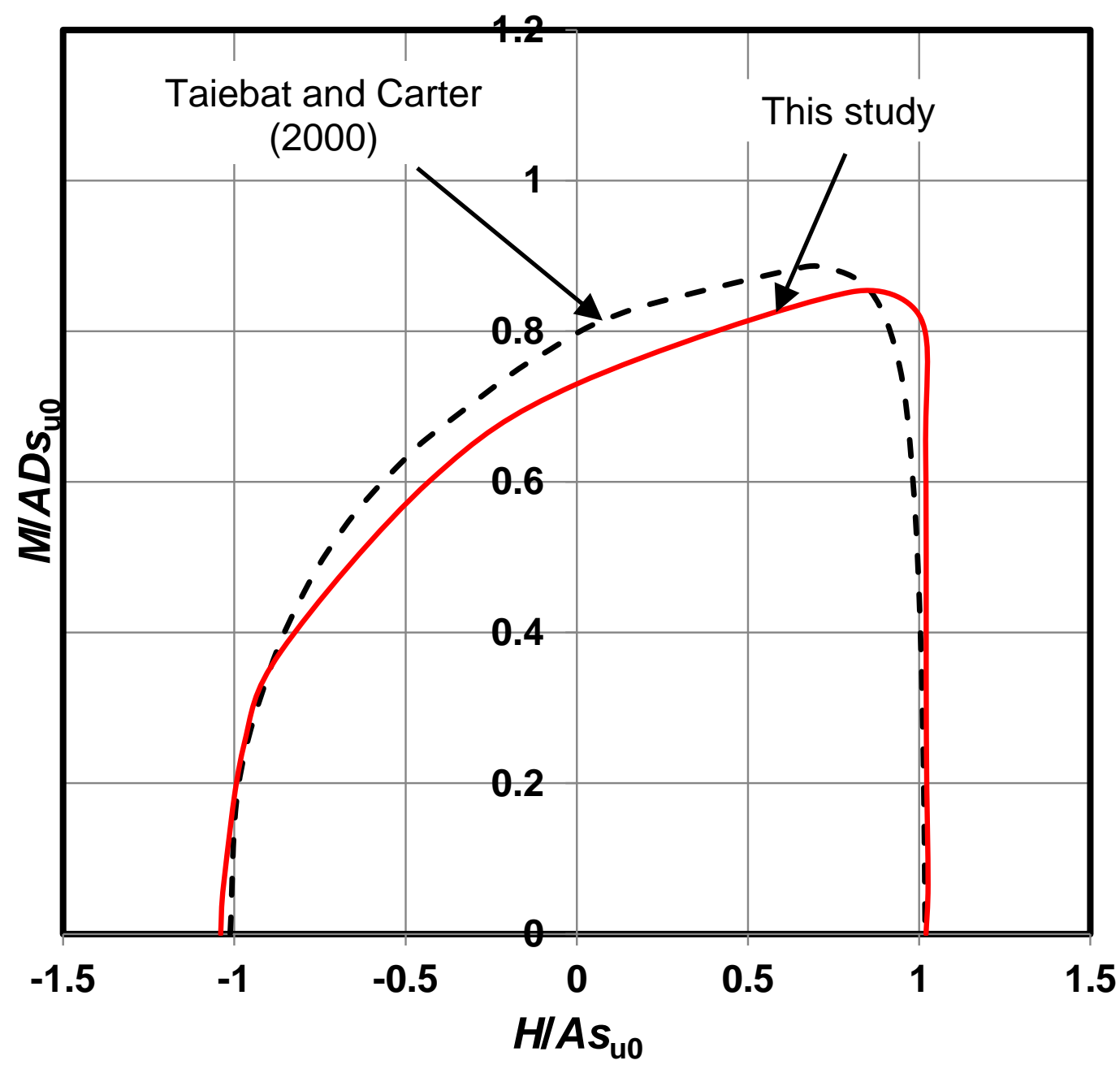

709

(a) Failure envelopes in $H-M$ space $(V=0)$

711

712

713

714 


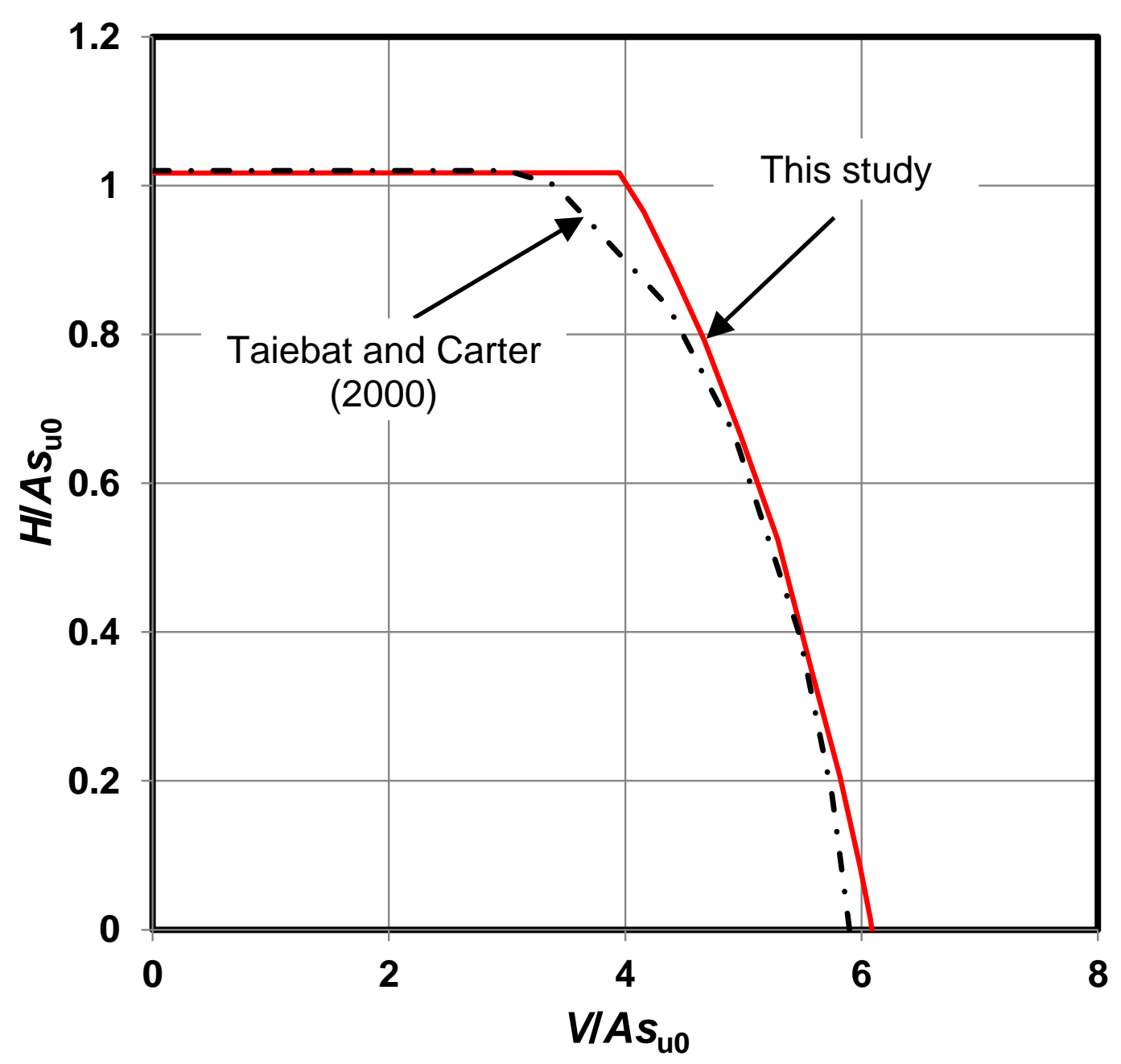

715

(b) Failure envelopes in $V-H$ space $(M=0)$

Figure 3 Failure envelopes of surface circular footing on uniform clay $(d / D=0$,

$$
\left.T_{\mathrm{s}} / D=0, \kappa_{\mathrm{c}}=0\right)
$$




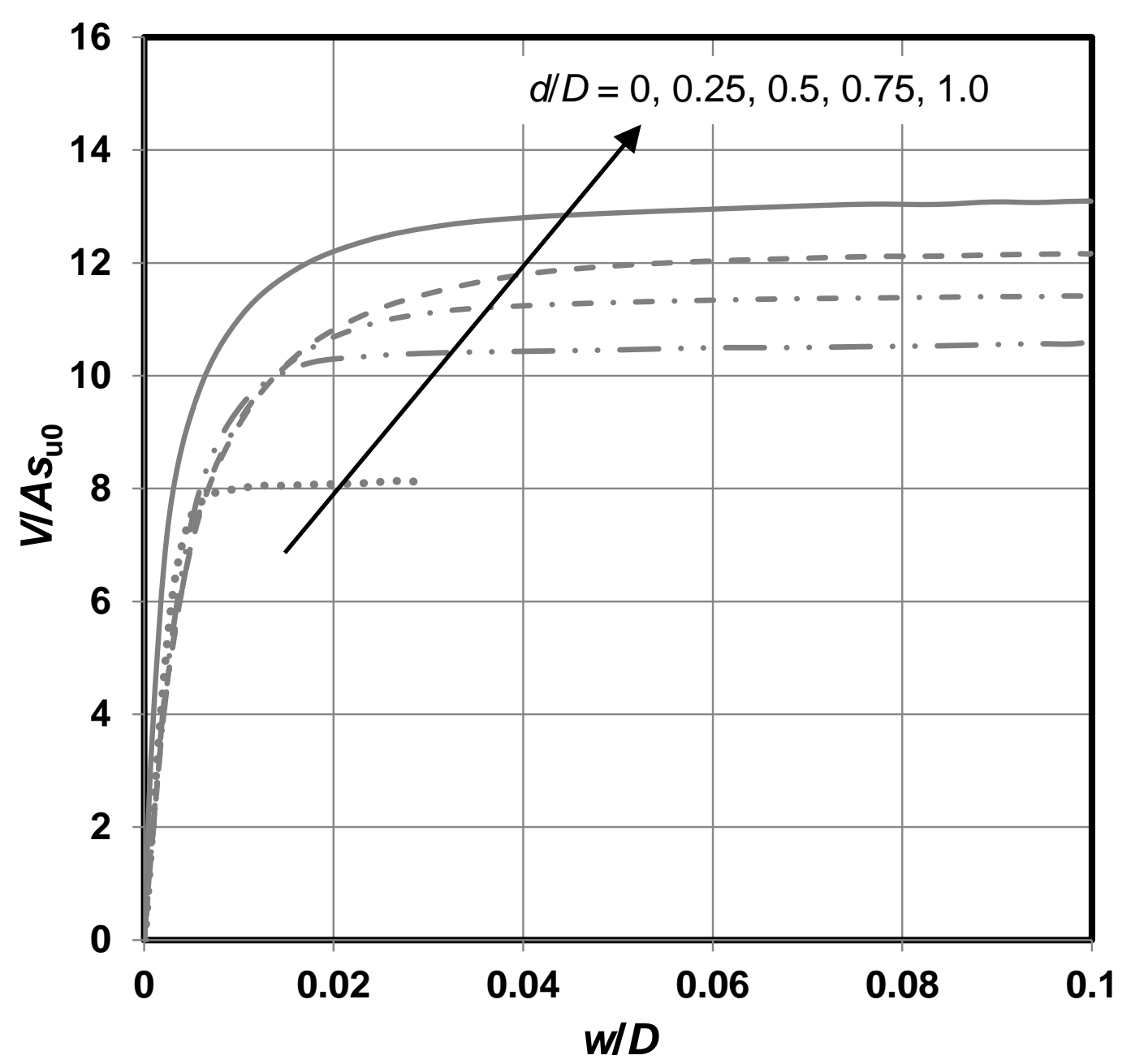

722

723 (a) Typical vertical load-displacement response in clay $\left(T_{\mathrm{s}} / D=0, \kappa_{\mathrm{c}}=3\right)$ 


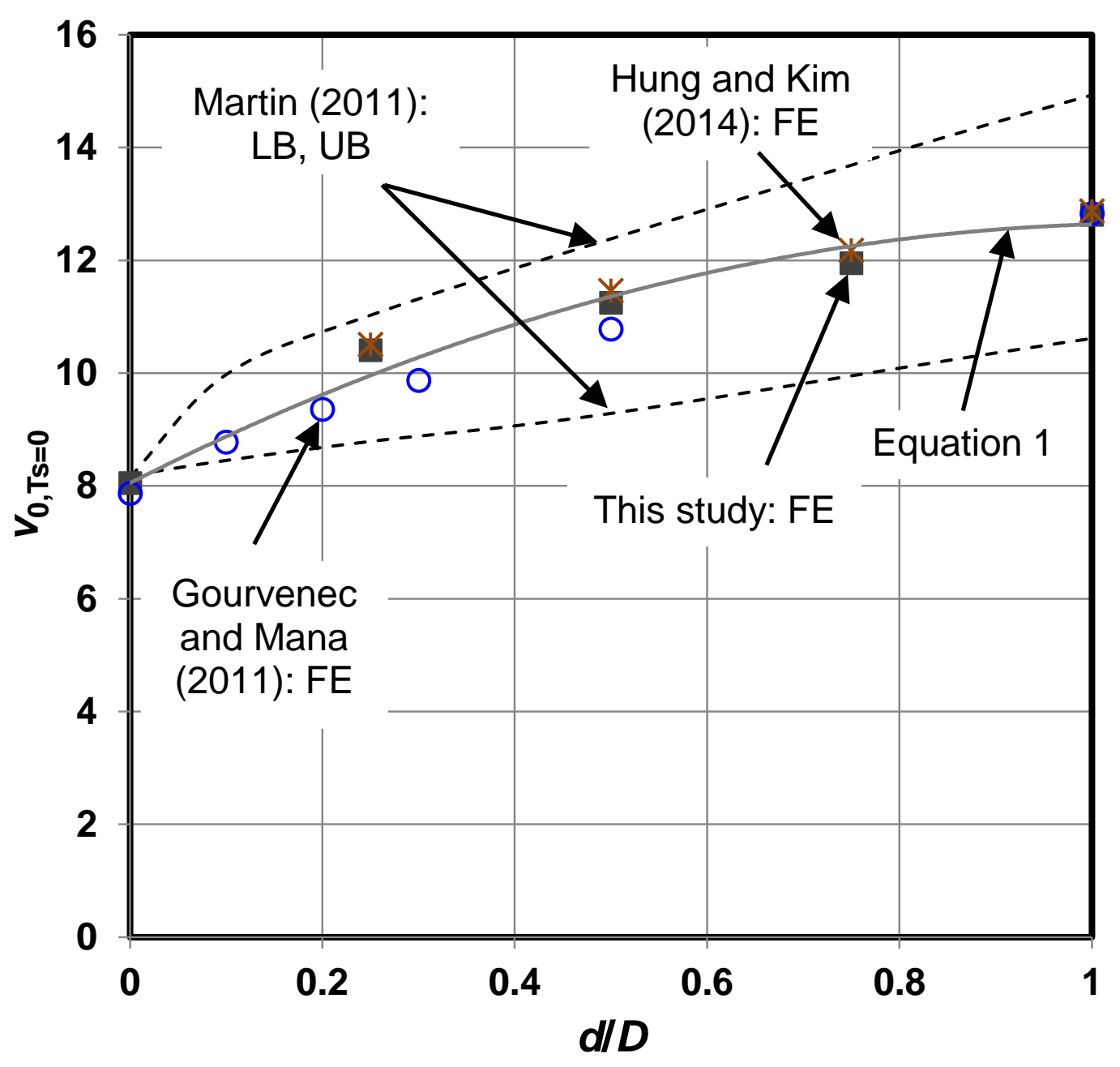

(b) Ultimate uniaxial vertical load $\left(T_{\mathrm{s}} / D=0, \kappa_{\mathrm{c}}=3\right)$ 


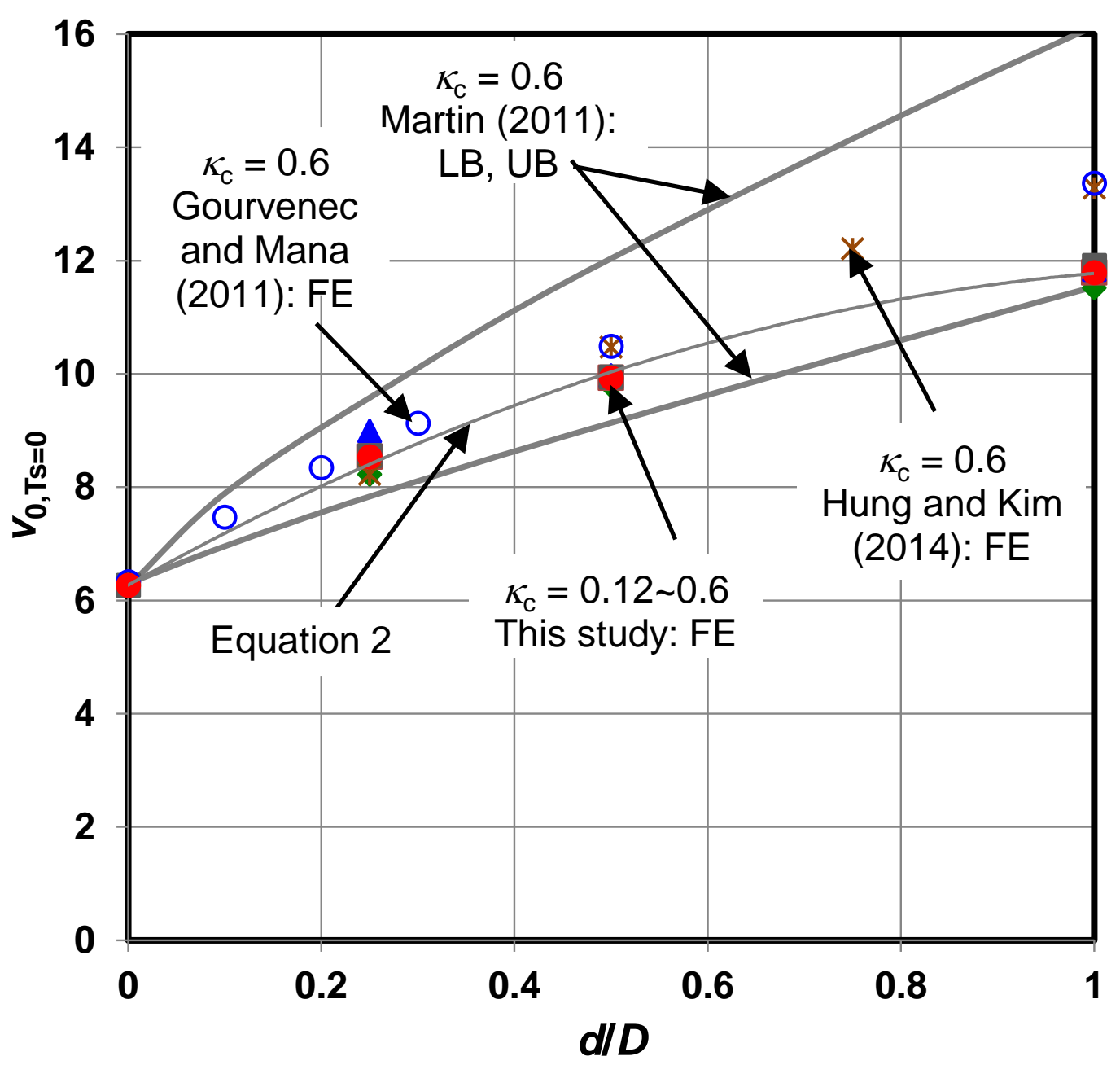

(c) Ultimate uniaxial vertical load $\left(T_{\mathrm{s}} / D=0, \kappa_{\mathrm{c}}=0.12 \sim 0.6\right)$ 


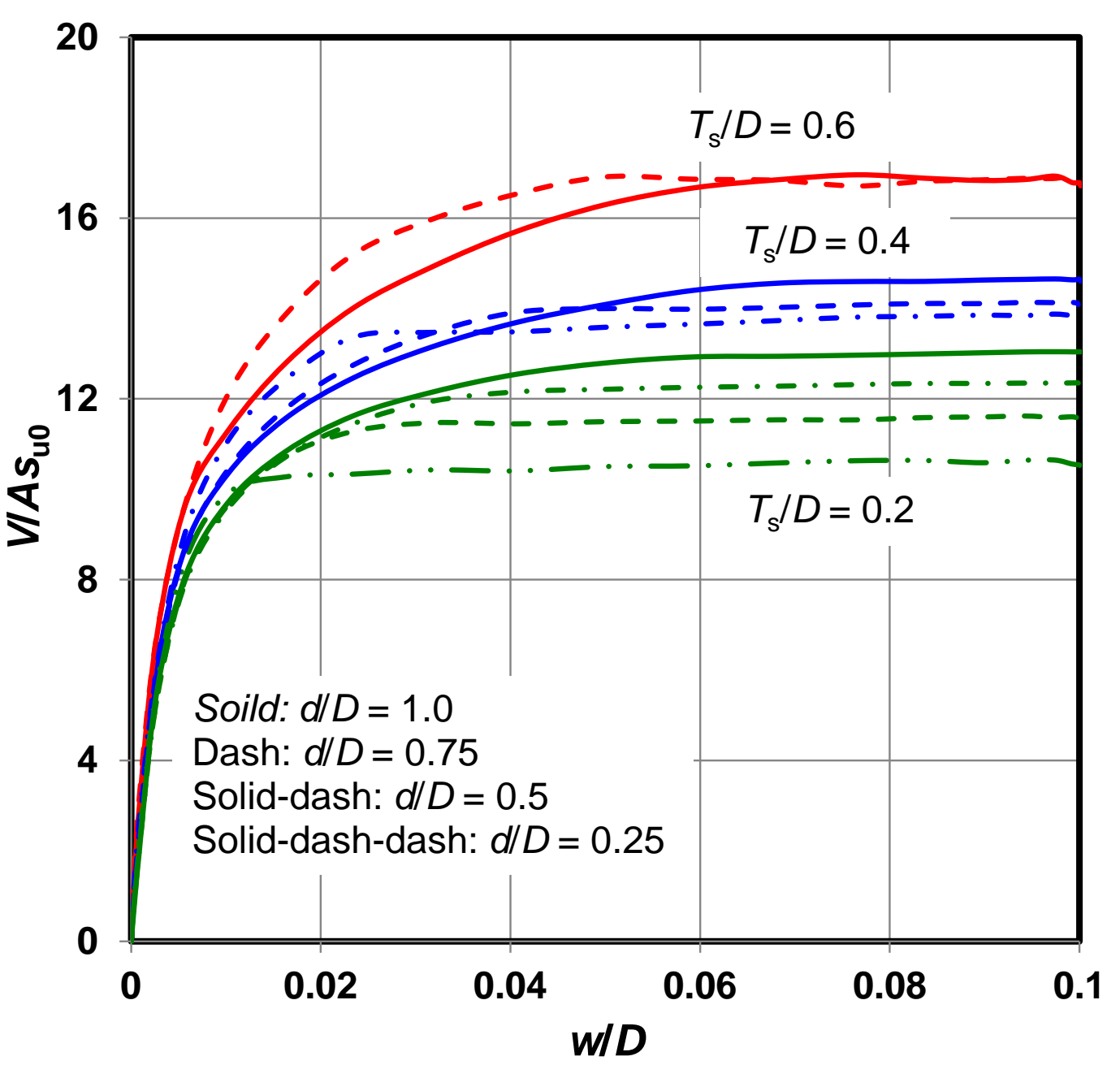

(a) Vertical load-displacement response $\left(\kappa_{\mathrm{c}}=3\right)$ 


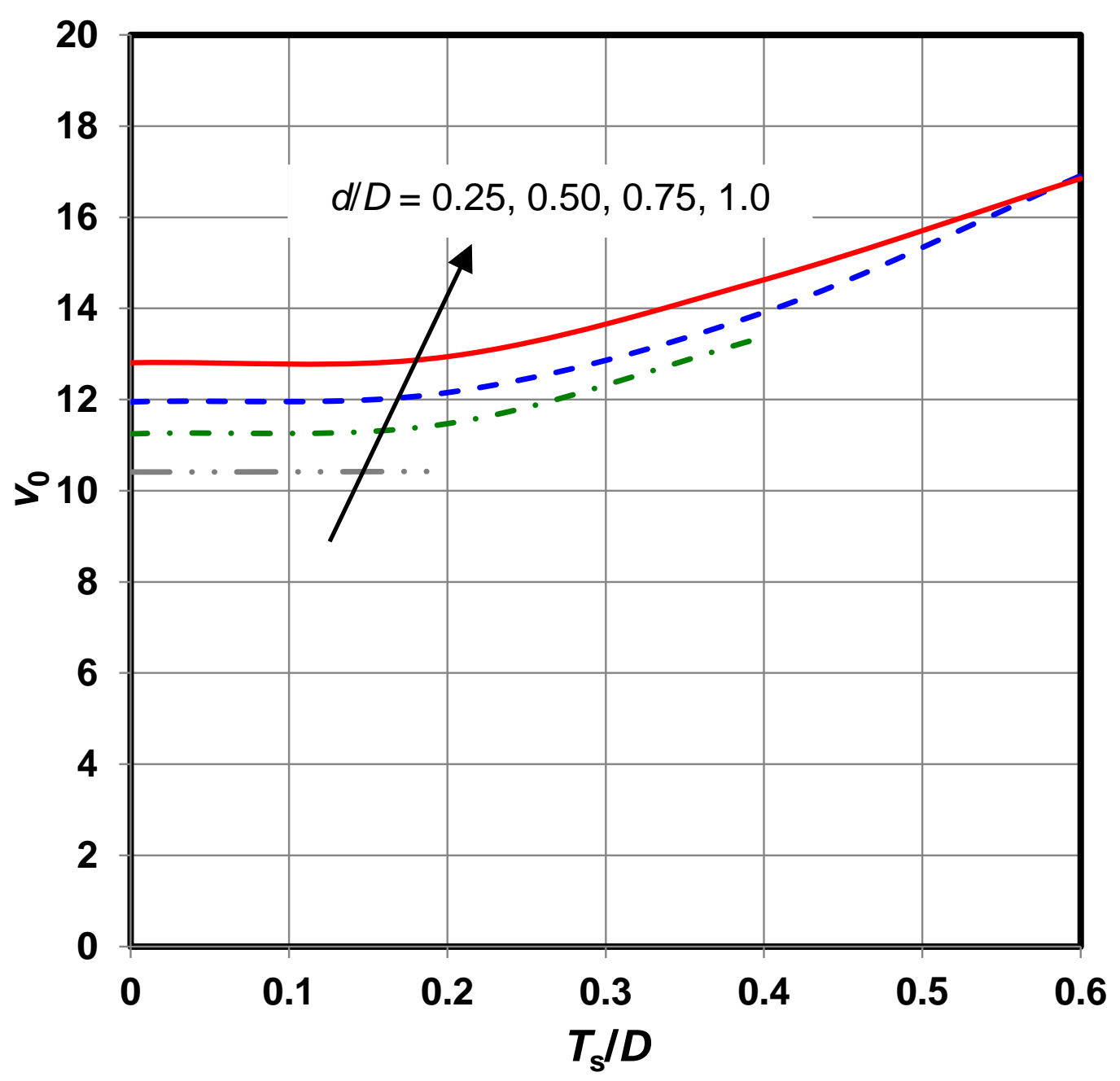

732

733

(b) Ultimate uniaxial vertical load $\left(\kappa_{\mathrm{c}}=3\right)$

734

735 


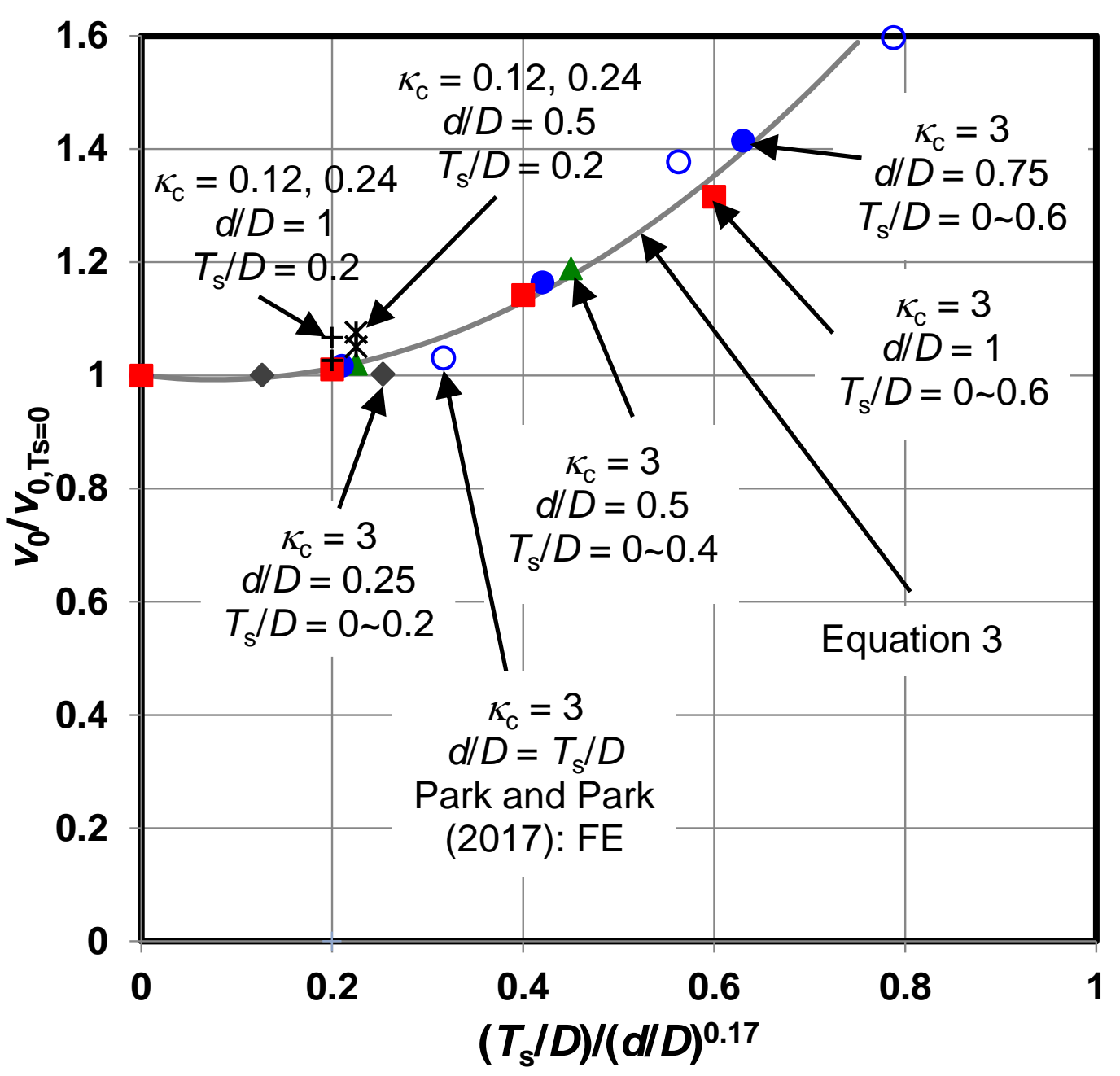

(c) Normalised ultimate uniaxial vertical load $\left(\kappa_{\mathrm{c}}=0.12 \sim 3\right)$

Figure 5 Skirted foundations in sand-over-clay under uniaxial vertical loading 742 


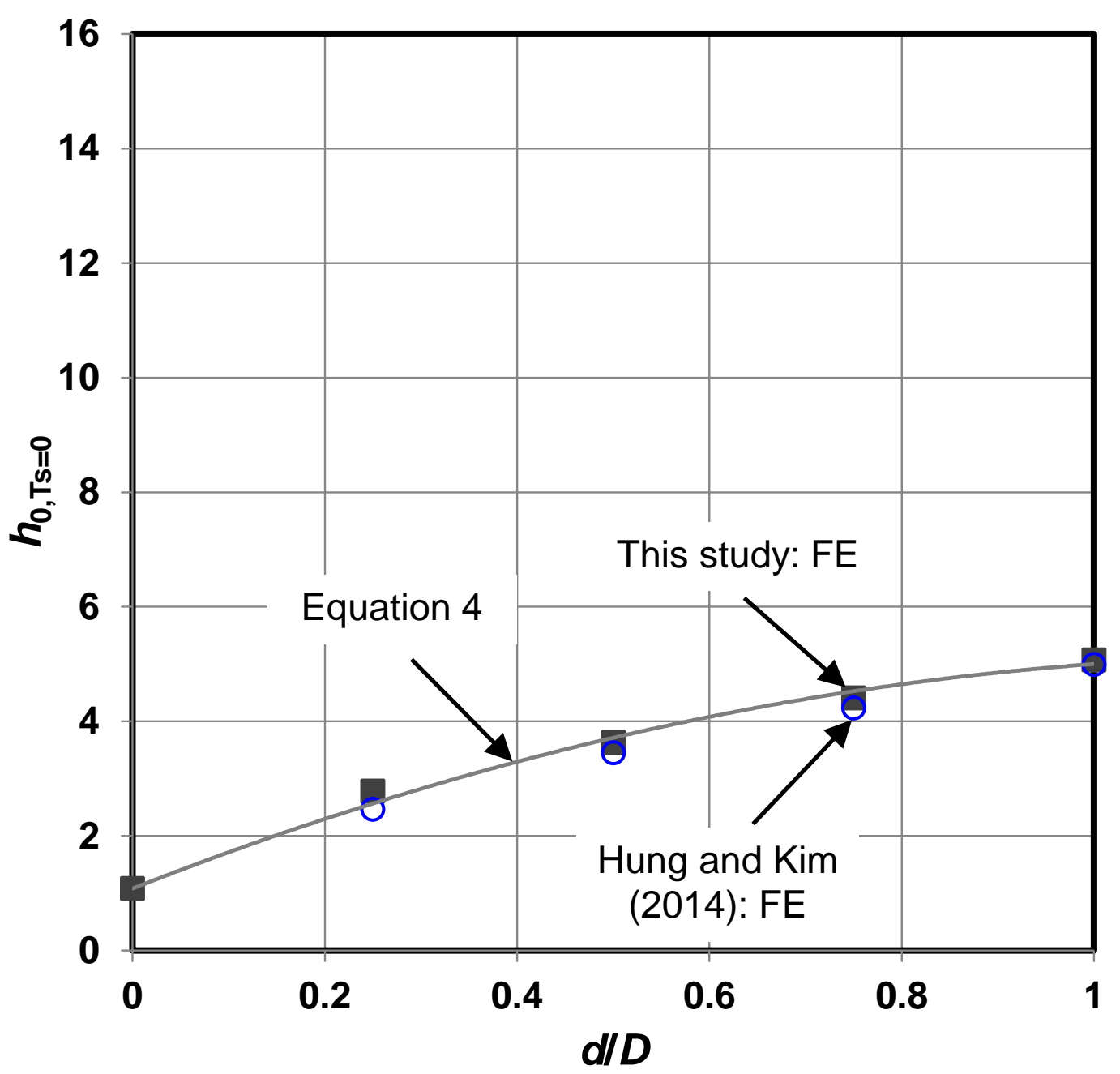

745

746

(a) Ultimate uniaxial horizontal load in clay $\left(T_{\mathrm{s}} / D=0, \kappa_{\mathrm{c}}=3\right)$ 


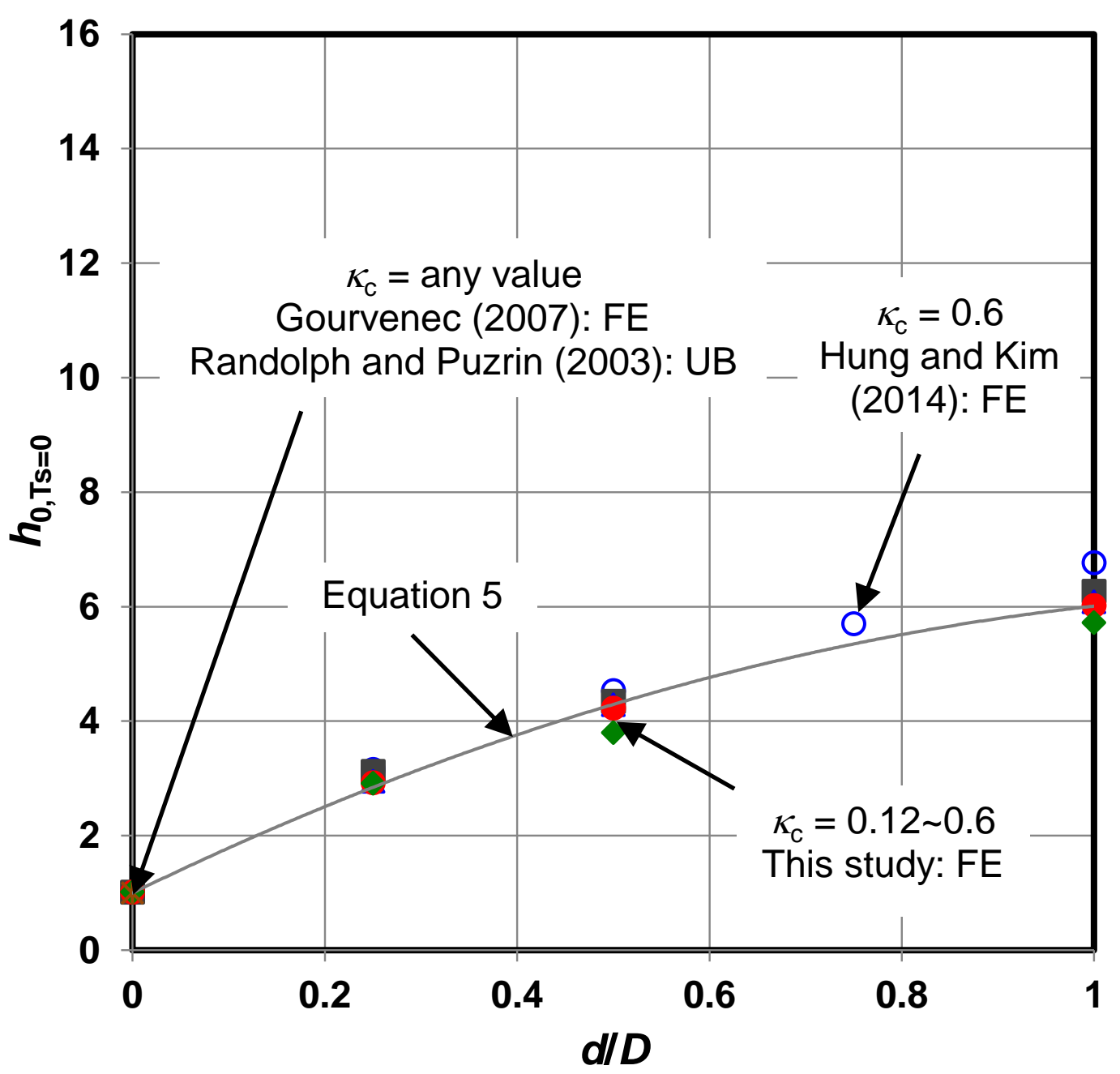

(b) Ultimate uniaxial horizontal load in clay $\left(T_{\mathrm{s}} / D=0, \kappa_{\mathrm{c}}=0.12 \sim 0.6\right)$ 


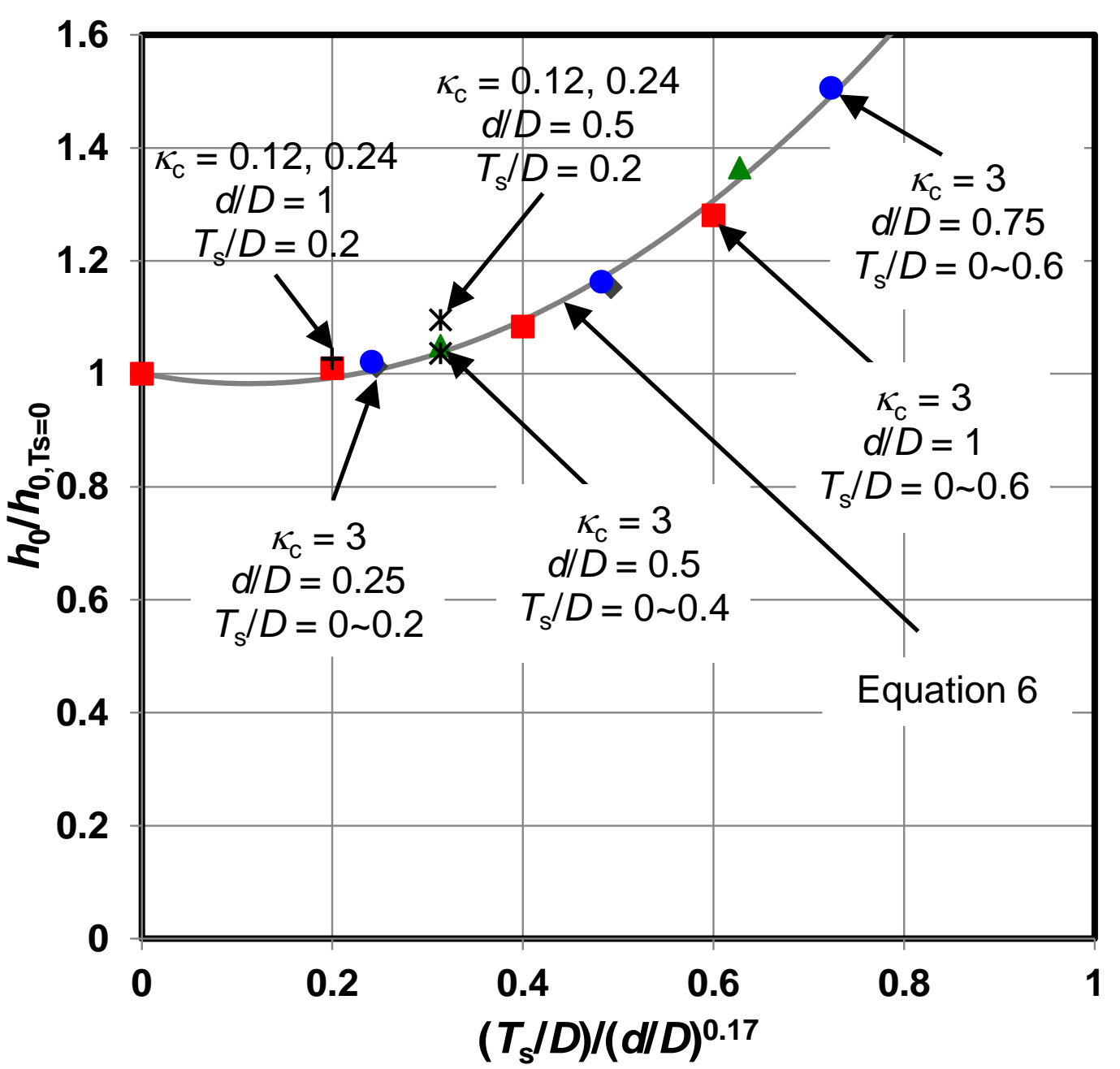

751 (c) Normalised ultimate uniaxial horizontal load in sand-over-clay $\left(\kappa_{\mathrm{c}}=0.12 \sim 3\right)$ 


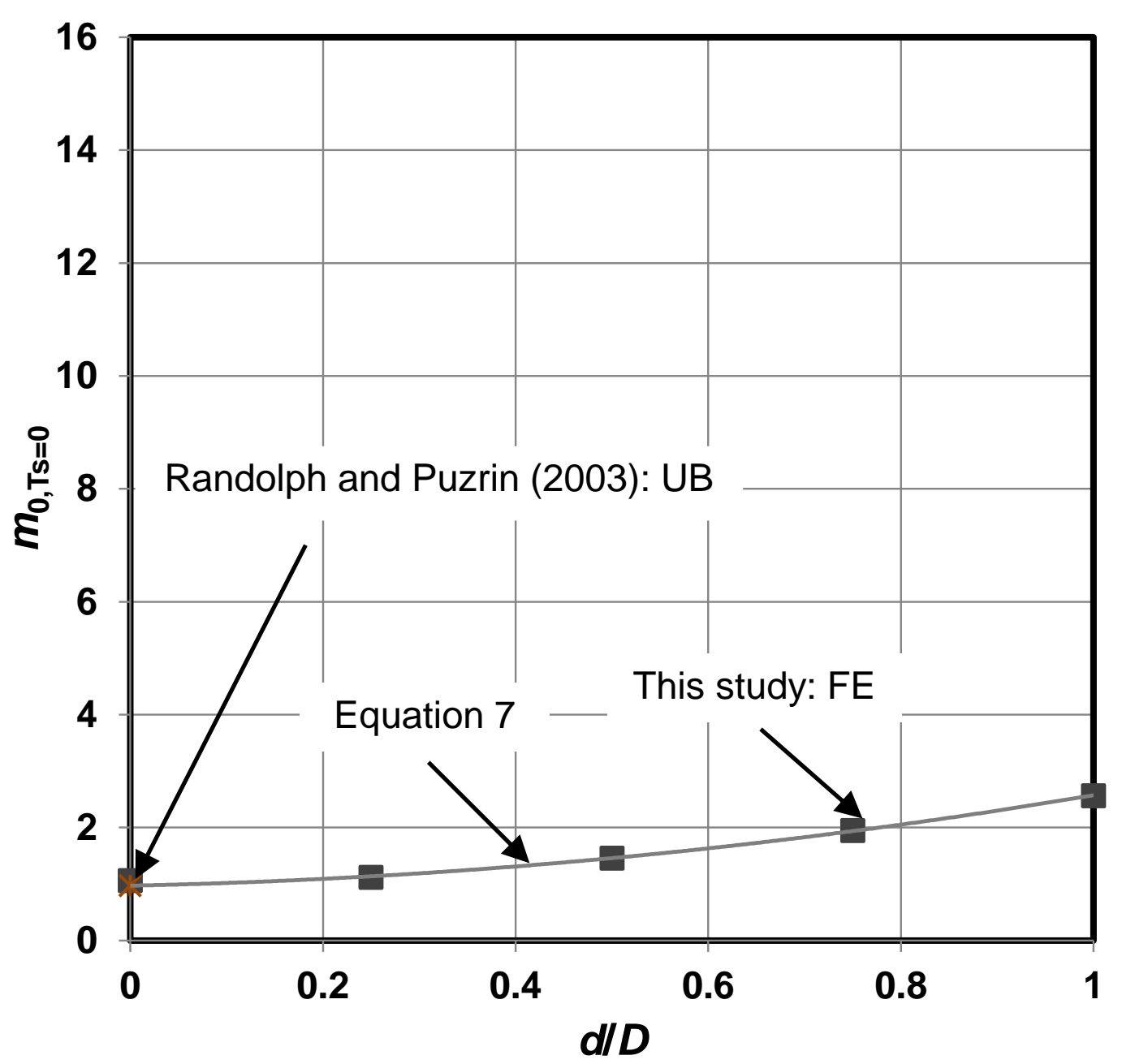

756

757

(a) Ultimate uniaxial moment load in clay $\left(T_{\mathrm{s}} / D=0, \kappa_{\mathrm{c}}=3\right)$

758 


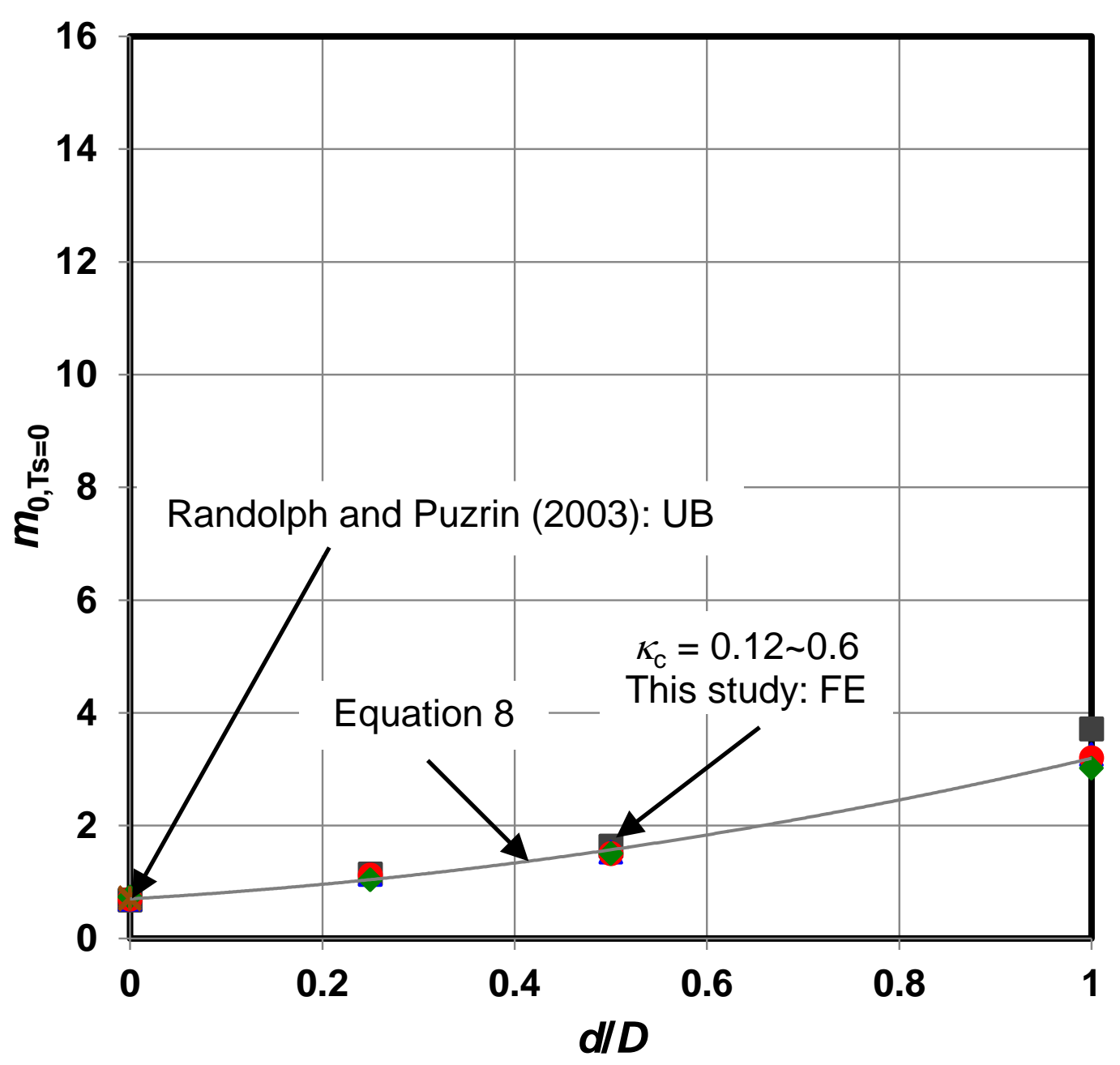

759

760

(b) Ultimate uniaxial moment load in clay $\left(T_{\mathrm{s}} / D=0, \kappa_{\mathrm{c}}=0.12 \sim 0.6\right)$

761

762 


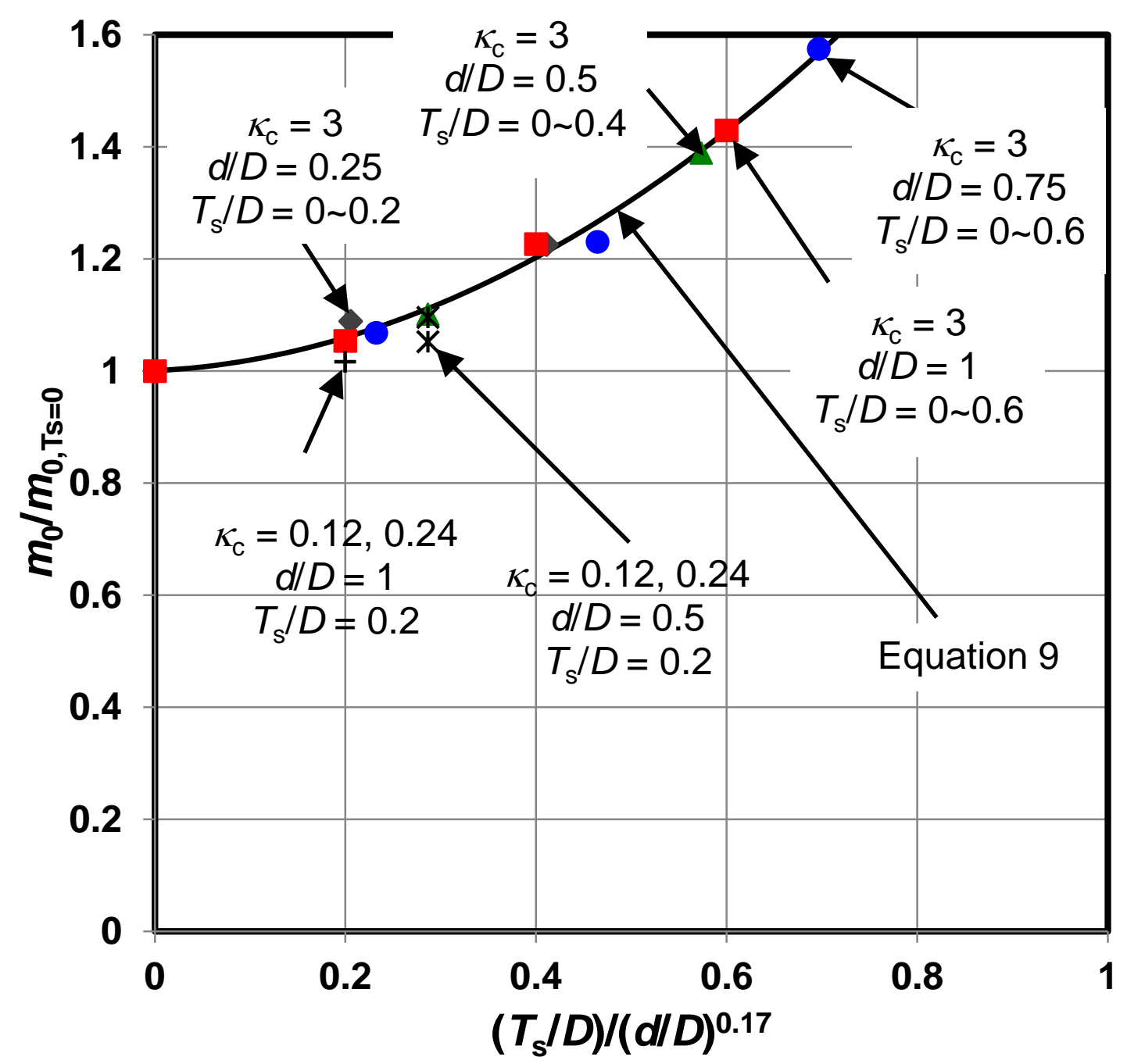

763

764 (c) Normalised ultimate uniaxial moment load in sand-over-clay $\left(\kappa_{\mathrm{c}}=0.12 \sim 3\right)$

Figure 7 Skirted foundations under uniaxial moment loading 


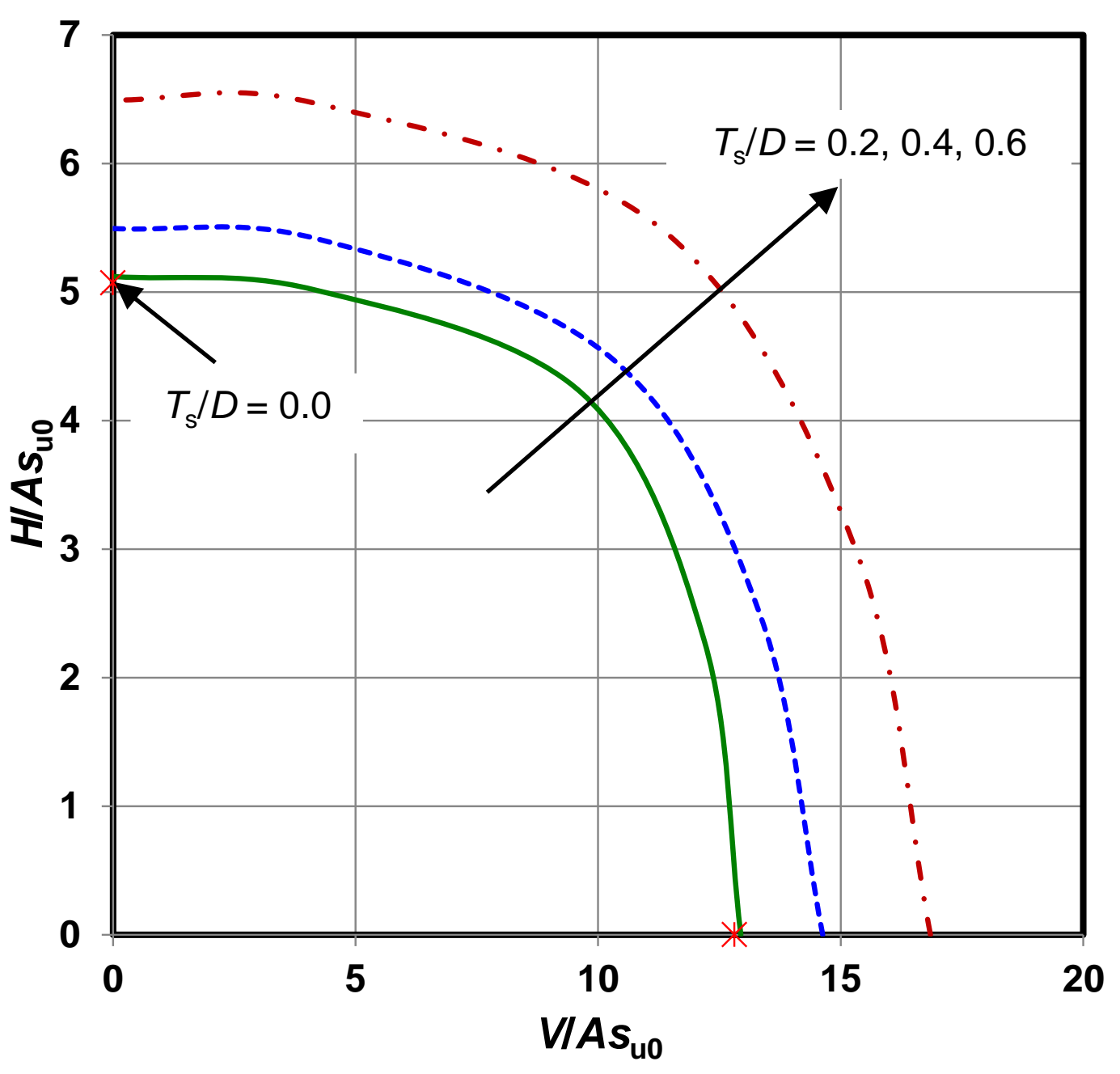

767

768

(a) $d / D=1.0$

769 


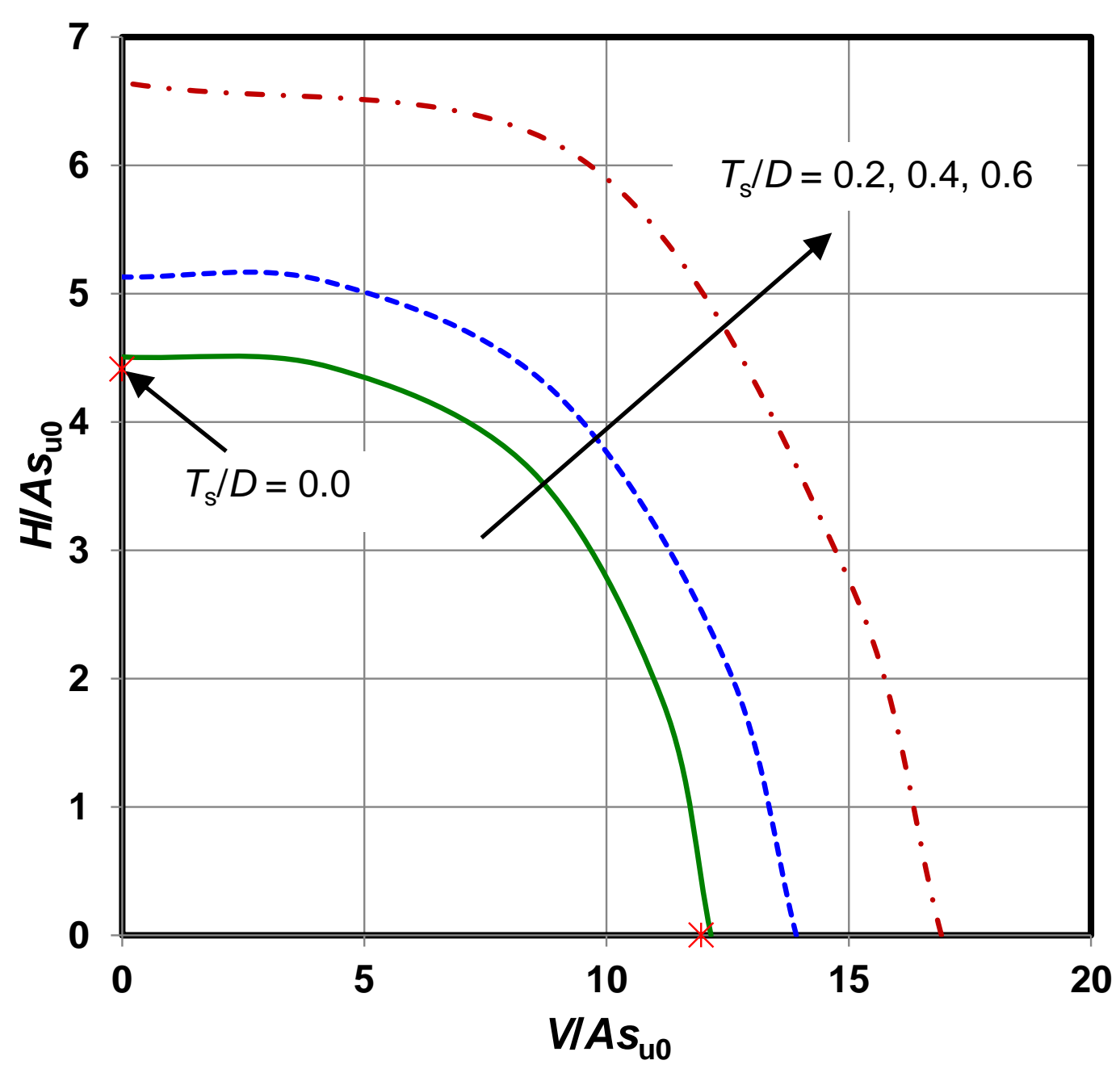

770

(b) $d / D=0.75$ 


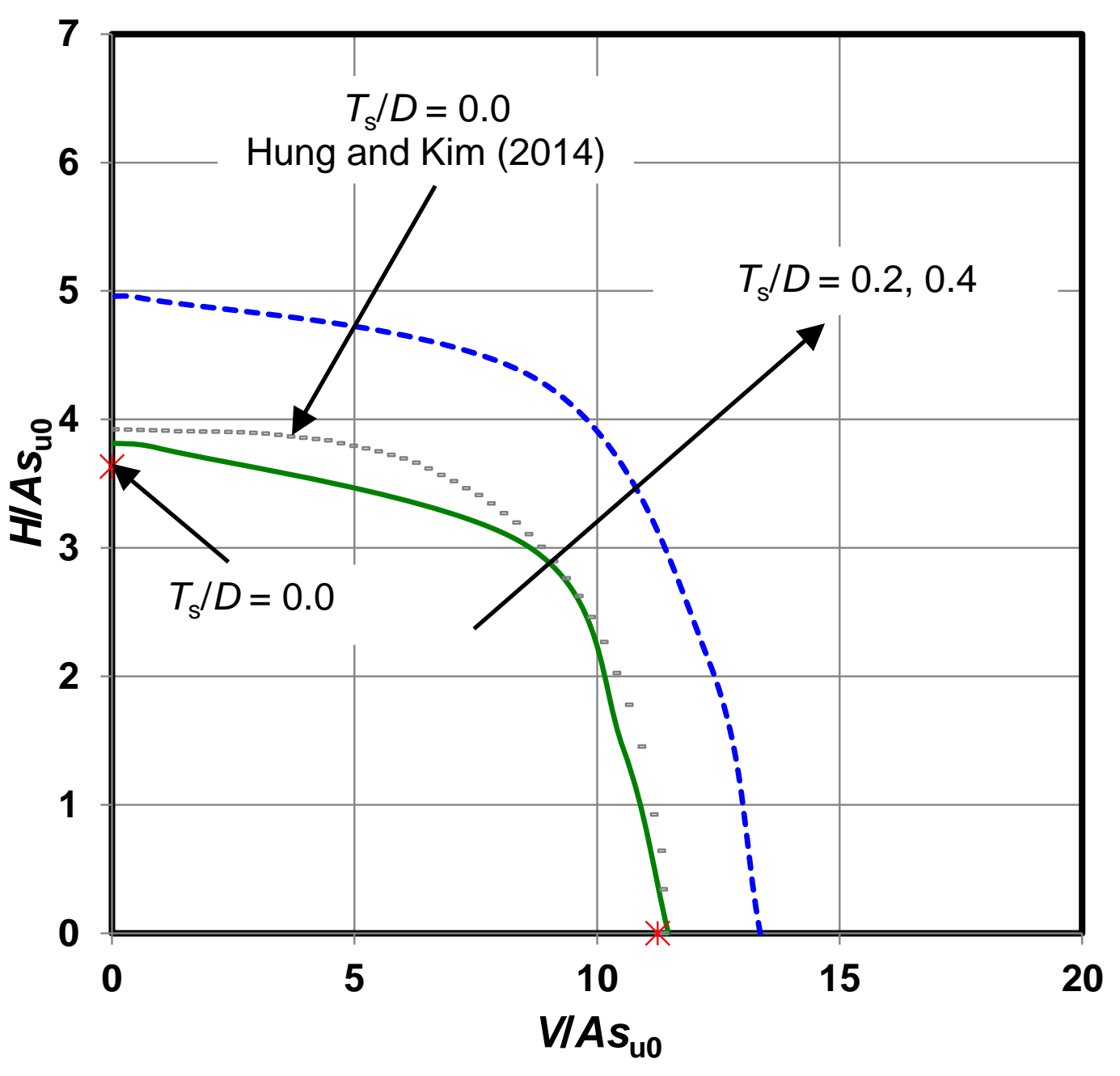

773

(c) $d / D=0.5$ 


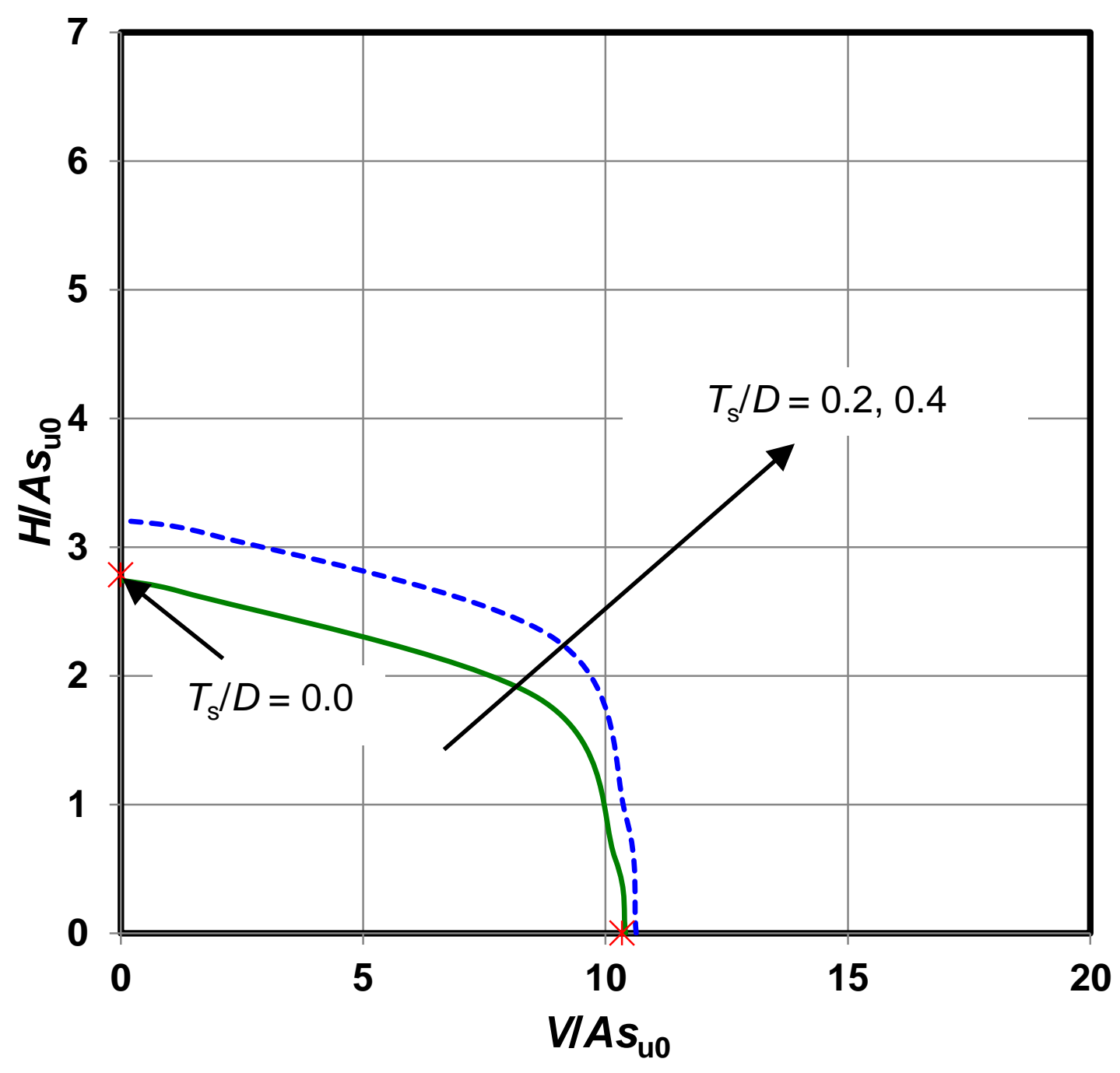

(d) $d / D=0.25$ 


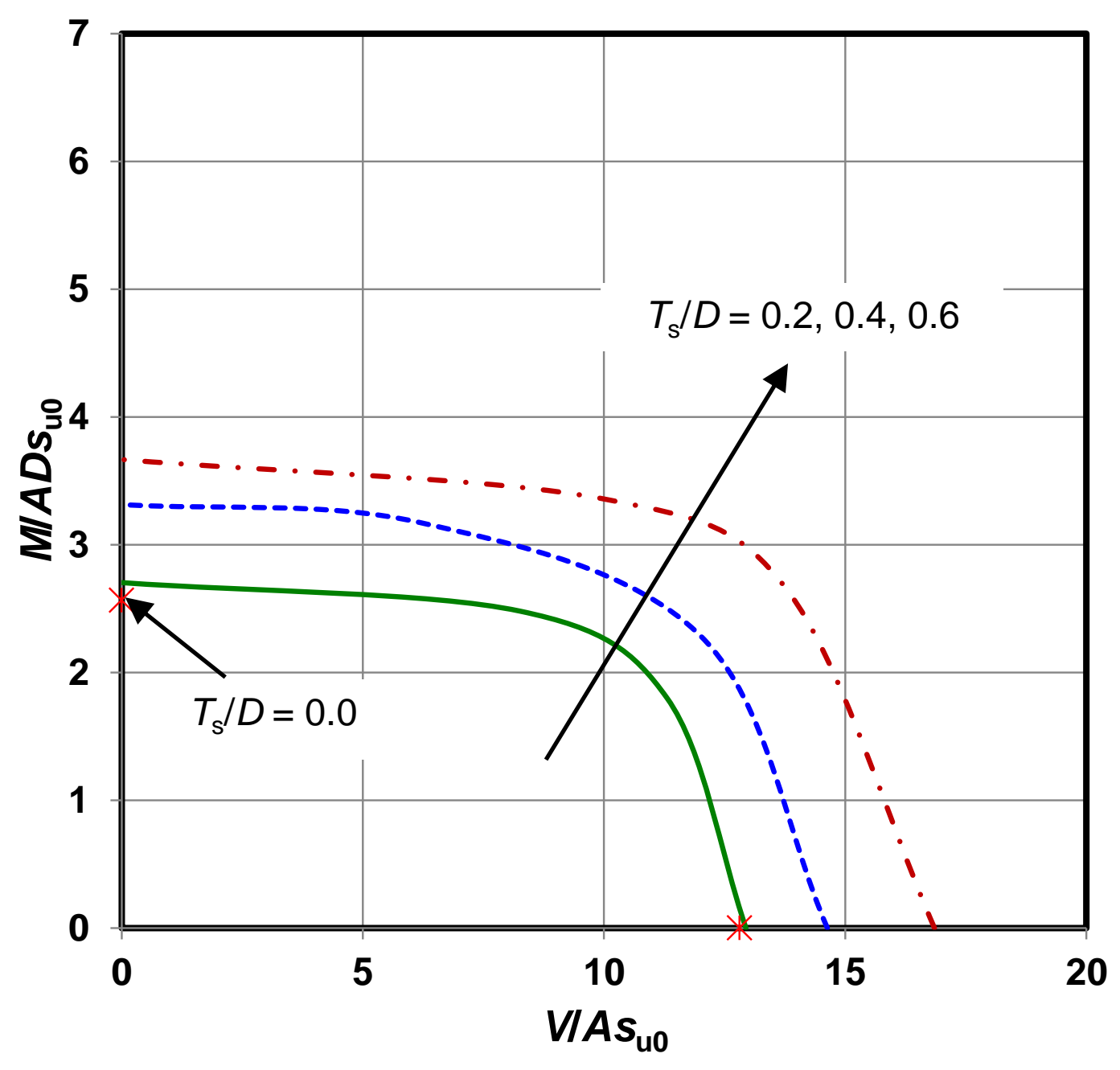

781

(a) $d / D=1.0$ 


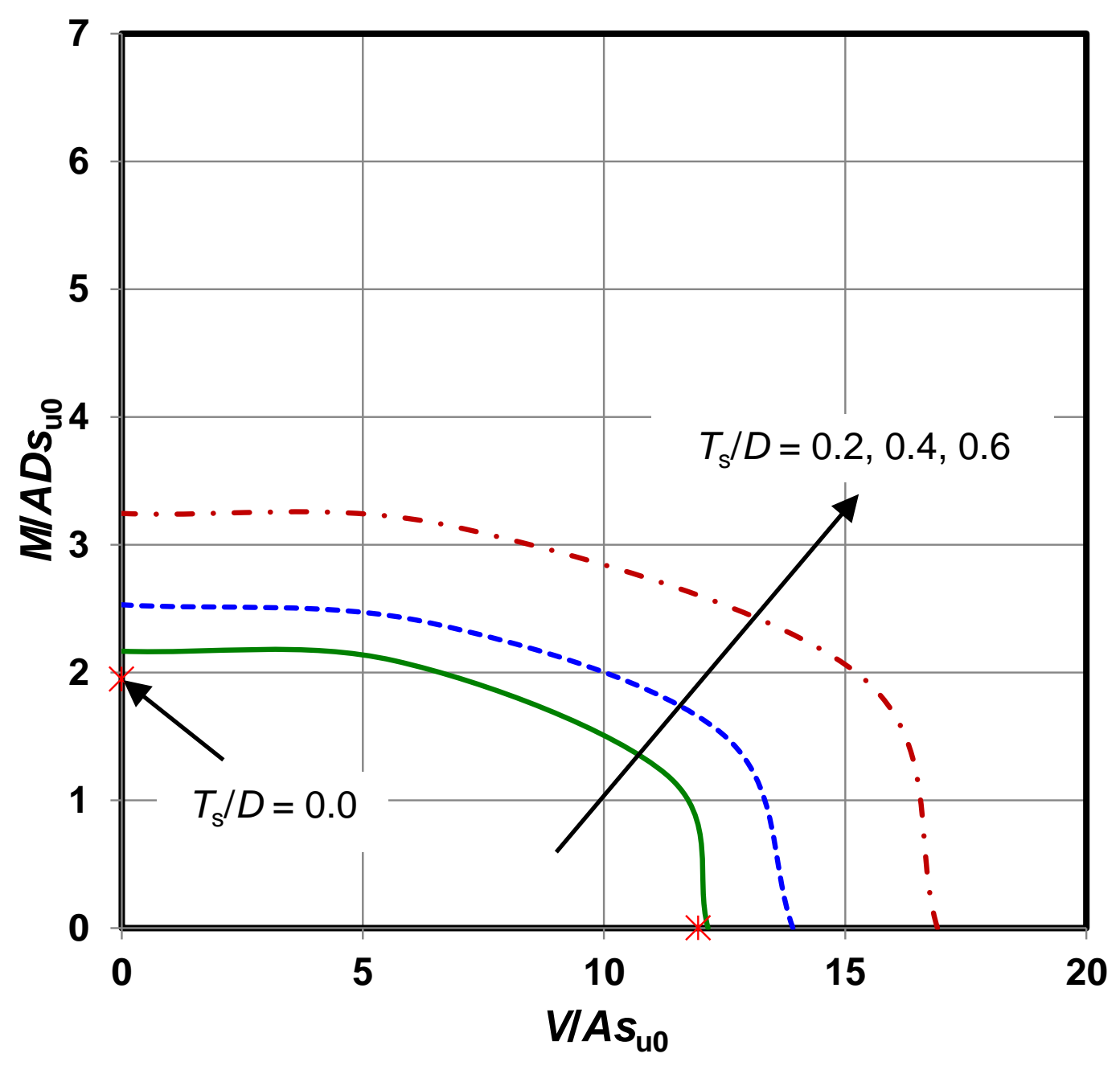

784

785

786

(b) $d / D=0.75$ 


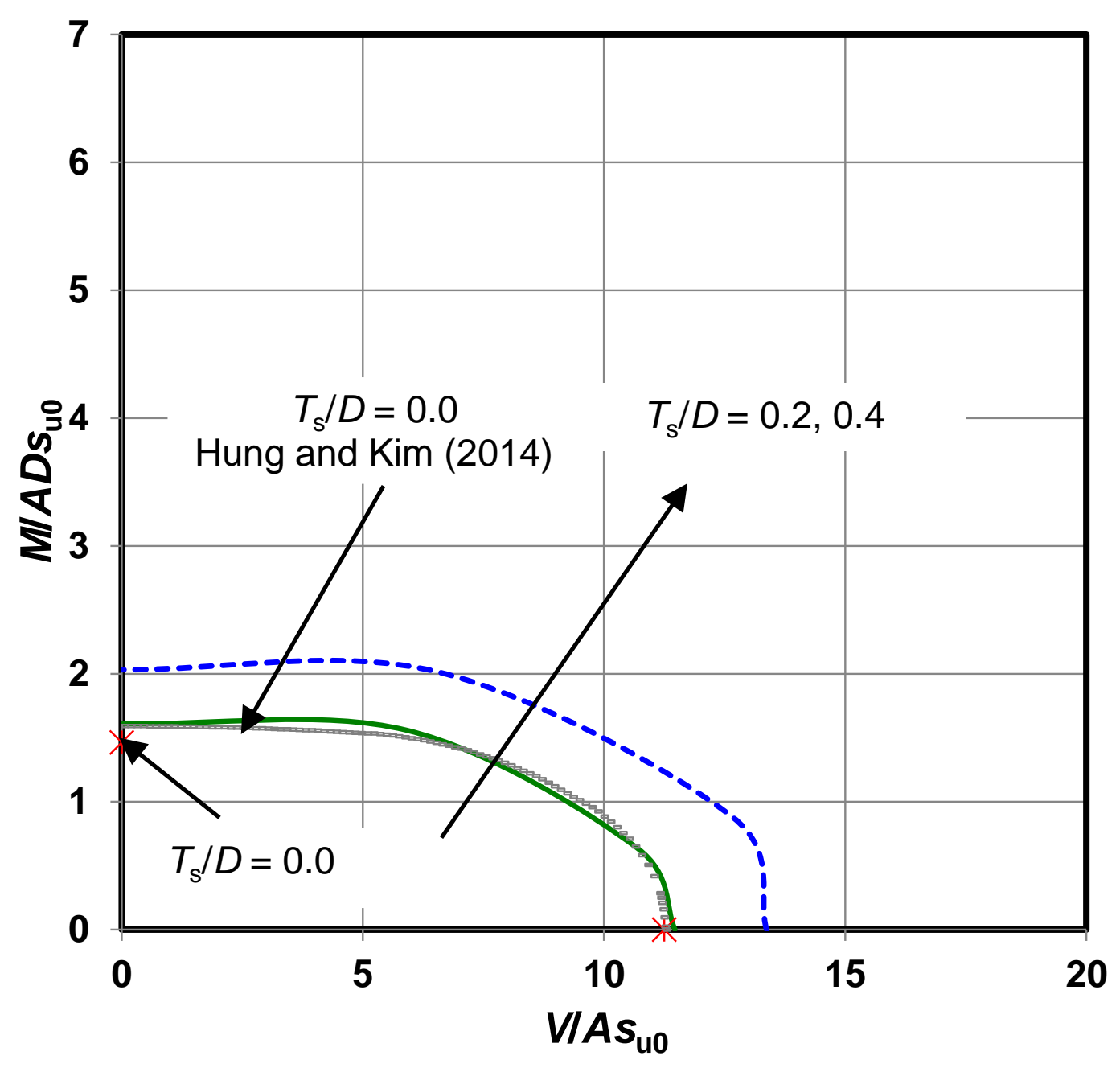

787

(c) $d / D=0.5$ 


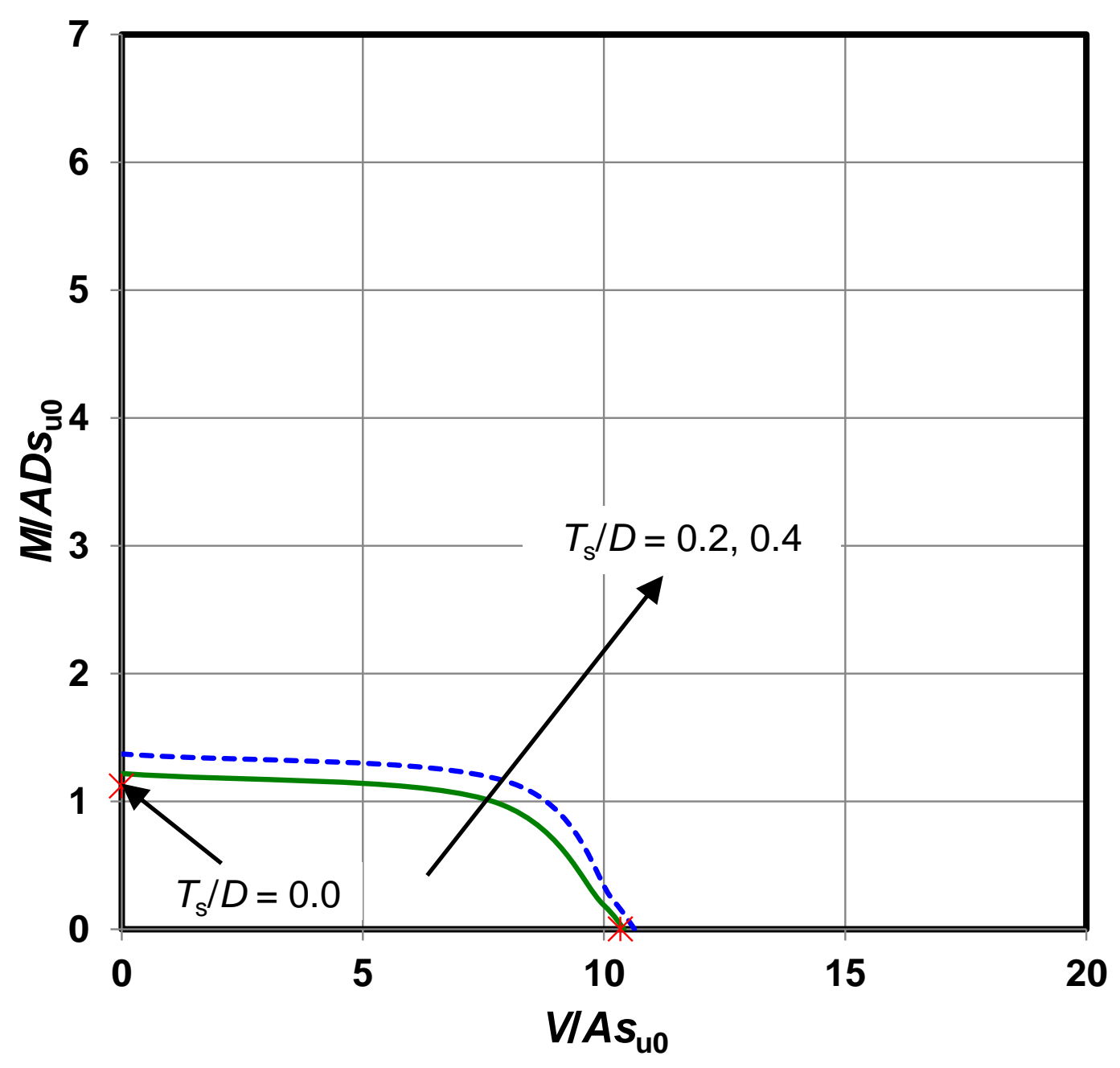

790

791

792

793

794

795

(d) $d / D=0.25$

Figure 9 Failure envelopes in $V-M$ space 


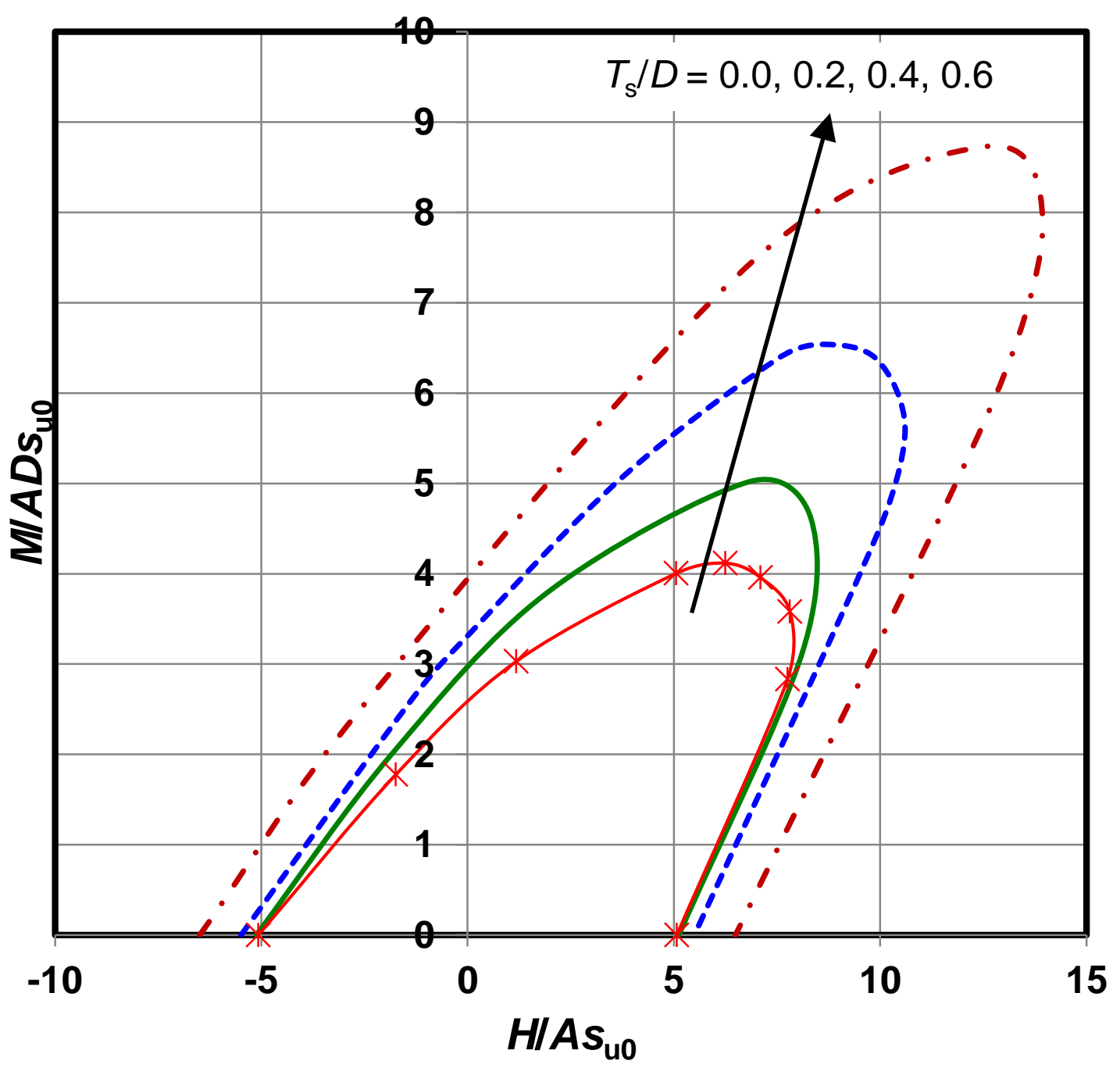

796
797

(a) $d / D=1.0$

798 
799

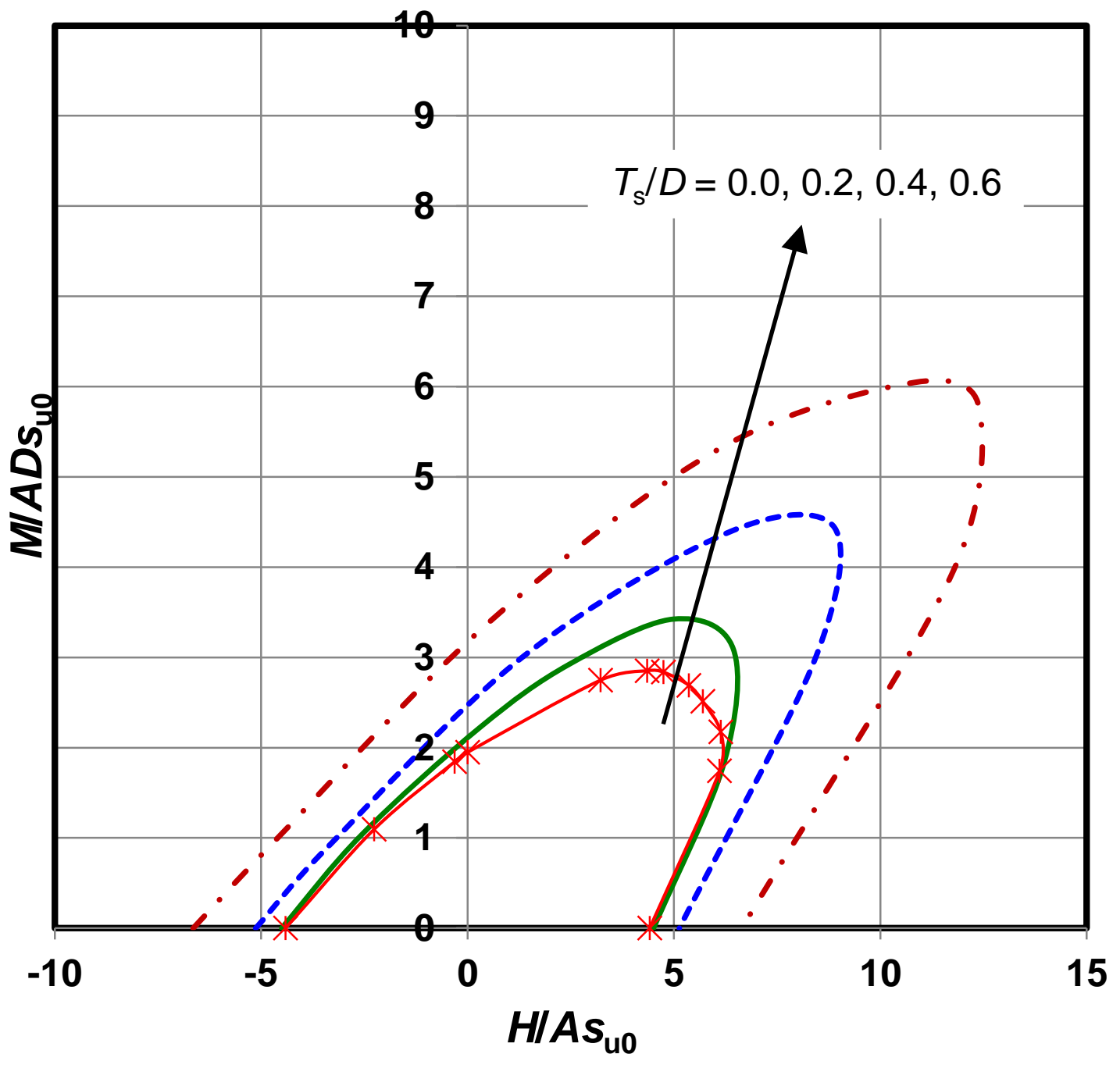

800

801

(b) $d / D=0.75$

802 
803

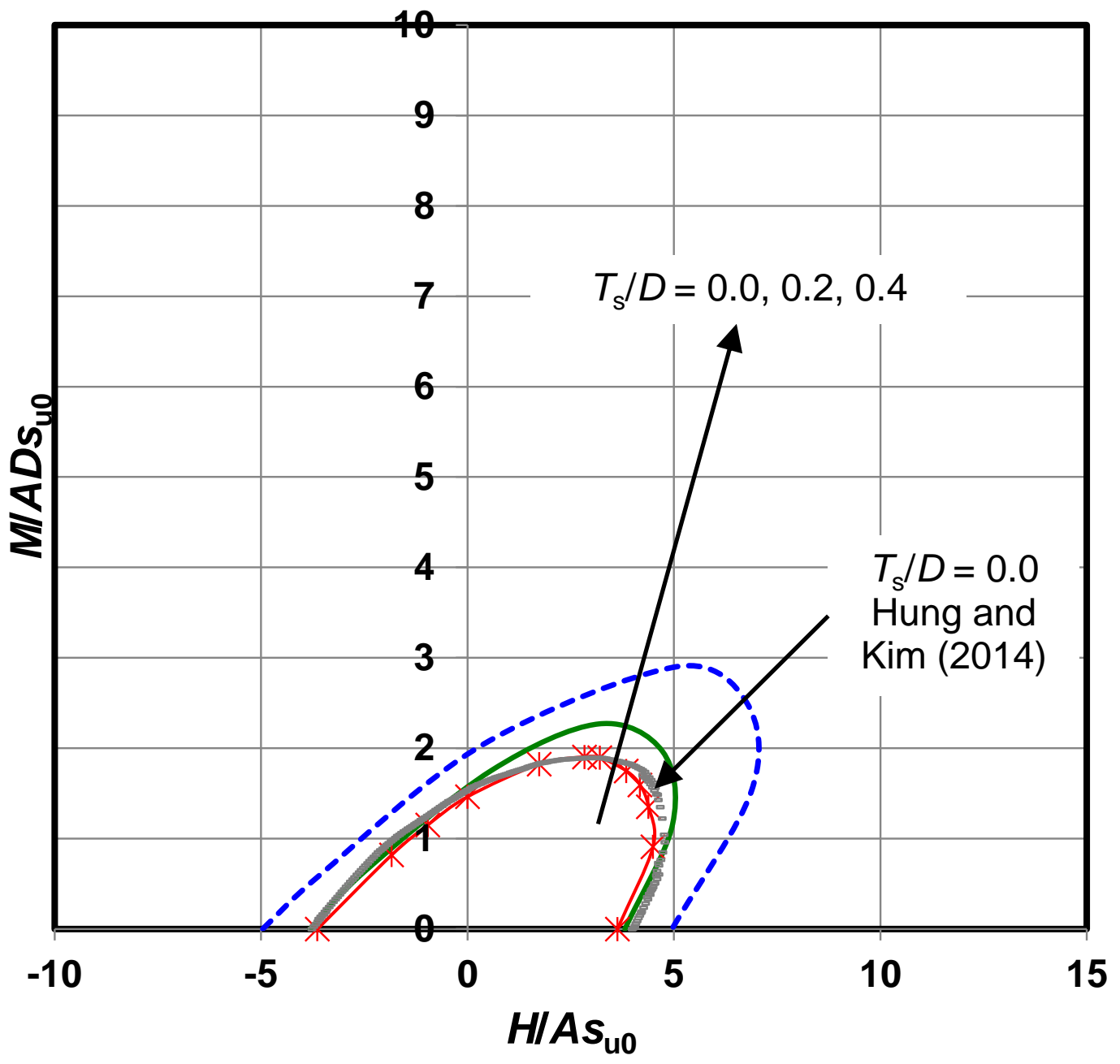

804

805

(c) $d / D=0.5$

806 
807

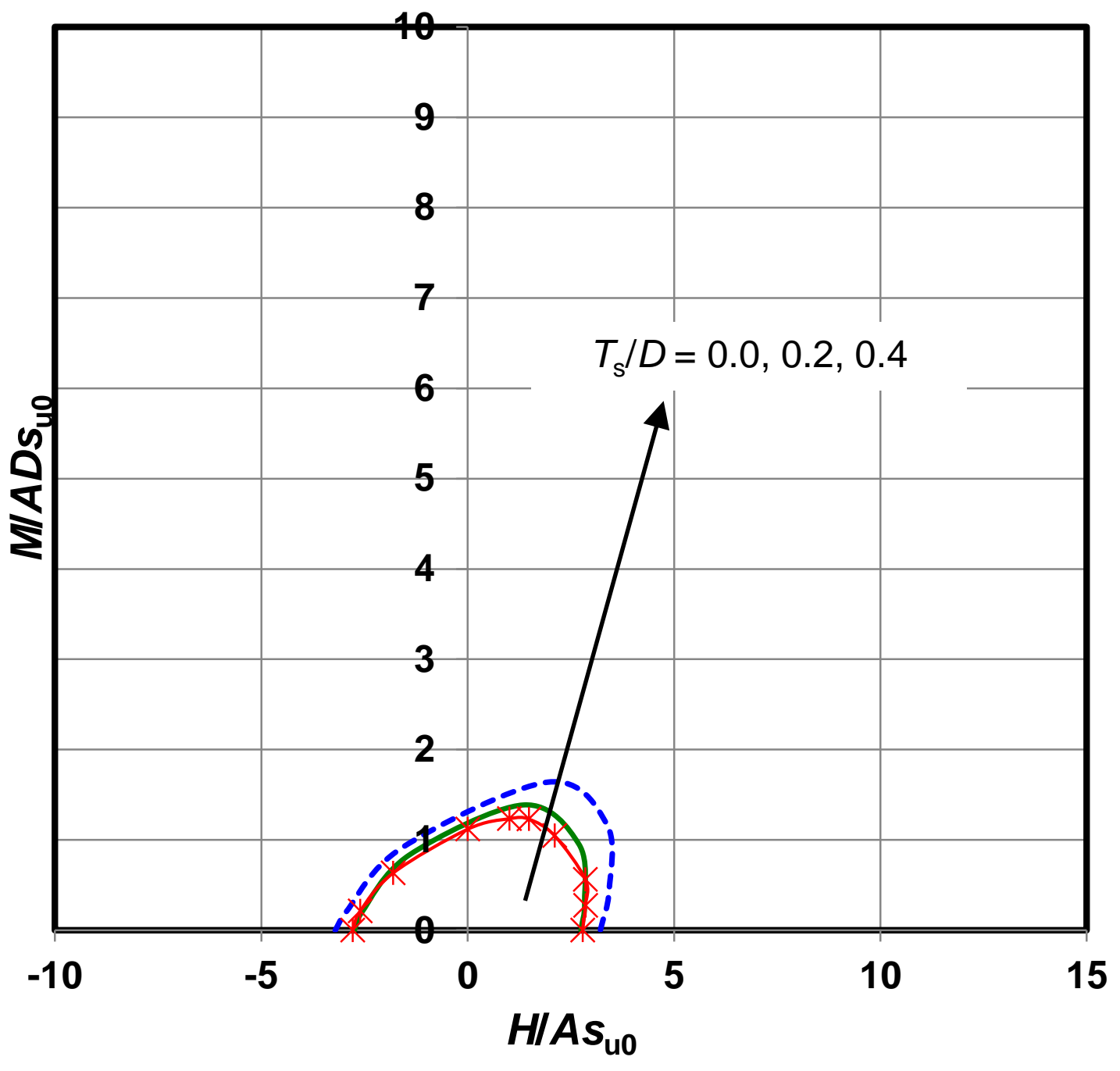

(d) $d / D=0.25$

810

811

812

Figure 10 Failure envelopes in $H-M$ space 


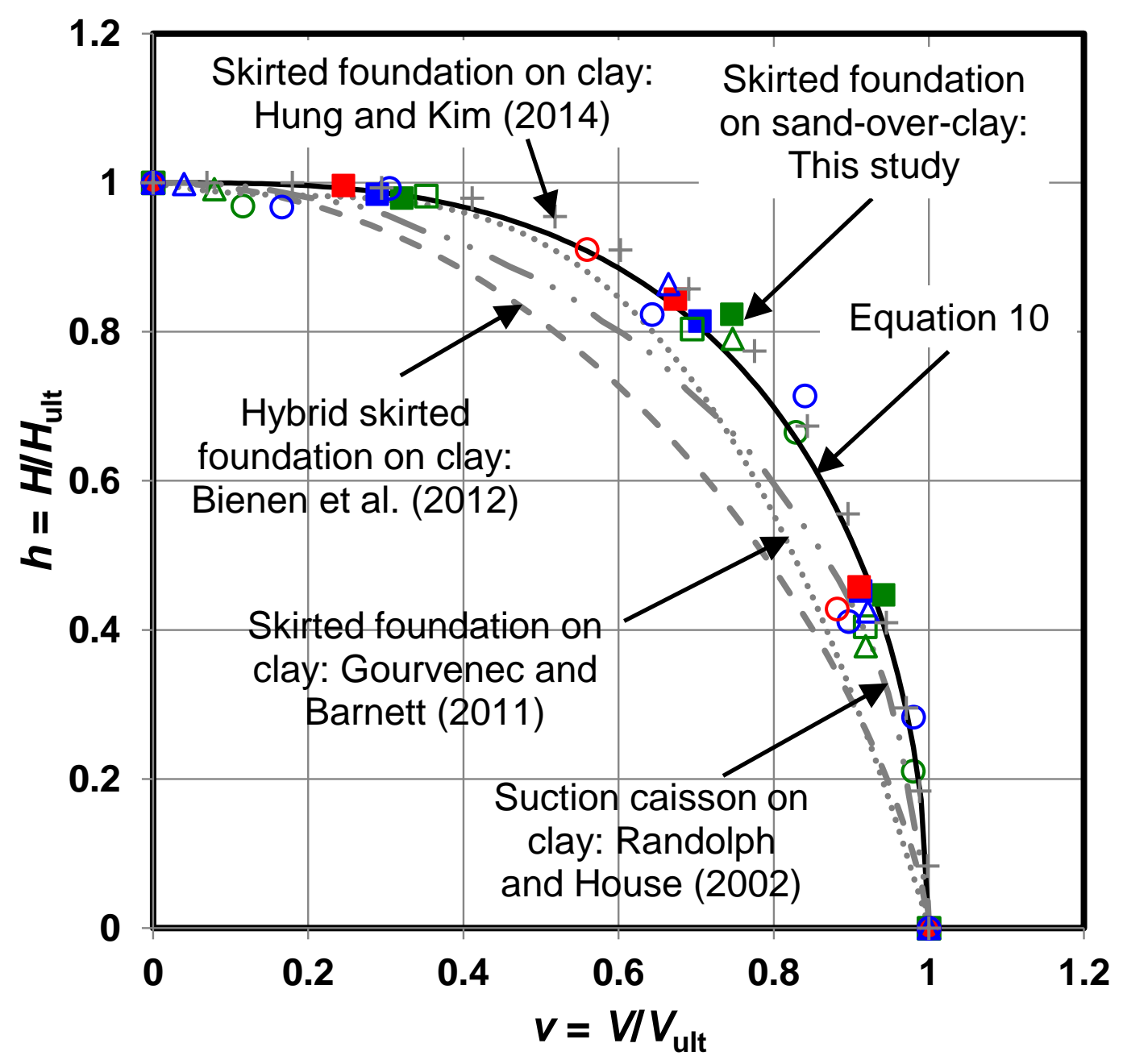

(a) $v$ - $h$ space 


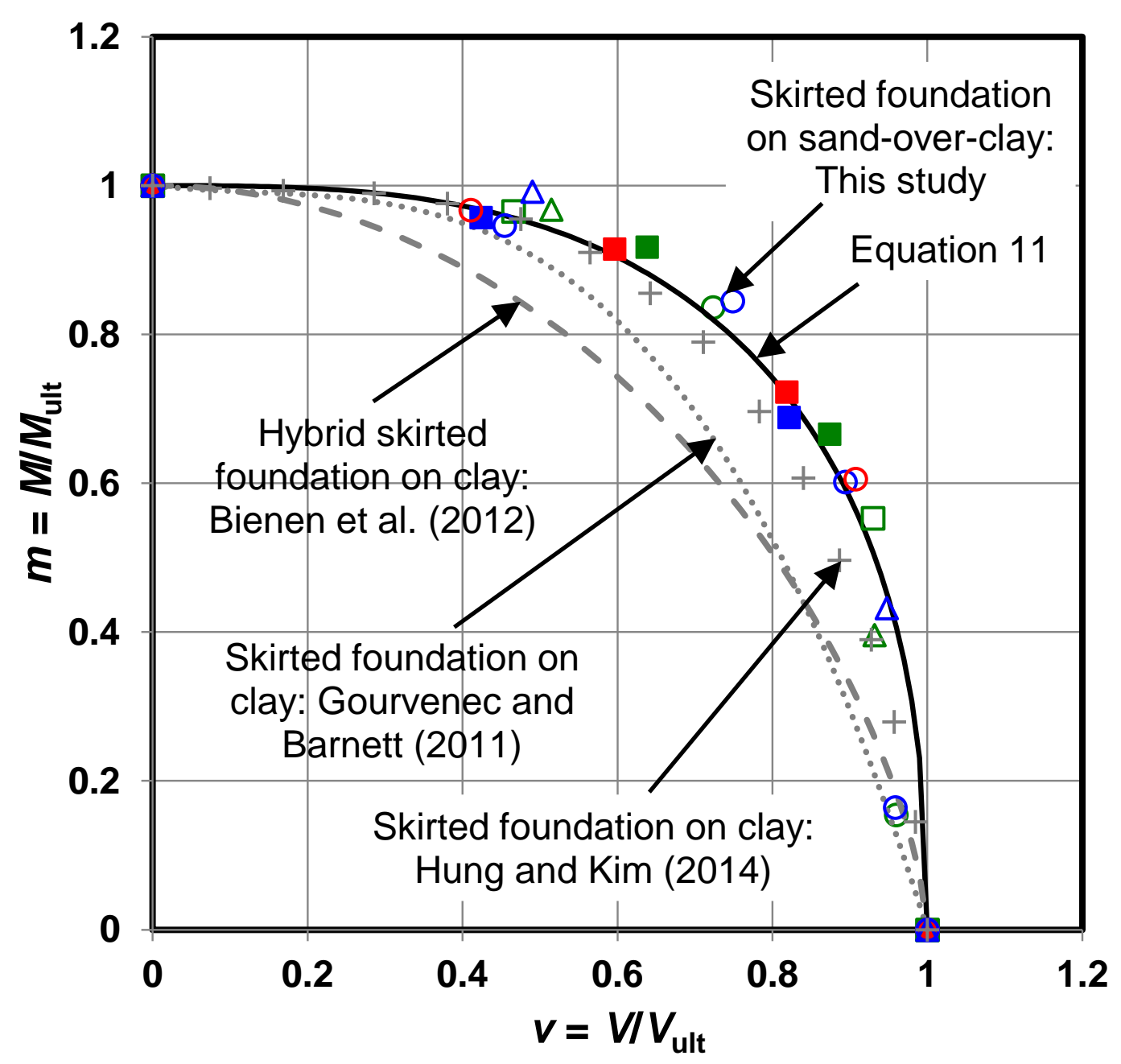

(b) $v-m$ space

Figure 11 Normalised failure envelopes

821 


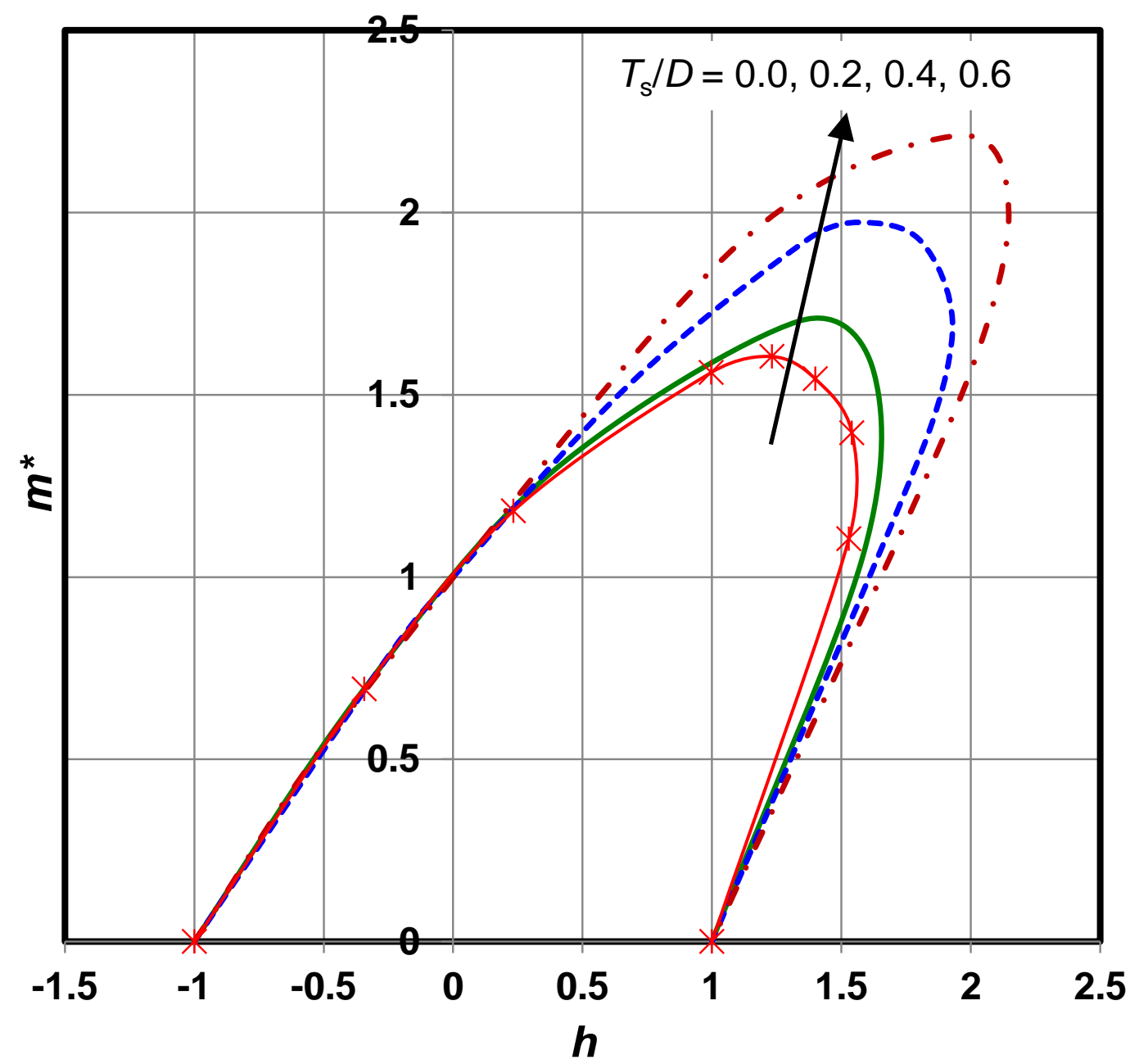

823

824

825

(a) $d / D=1.0$

826

827

828

829

830

831

832

833 


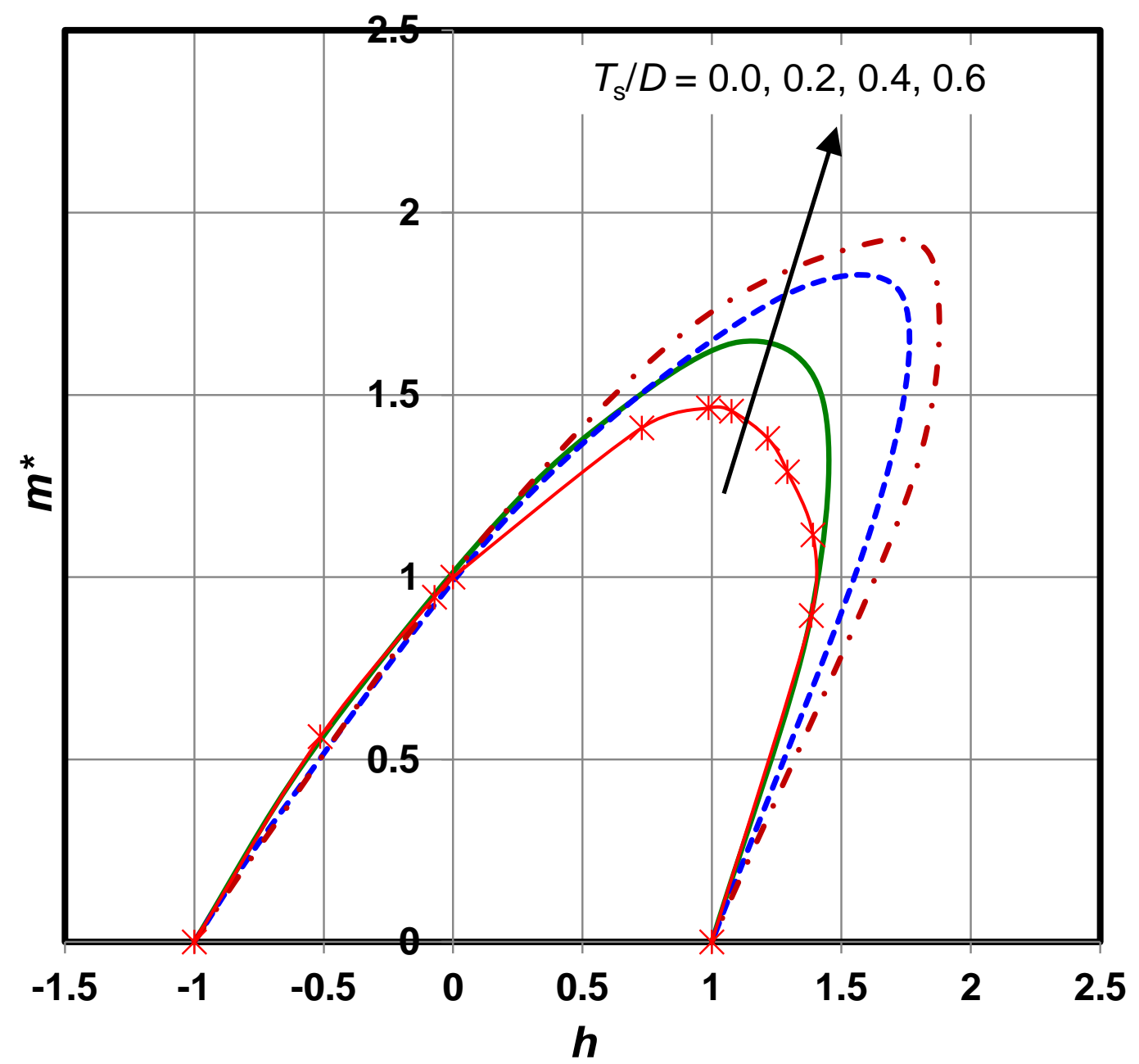

834

835

836

(b) $d / D=0.75$

837

838

839

840

841

842

843

844 


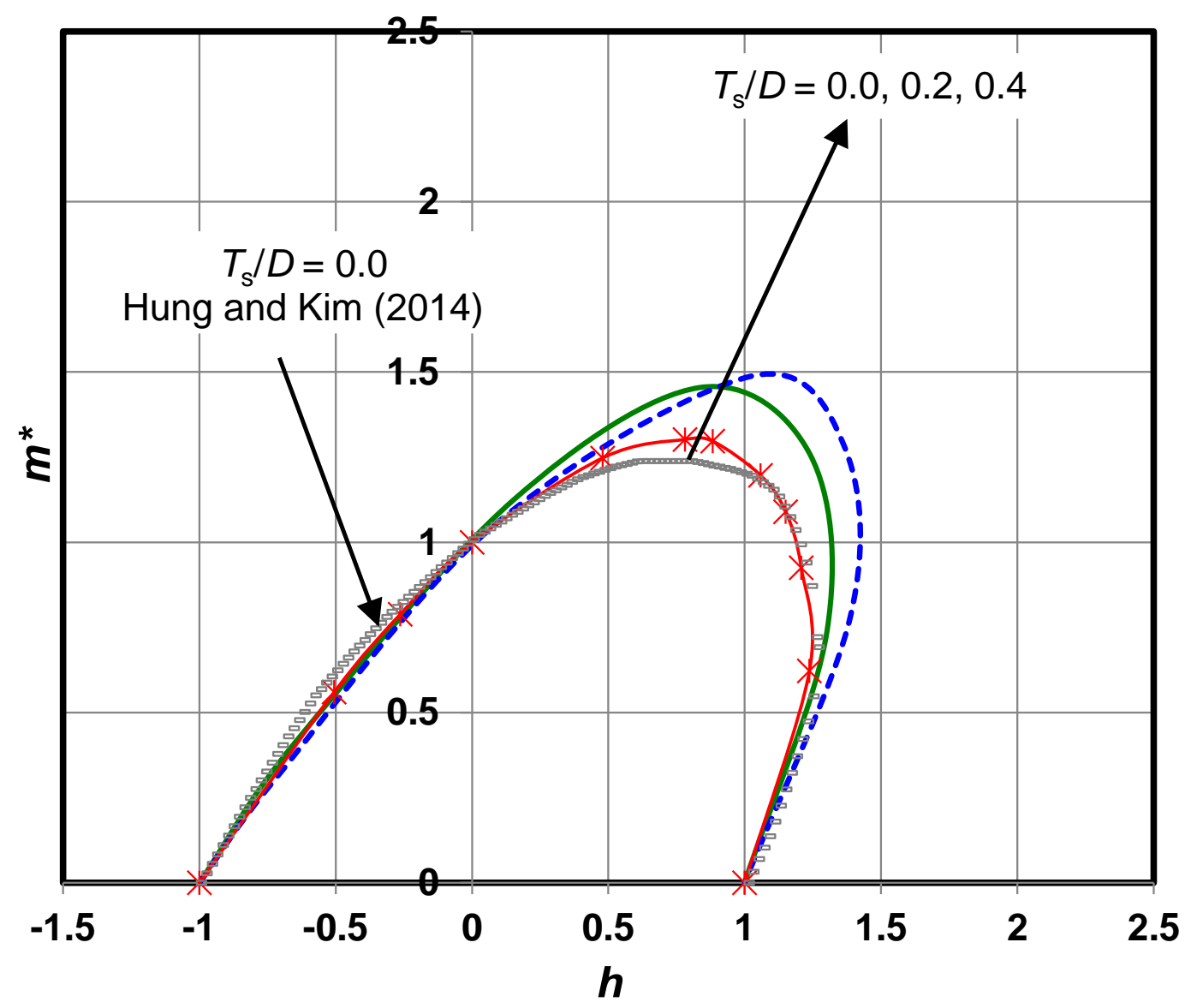

845

846

(c) $d / D=0.5$

847

848

849

850

851

852

853

854

855 


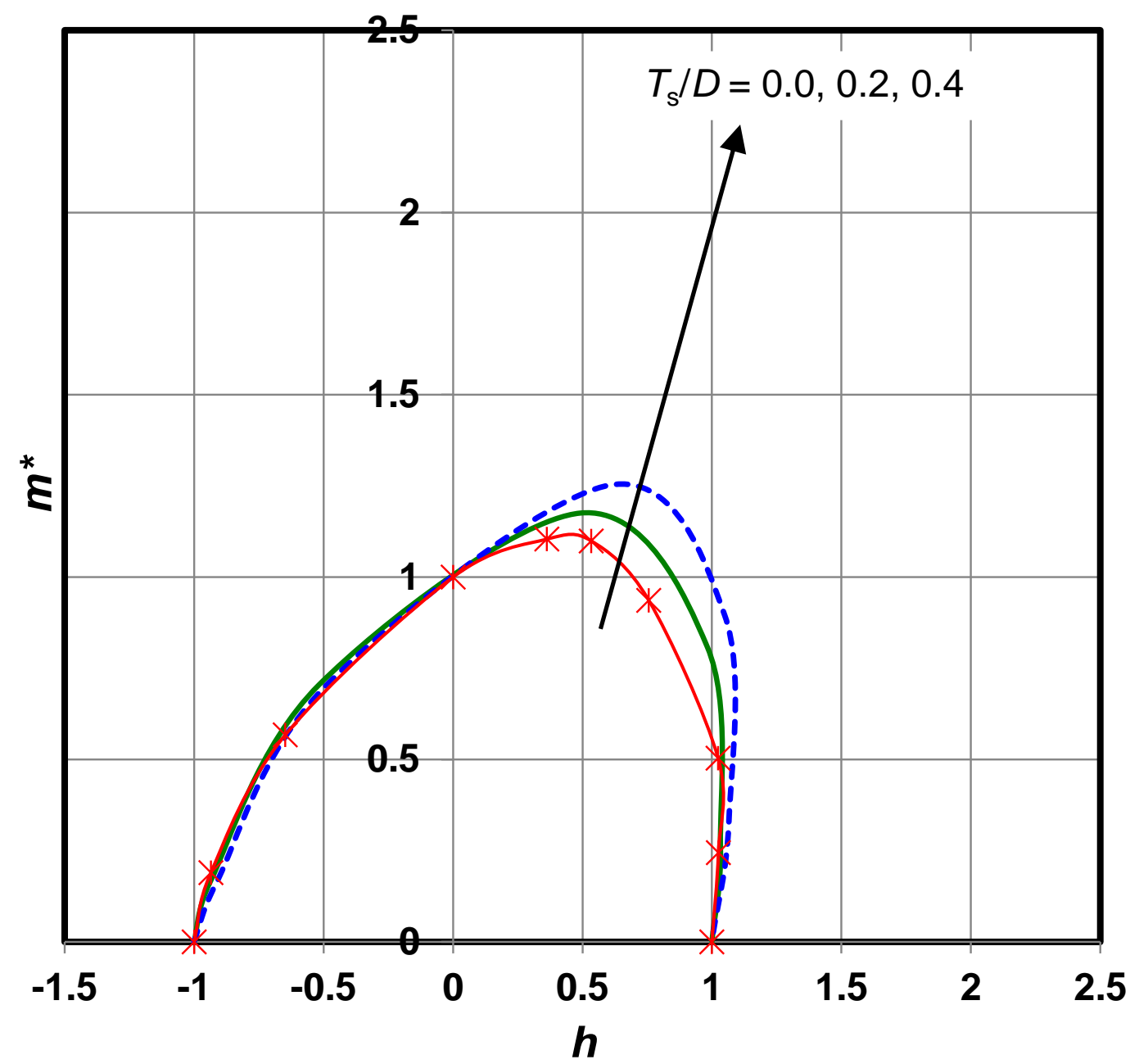

856

(d) $d / D=0.25$

858

859

860

861

862

863

864

Figure 12 Normalised failure envelopes in $h-m$ space $(v=0)$ 


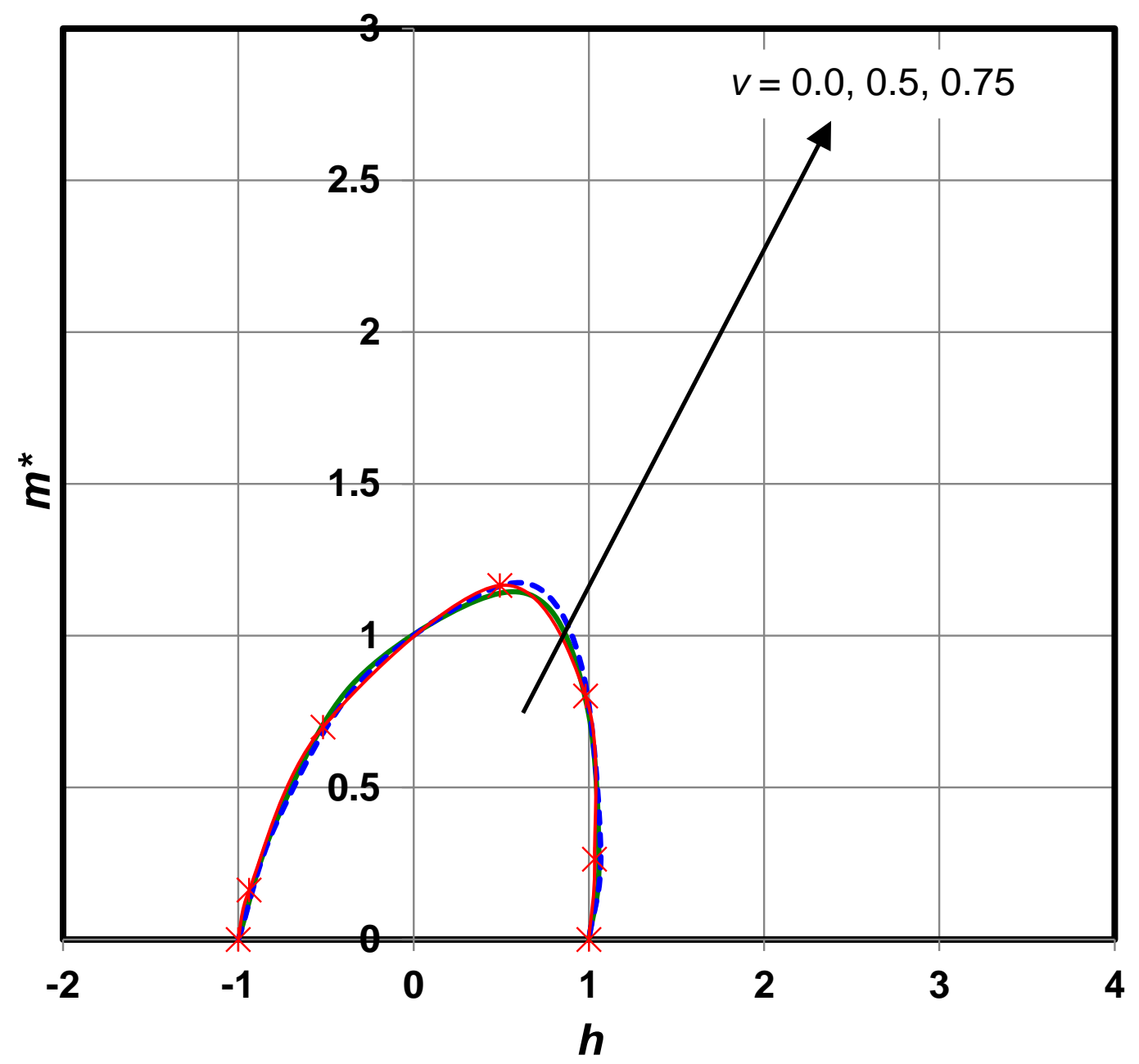

865

866

867

(a) $T_{\mathrm{s}} / D=0.1$

868

869

870

871

872

873 


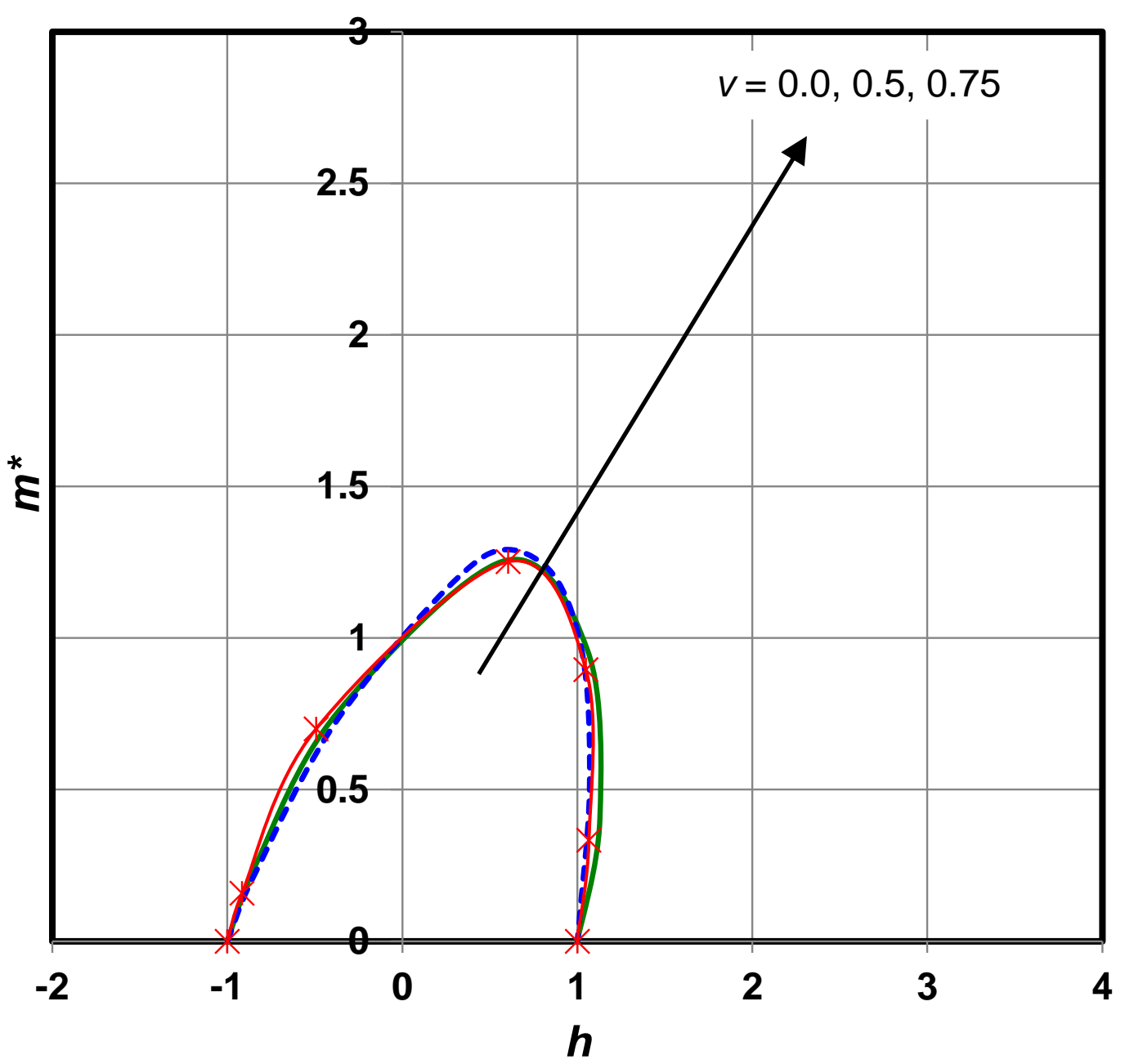

874

875

876

877

878

879

880

881

882

883

(b) $T_{\mathrm{s}} / D=0.2$

Figure 13 Effect of vertical mobilisation $v$ on normalised failure envelopes in $h-m$ space: $d / D=0.25$ 


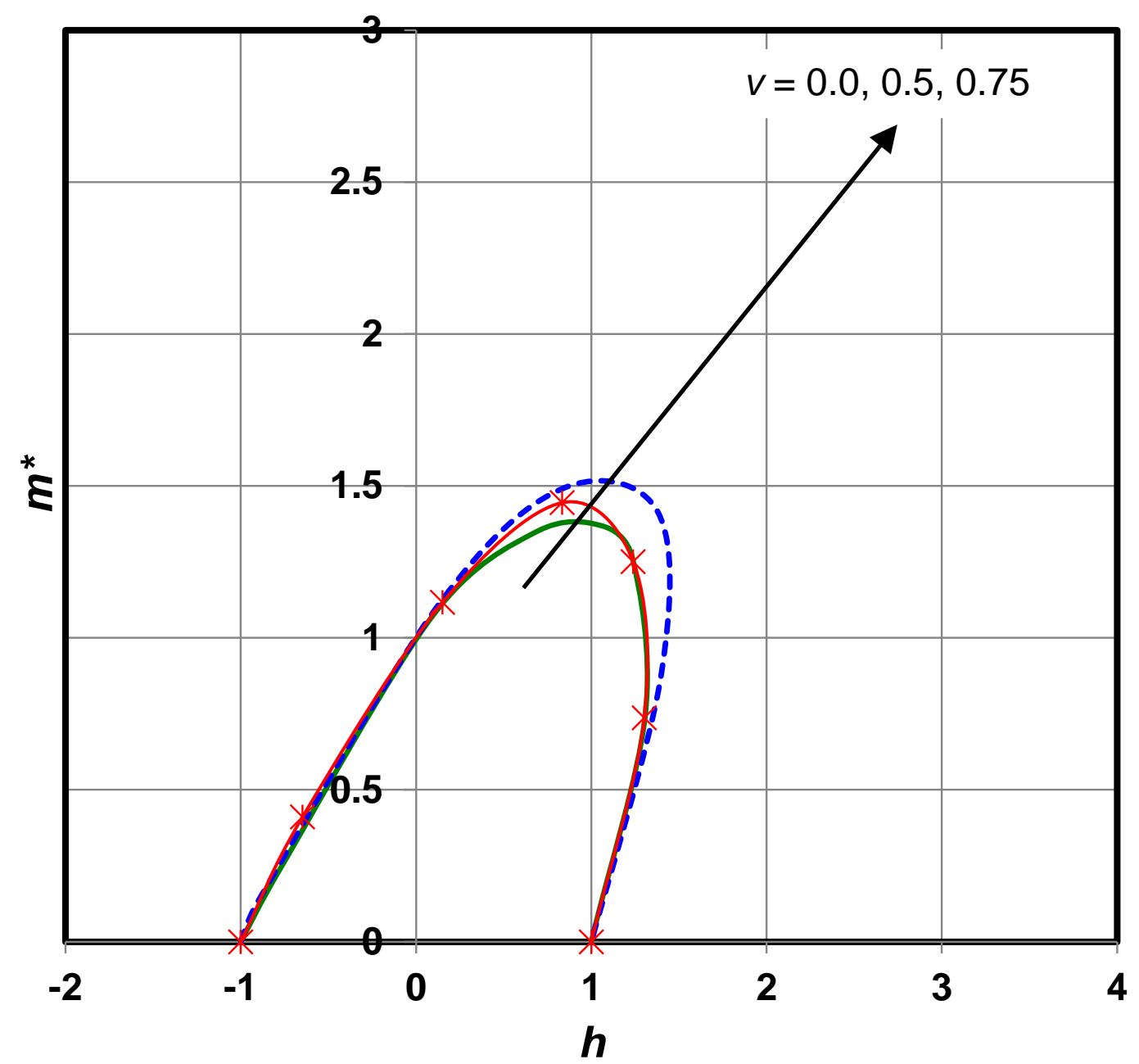

884

885

(a) $T_{\mathrm{s}} / D=0.2$

886

887

888

889

890

891

892 


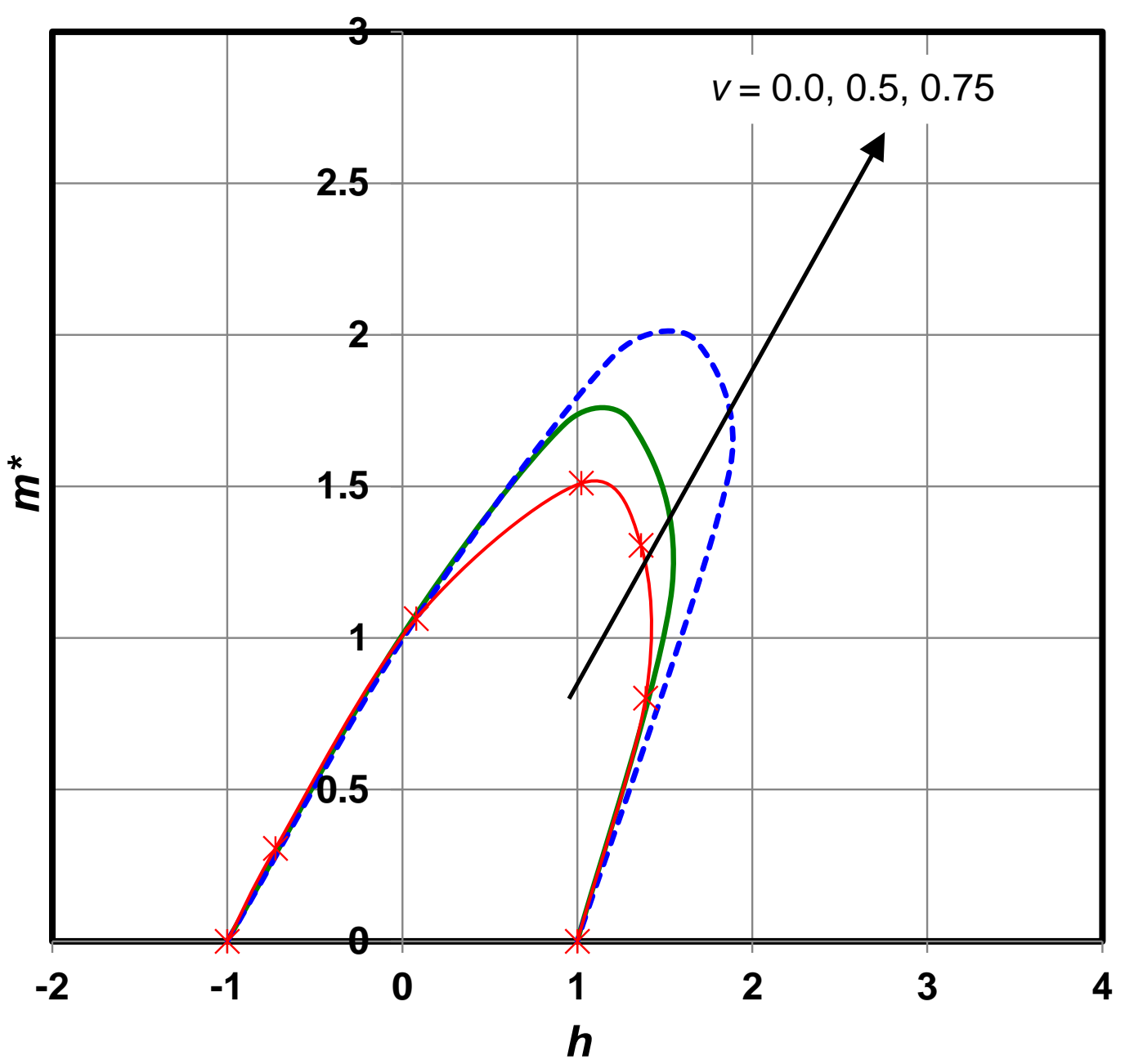

893

894

895

896

897

898

899

900

901

902

(b) $T_{\mathrm{s}} / D=0.4$

Figure 14 Effect of vertical mobilisation $v$ on normalised failure envelopes in $h-m$ space: $d / D=0.5$ 


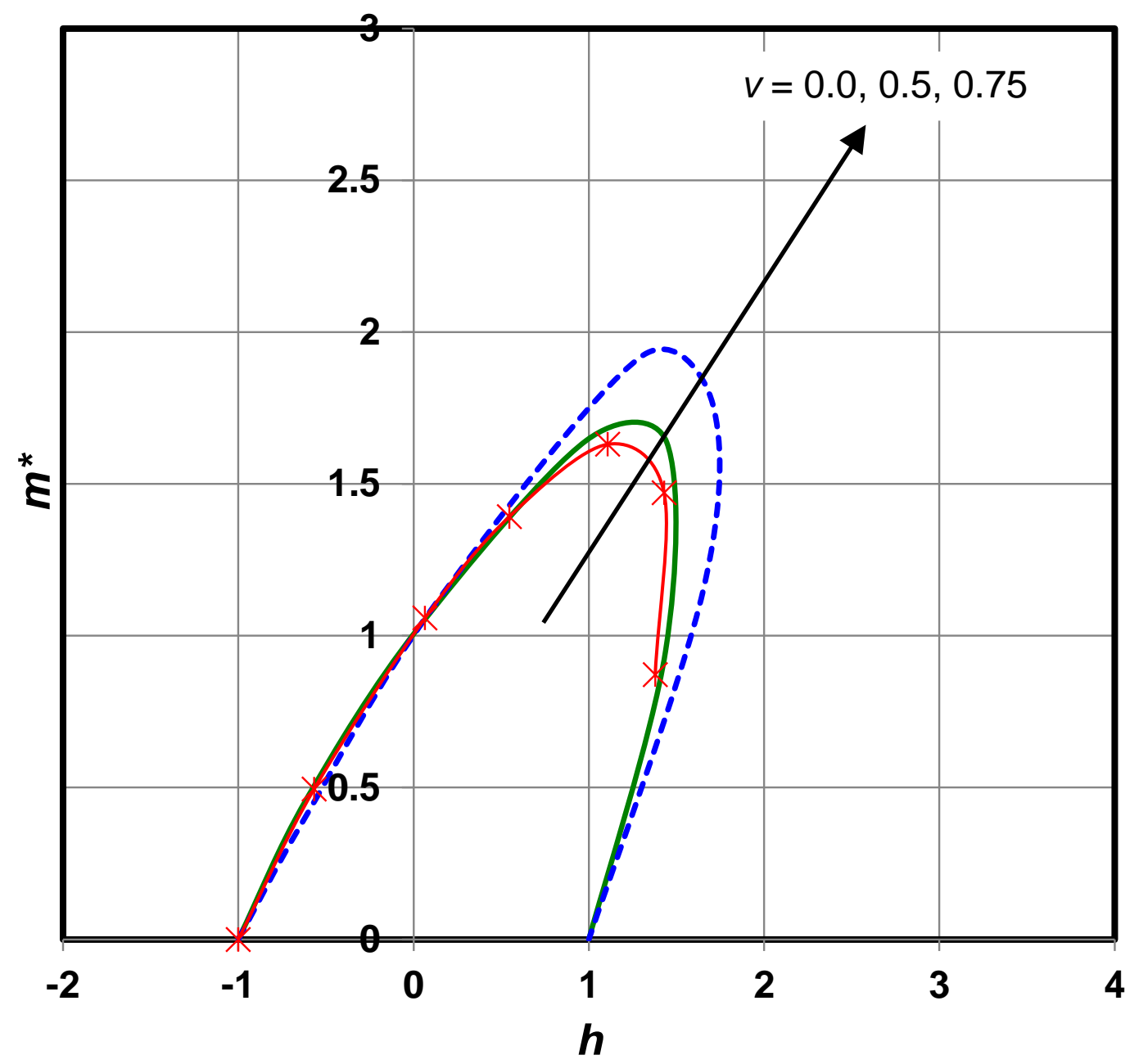

903

904

905

(a) $T_{\mathrm{s}} / D=0.2$

906

907

908

909

910

911

912 


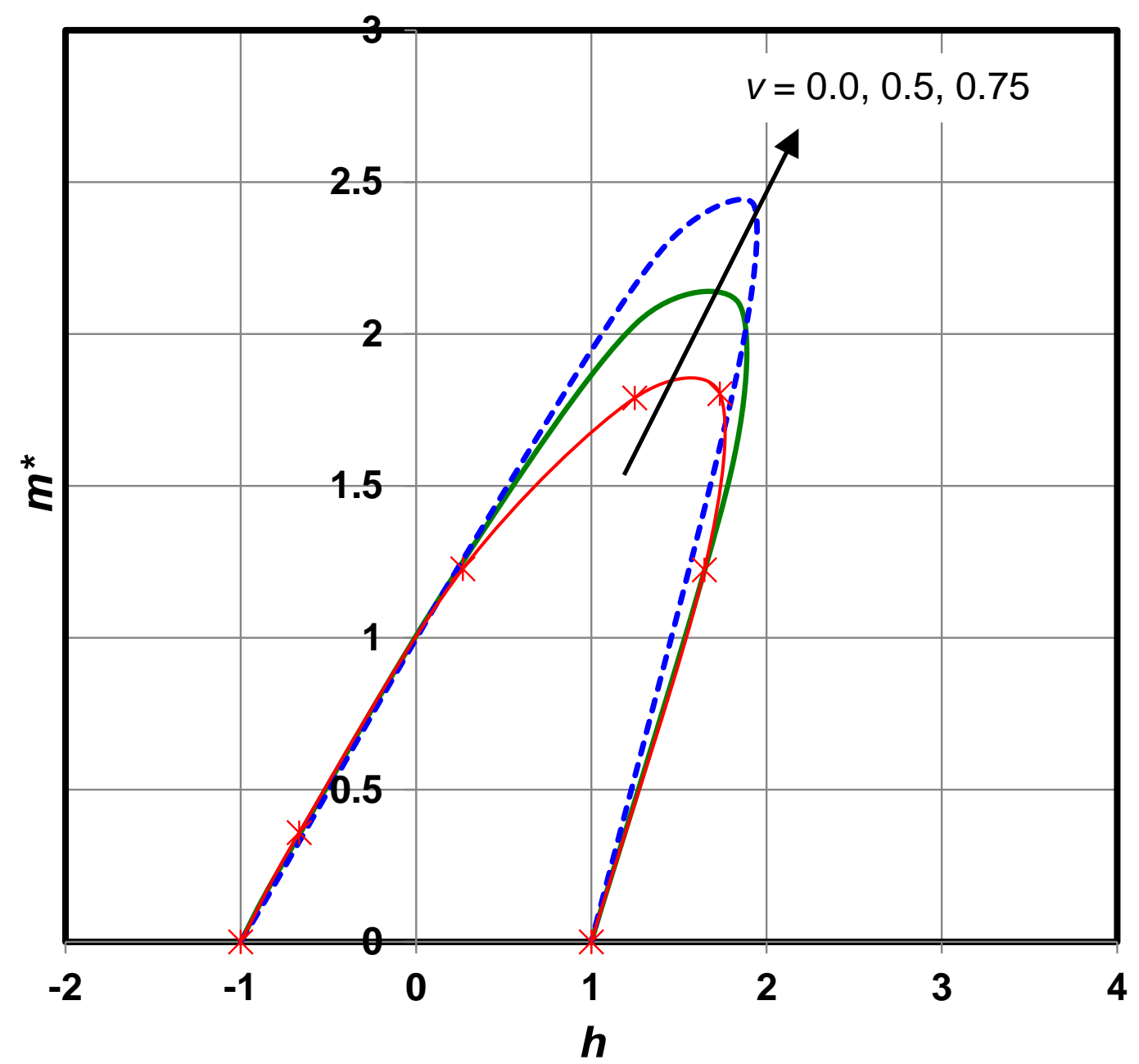

913

914

915

(b) $T_{\mathrm{s}} / D=0.4$

916

917

918

919

920

921

922

923 


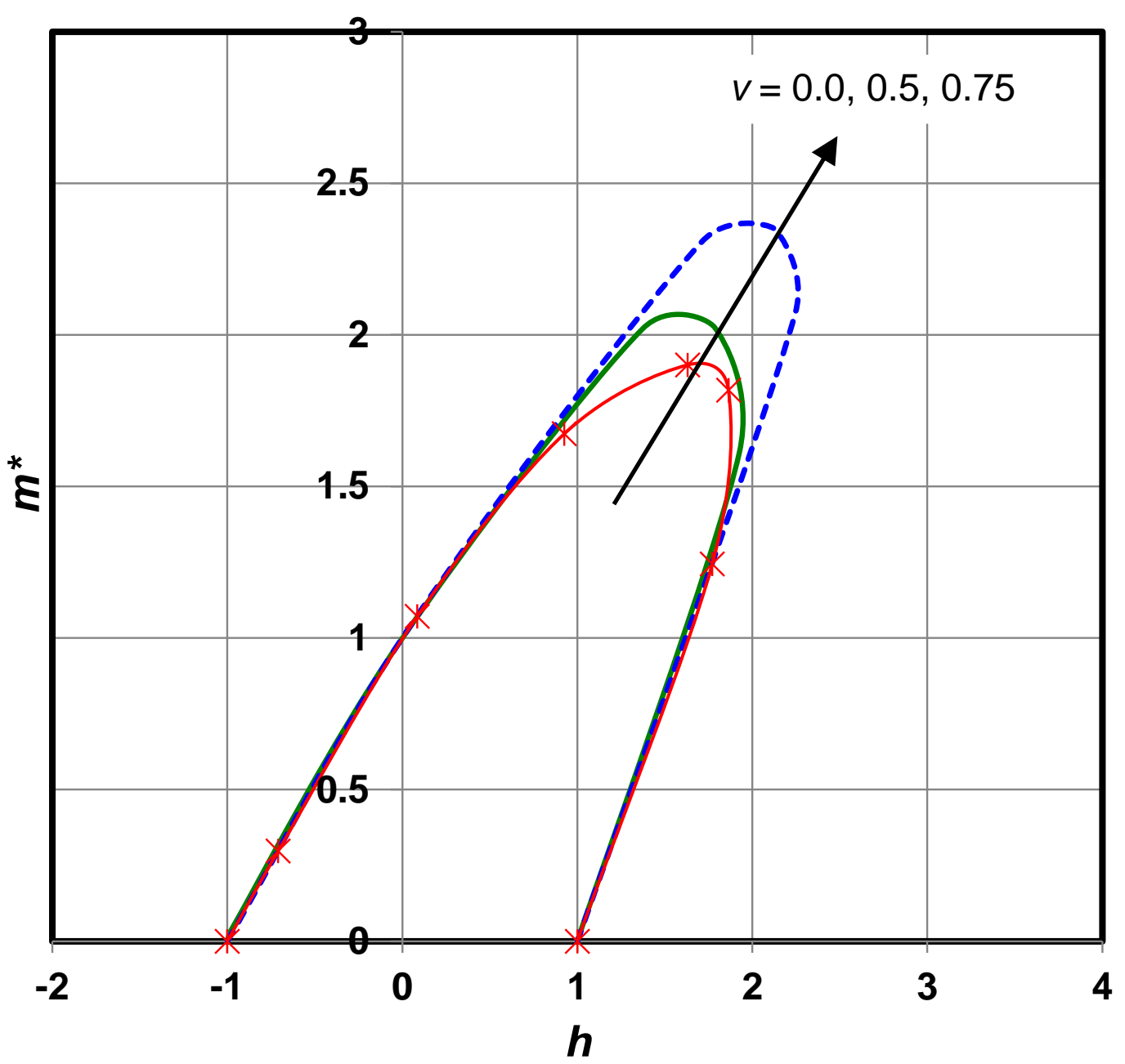

924

925

926

927

928

929

930

931

932

933

934

(c) $T_{\mathrm{s}} / D=0.6$

Figure 15 Effect of vertical mobilisation $v$ on normalised failure envelopes in $h-m$ space: $d / D=0.75$ 


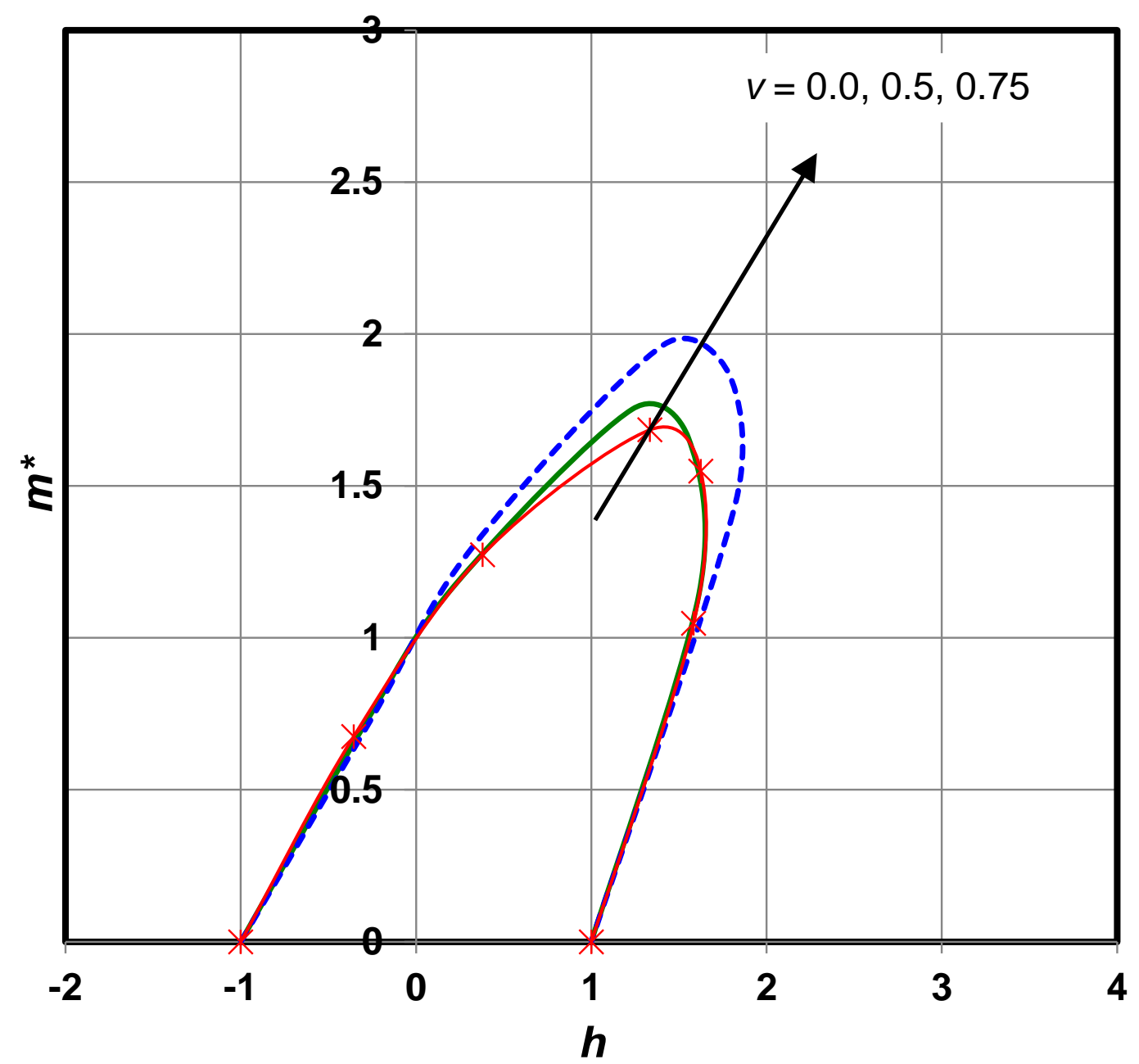

935

936

937

(a) $T_{\mathrm{s}} / D=0.2$

938

939

940

941

942

943 


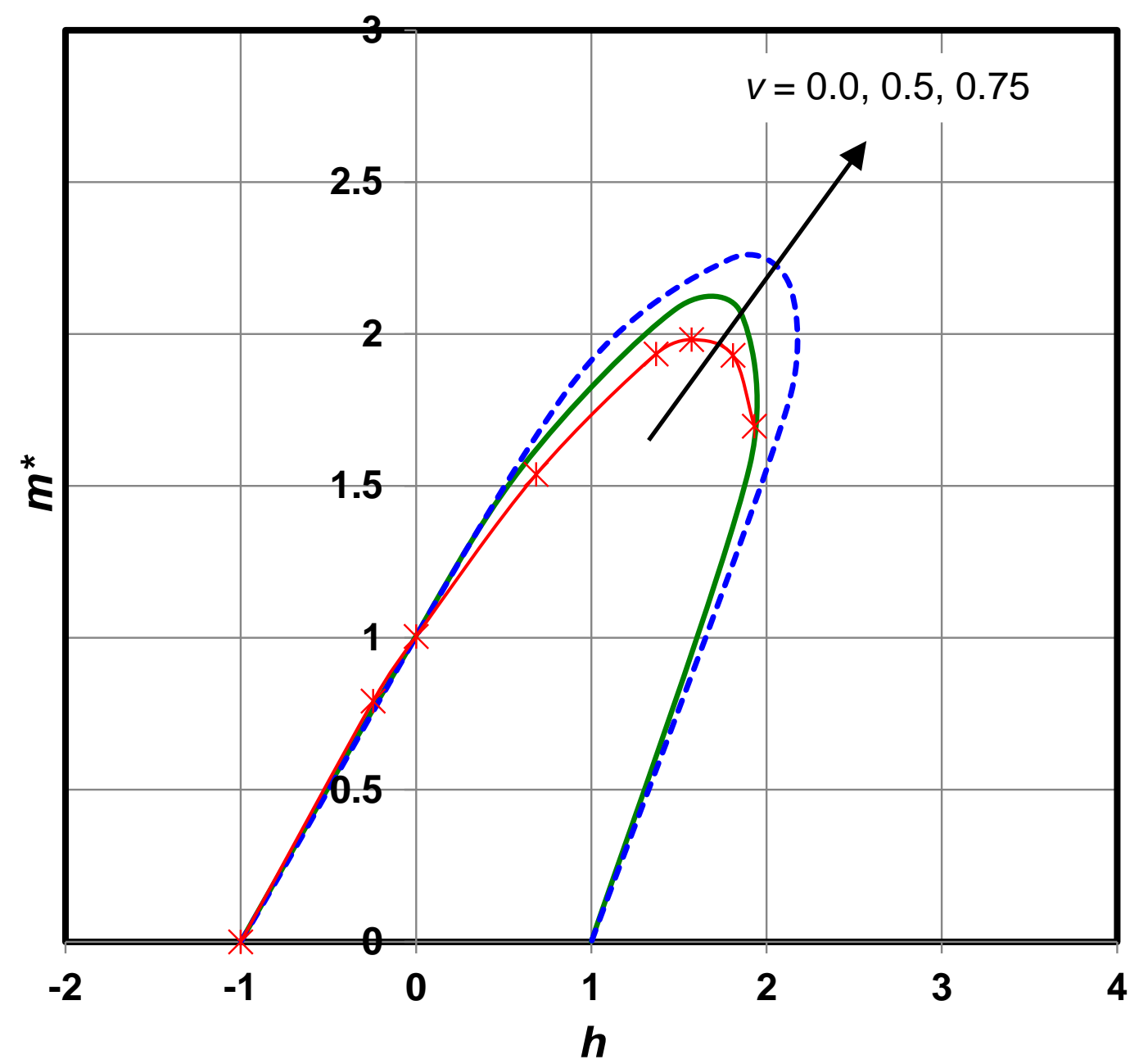

944

945

946

(b) $T_{\mathrm{s}} / D=0.4$

947

948

949

950

951

952

953 


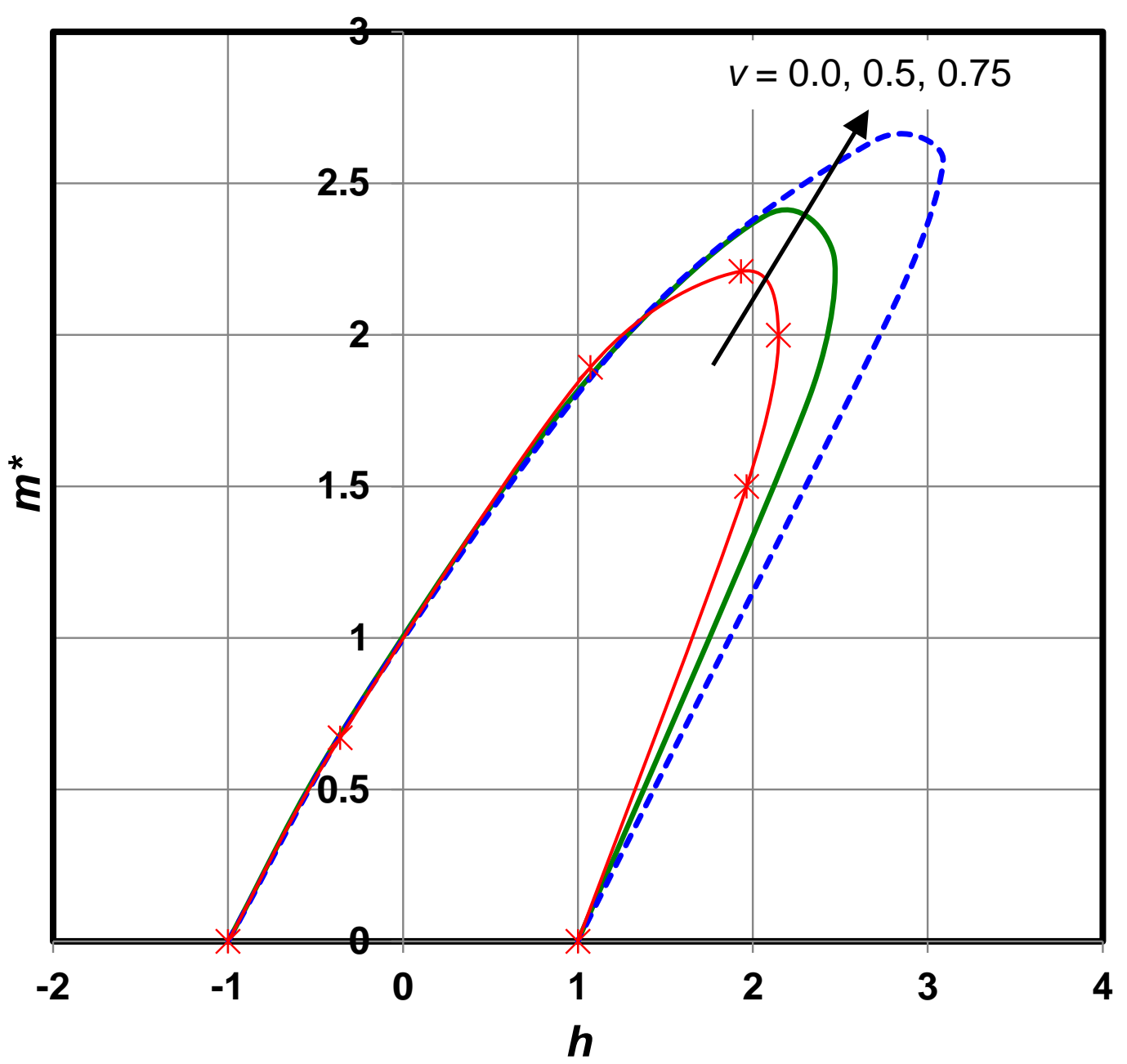

954

955

956

(c) $T_{\mathrm{s}} / D=0.6$

957

958

959

Figure 16 Effect of vertical mobilisation $v$ on normalised failure envelopes in $h-m$ space: $d / D=1.0$

960 


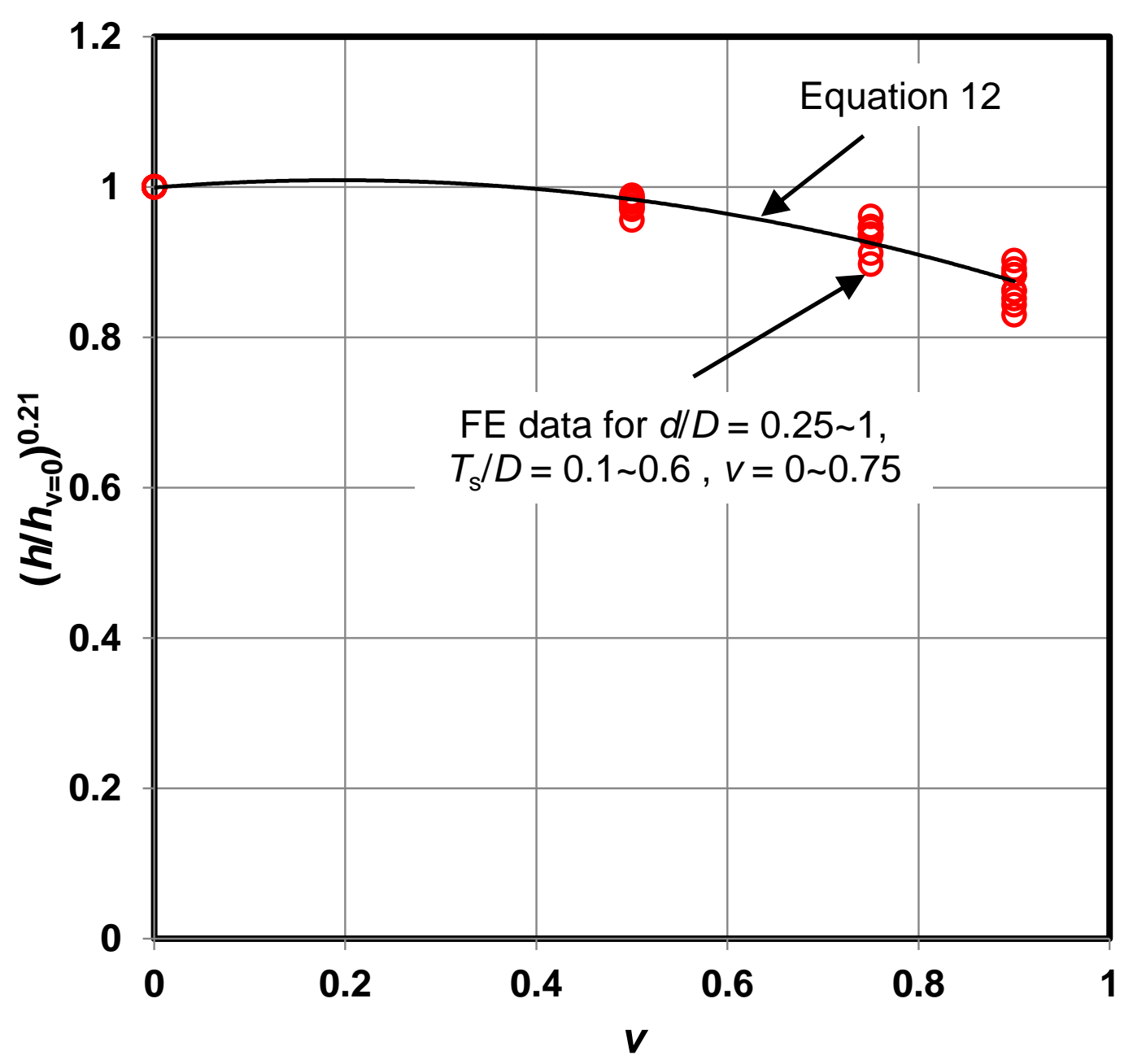

961

962

963

964

(a) $v-h$ space 


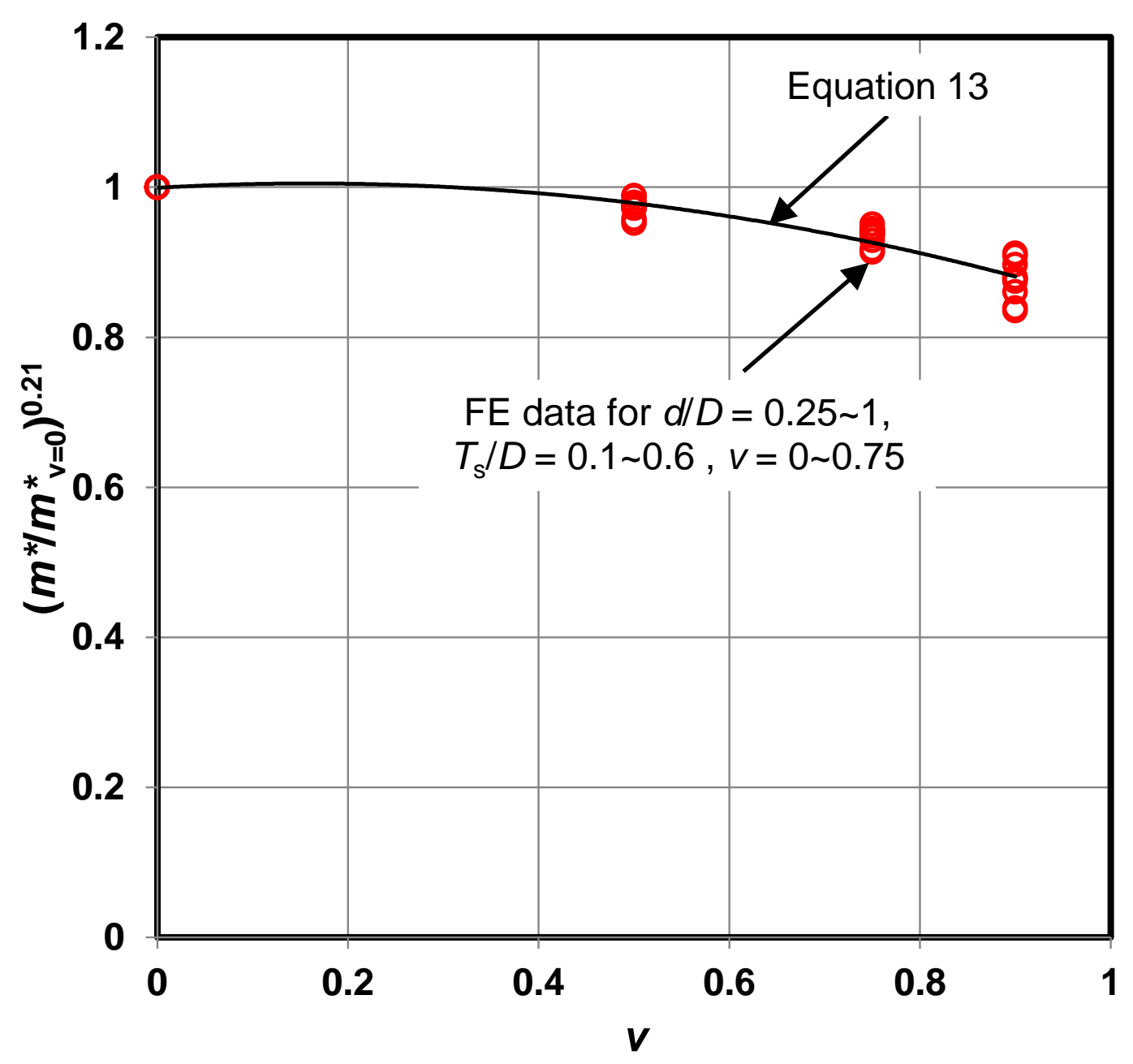

965

966

967

968

(b) $v-m^{*}$ space

Figure 17 Design charts for quantifying effect of vertical mobilisation $v$ 